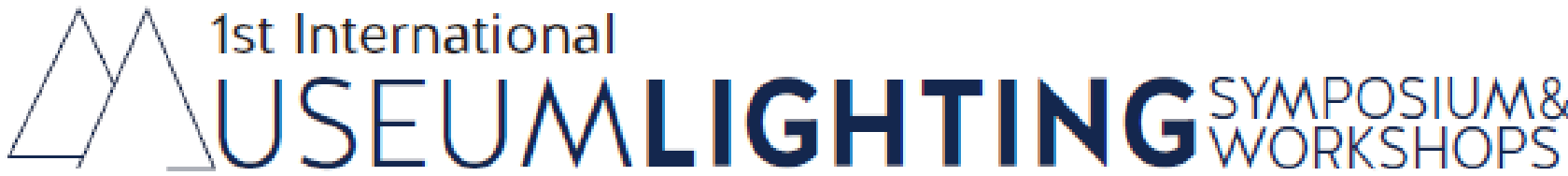

\section{1-12 September 2017}

University College London

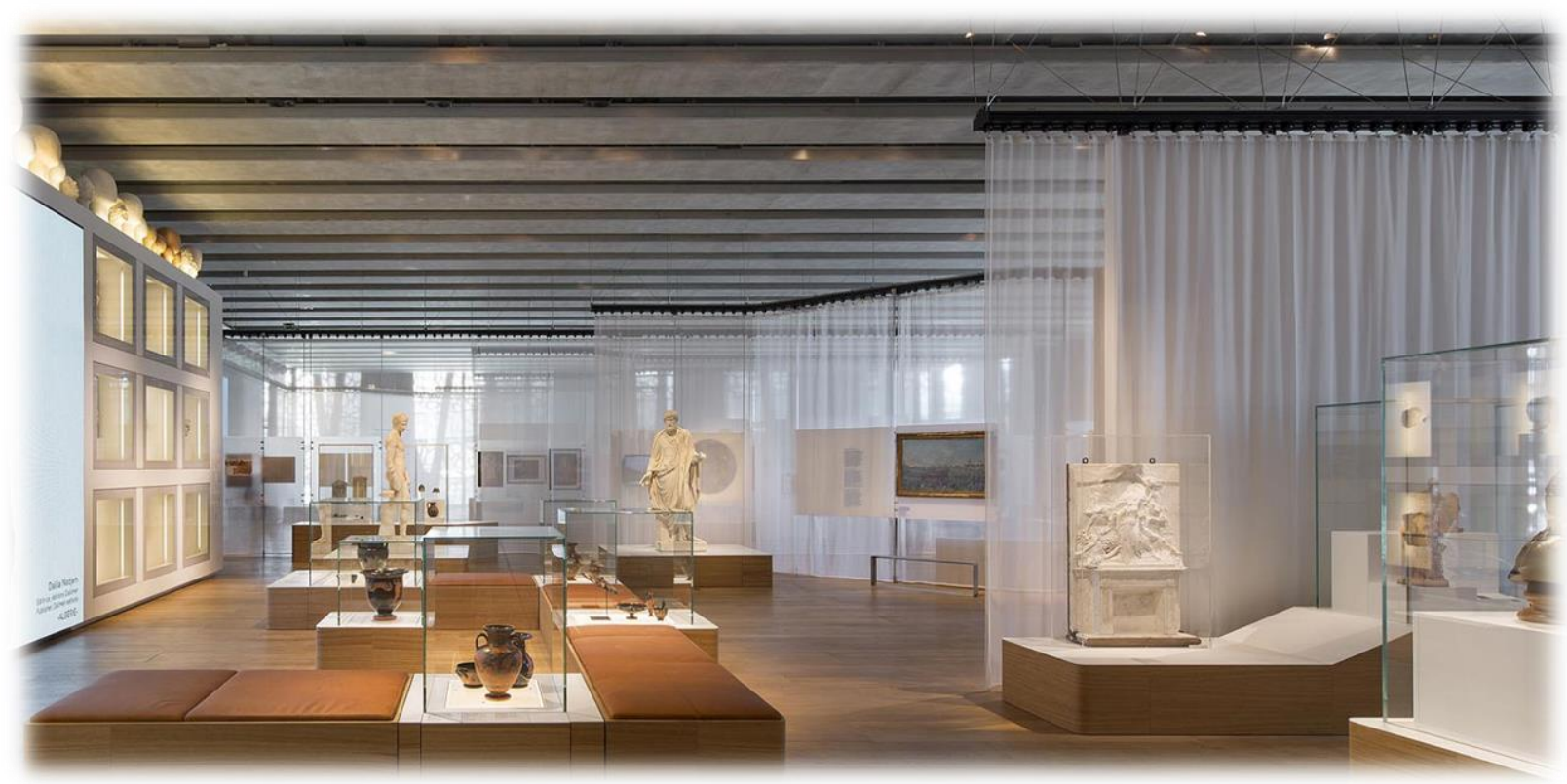




\section{Organising Committee:}

Panos Andrikopoulos, PhD Researcher, SEAHA-CDT, UCL

Conference Chair

Daniel Garside, PhD Researcher, UCL

Secretary and Treasurer

Carolien Coon, PhD Researcher, SEAHA-CDT, UCL

Venue and Logistics

Anna Pokorska, PhD Researcher, SEAHA-CDT, UCL

Submissions Secretary

Brendan Keely, Secretary, SLL

\section{Scientific Committee:}

Prof. Anya Hurlbert, Chair

Professor of Visual Neuroscience, Dean of Advancement, University of Newcastle;

Scientific Trustee National Gallery

Jim Druzik

Senior Conservation Scientist, Getty Conservation Institute

Prof Ronier Luo

Professor of Colour and Imaging Science, Leeds University; Global Expertise Professor, Zhejiang University Chair Professor, National Taiwan University of Science and technology; Vice-President of CIE

\section{Dr Sergio Nascimento}

Associate Professor, University of Minho

Joseph Padfield

Conservation Scientist, National Gallery, London

Boris Pretzel

Head of Science, Conservation and Collections Management, V\&A

David Saunders

Vice President, International Institute for Conservation

Prof Andrew Stockman

Steers Professor of Investigative Eye Research 


\section{Commercial Partners:}
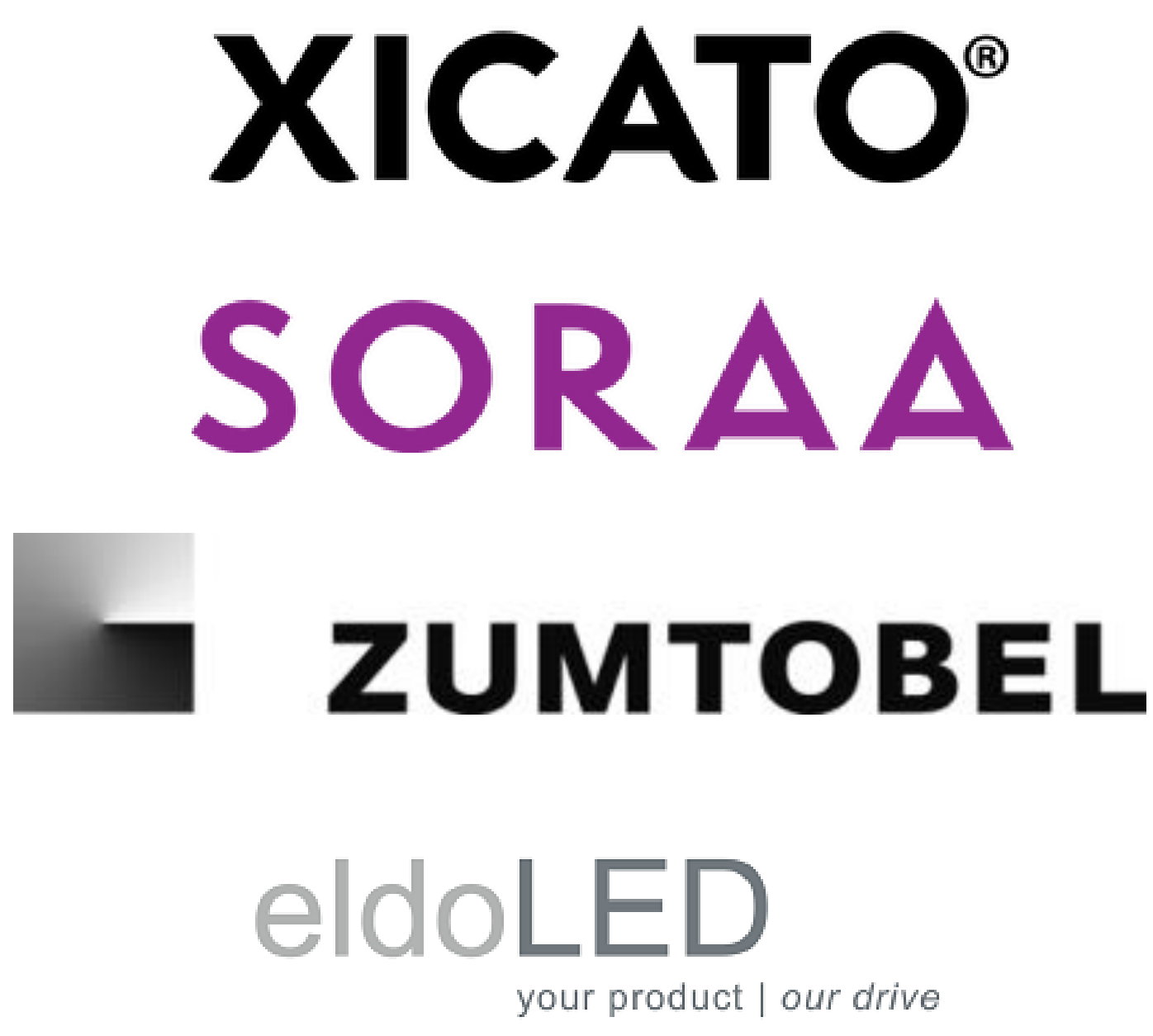

\section{MIKE STOANE LIGHTING}

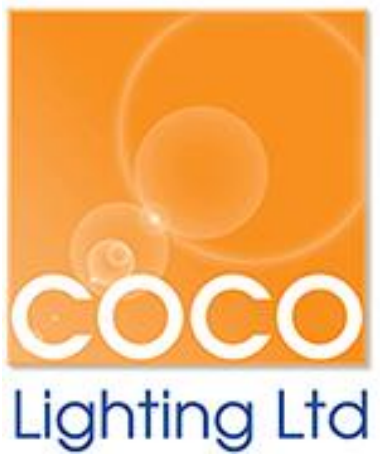

2| P a g e 


\section{Welcome Address}

Museum lighting is like no other lighting field. Or any other vision, colour, conservation or material science field. Museum lighting involves many disciplines and an even greater number of stakeholders; lighting designers, architects, exhibition designers, conservators, material, vision and lighting scientists, to name a few. All these practitioners approach the problem with different perspectives, interests, backgrounds and methods, and they each employ a subtly different professional language. This can cause miscommunication and isolation.

Museum and gallery illumination is at a crossroad. The drive to reduce energy consumption has led to a wide and rapid adoption of LED technology by museums and heritage institutions. LED technology creates new opportunities and poses new challenges to colour, lighting and conservation science and practice. While LED technology allows for novel applications such as optimisation of the spectrum for vision and/or preservation, it has revealed inadequacies in existing colour reproduction measures, has not yet proven to be cost effective, and has raised concern over light induced damage. Projects like the illumination of the Sistine Chapel, where the light source was specifically optimised to the pigments used for the murals, showcase the possibilities but highlight the need for engineering the capabilities of LED technology.

When we conceived the idea for a Museum Lighting event, we had all the above in mind. We envisaged a symposium acting as a round table for all the disciplines involved in the field, whether within industry or academia. A showcase where industry professionals would be able to discuss state of the art research in order to apply it in the real world, and where researchers would be able to learn more about the challenges of real-world application.

From our programme, and the demographics of the audience, we are hopeful that we will accomplish the above aims. Our audience is diverse: $26 \%$ of the audience are museum professionals, while $24 \%$ comes from academia. $23 \%$ are part of the lighting manufacturing industry, while $15 \%$ are lighting designers and specifiers. I believe that this split, along with the fact that the event has been twice sold out long before the actual date, demonstrates a great and growing interest for the field from all the stakeholders.

In organising the event we have not been alone. Firstly, we had the support of our academic home: The Centre for Doctoral Training in Science and Engineering in Arts, Heritage and Archaeology (SEAHA-CDT). We also had the support of the Chartered Institution for Building Services Engineers, Society of Light and Lighting. They supported and believed in the event from day one. 
And this is where we normally acknowledge sponsors. Except we did not have any. Instead of sponsors we had commercial partners. Whilst this might sound like sophistry, it is not. When we first started looking for commercial partners, we had to introduce a new framework for collaboration in a conference, something we really believed in. That is, we asked commercial partners to collaborate with us in providing workshops - sharing their knowledge and expertise. As a result of this, our programme includes four workshops. Workshop A: "Relighting the Petrie Museum: Smart Lighting and Proximity Aware Services in Museums", organised in association with Xicato and Mike Stoane Lighting and led by Boris Pretzel, is not only a demonstration of the capabilities of connected lighting in museum environments, but also an open discussion on the potential of the technology. Workshop B, "Precision LED drivers for viewing and digital imaging" provided by eldoLED, is a demonstration of the implications and importance of dimming LEDs in museums. Workshop C:

"Psychophysiological Methods for Lighting Research and Design" provided by Zumtobel and led by Prof Anya Hurlbert, introduces new methods and techniques to be employed for post- and pre-occupancy evaluation. Workshop D: "Modern Colour Science for Museum Lighting", provided by Soraa and Coco Lighting and led by Aurelien David, discusses all the latest advancements in modern colour science.

Museum lighting research usually happens in the lab, outside of its real context. Although this is not ideal, it is often a pragmatic decision. Depending on the application, the importance of lighting research in situ is widely acknowledged. For this event, we have collaborated with the UCL Museums and Collections, to which we are deeply grateful, for providing an opportunity to be able to have some of the workshops in real museum environments. This aligned well with the aim of UCL Museums and Collections to become a 'museum research hub'. As a legacy of the Museum Lighting Symposium and Workshops a lighting system, which is optimisable up to the last spotlight and with the ability to track the location of visitors, has been installed in the Petrie Museum. This system is open to UCL and non-UCL researchers for lighting studies.

We would also like to express our gratitude to the members of the scientific committee for the hours spent in reviewing the abstracts and drafting an excellent programme. Their contribution was the most important and their trust in the event is something I hope we can live up to. We would also like to thank the The Colour Group (GB) for their support in advertising the event which, as a first-time event has been important.

Finally, but most importantly, we would like to thank all the delegates for joining this event from around the world, despite the time and cost implications. Our aim was to create a round table for the different disciplines and your presence at the event is key to its success. 


\section{XICATO}

Xicato designs and manufactures intelligent lighting components that enable designers to create beautiful, smart spaces in which people love to live and work. Xicato is defining the future of intelligent light sources by integrating electronics, software and connectivity.

Xicato's XIM Gen4 integrates Corrected Cold Phosphor Technology® for the highest quality, longest lasting light, a deep dimming driver, wired and wireless control, and Bluetooth beacons, all in a compact, efficient package. The XIM Gen4 ecosystem includes switches, sensors, gateways and software that are designed for scalable commercial applications.

For museums, smart lighting can offer savings via lower energy consumption, sensor triggering and predictive maintenance. Commissioning is simplified. Visitor experiences can be enhanced with proximity aware services. Upgrades to smart lighting can be realized without disruption or gallery closure. Founded in 2007 is headquartered in Silicon Valley, Xicato has offices globally.

For further information: www.xicato.com

\section{SORAA}

Soraa has pioneered the use of LEDs built from pure gallium nitride substrates (GaN on GaN $\left.{ }^{\mathrm{TM}}\right)$, making ordinary lighting extraordinarily brilliant and efficient. Soraa is the world leader in LED technology and the illuminator of the world's most renowned museums, historical buildings, hotels, and luxury shops. Soraa products have also been installed at the San Francisco Museum of Modern Art, the J. Paul Getty Museum, and the Ashmolean Museum in Oxford.

Soraa's full spectrum GaN on GaN ${ }^{\mathrm{TM}}$ LED lamps have superior colour rendering and beam characteristics compared to LED sources created from non-native substrates. Founded in 2008, Soraa is located in Fremont California, where it manufactures its GaN on GaN ${ }^{\mathrm{TM}}$ LEDs in the company's state-of-the-art facility. For additional information, please visit www.soraa.com and follow us on Twitter, Facebook, Instagram, and LinkedIn. 


\section{ZUMTOBEL}

As a leader in innovation, Zumtobel develops sustainable lighting solutions tailored to the needs of people in their respective applications. With a comprehensive portfolio of high-quality luminaires and intelligent lighting management systems, the Austrian company provides optimum indoor and exterior products for working and living spaces - the right light for every activity at any time of day. The applications office, education, presentation and retail, hotel and wellness, health, art and culture and industry are now perfectly complemented with portfolios for living and outdoor areas. Zumtobel is a brand of Zumtobel Group AG with its head office in Dornbirn, Vorarlberg (Austria). Zumtobel. The Light.

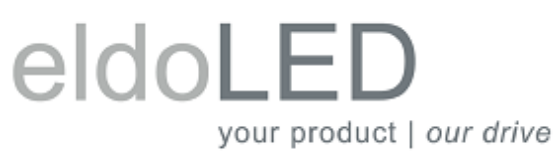

eldoLED is a world leader in the design and manufacture of intelligent drive solutions for LED based lighting systems. eldoLEDs technologies empower their customers to deliver the promise of LED lighting: smarter, sleeker and more efficient systems. More importantly, eldoLED focusses on 'Quality of Light'. The choice of the driver is crucial to achieve healthy light: best smooth dimming all the way down to $0.1 \%$ / dark combined with truly 'flicker-free' light, according to IEEE1789 regulation, which mitigates adverse effects caused by flicker. eldoLED is where lighting electronics meets the human body.

\section{MIKE STOANE LIGHTING}

Mike Stoane Lighting is a design led specialist manufacturer of architectural lighting equipment based in Edinburgh, Scotland. The company was founded in 1995 when Mike started making light fittings in his garage. We have grown considerably since then and are now an Employee Owned company. Our close relationship with lighting designers and architects has resulted in supply of our luminaires to prestigious projects worldwide; from iconic new buildings to historic castles, palaces and places of worship. Built to order in 6 | P a g e 
Edinburgh, all of our equipment is designed and tested to be suitable for the specific demands of each project. We have established our reputation by manufacturing solidly built, easy to use, aesthetically simple but technically

advanced luminaires, particularly for the museum and gallery sector. We are well known for our flexibility and capability when it comes to the manufacture of bespoke luminaires. The scale and complexity varies hugely, sometimes requiring development of out-and-out specials but very often utilising equipment from our extensive catalogue of standard hand built equipment.

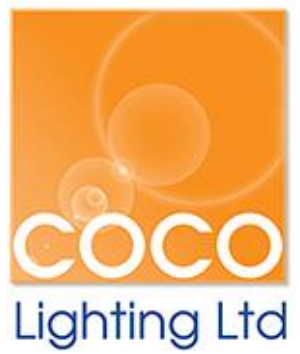

COCO Lighting is the largest distributor of SORAA products within the UK, working side-by-side with the LED specialists to deliver exceptional quality of light products to its growing customer base. As the UK's only SORAA Gold Partner distributor, COCO Lighting retains extensive stock levels to ensure quick project fulfillment.

In addition, COCO Lighting is an ICEL 1004:2014 accredited Emergency Lighting and LED Conversion Specialist with over 30 years' experience in luminaire conversion procedures. With a team of experienced engineers, COCO Lighting can 're-engineer' just about any light fitting to LED and/or emergency, saving up to $90 \%$ in energy costs.

COCO Lighting takes pride in its "Rapid Response Policy" applying this to all projects and administrative requirements, ensuring their customers receive information and merchandise as quickly as possible. This procedure is endorsed by ensuring that their carefully selected teams are fully versed in all ISO 9001 and ISO 14001 procedures, offering a high quality, reliable and efficient service at competitive prices.

For more information visit: www.cocolighting.com or follow us on Twitter. 


\section{Programme:}

\begin{tabular}{|c|c|c|c|}
\hline \multicolumn{4}{|l|}{ DAY 1} \\
\hline 9:00 & \multicolumn{2}{|l|}{ Registration } & \\
\hline 9:50 & Opening Address & $\begin{array}{l}\text { Anya } \\
\text { Hurlbert }\end{array}$ & $\begin{array}{l}\text { - Chair, Scientific } \\
\text { Committee }\end{array}$ \\
\hline \multicolumn{4}{|c|}{ Case Studies } \\
\hline $10: 00$ & $\begin{array}{l}\text { Keynote: Lighting the } \\
\text { New Acropolis Museum }\end{array}$ & Florence Lam & $\begin{array}{l}\text { - } \text { Global Head of } \\
\text { Lighting, ARUP } \\
\text { Group }\end{array}$ \\
\hline $10: 50$ & \multicolumn{3}{|l|}{ Tea Break } \\
\hline $11: 20$ & $\begin{array}{l}\text { Museum Lighting - } \\
\text { Daylight Autonomy and } \\
\text { Application of Novel } \\
\text { Artificial Lighting } \\
\text { Technologies in } \\
\text { Museums }\end{array}$ & $\begin{array}{l}\text { Andreas } \\
\text { Schulz }\end{array}$ & $\begin{array}{l}\text { CEO, Licht Kunst } \\
\text { Licht AG, } \\
\text { Bonn/Berlin } \\
\text { - Chair IALD Europe } \\
\text { Steering Committee }\end{array}$ \\
\hline $11: 45$ & $\begin{array}{l}\text { Climate based daylight } \\
\text { modelling for light } \\
\text { management in historic } \\
\text { house showrooms }\end{array}$ & Nigel Blades & $\begin{array}{ll}\text { - } & \text { Preventive } \\
\text { Conservation Adviser } \\
\text { (Environment), } \\
\text { National Trust }\end{array}$ \\
\hline $12: 10$ & $\begin{array}{l}\text { Illuminating Artwork - } \\
\text { different project } \\
\text { examples in cooperation } \\
\text { with the Vatican } \\
\text { Museums }\end{array}$ & $\begin{array}{l}\text { Mourad } \\
\text { Boulouednine }\end{array}$ & $\begin{array}{l}\text { - Regional Head of } \\
\text { Projects Europe, } \\
\text { OSRAM }\end{array}$ \\
\hline $12: 35$ & \multicolumn{3}{|l|}{ Lunch } \\
\hline \multicolumn{4}{|c|}{ Light, colour and vision (Part I) } \\
\hline $13: 35$ & In Praise of Spotlighting & $\begin{array}{l}\text { Scott } \\
\text { Rosenfeld }\end{array}$ & $\begin{array}{l}\text { Lighting Designer, } \\
\text { Smithsonian Institute }\end{array}$ \\
\hline $14: 00$ & $\begin{array}{l}\text { Evaluation of colour } \\
\text { quality of LED } \\
\text { illumination for Museum } \\
\text { Applications }\end{array}$ & Ronnier Luo & $\begin{array}{l}\text { Vice-President of } \\
\text { International } \\
\text { Committee for } \\
\text { Illumination (CIE) } \\
\text { - Professor of Colour } \\
\text { and Imaging Science, } \\
\text { Leeds University } \\
\text { - Global Expertise } \\
\text { Professor, Zhejiang } \\
\text { University Chair } \\
\text { Professor, National } \\
\text { Taiwan University of } \\
\text { Science and } \\
\text { technology. }\end{array}$ \\
\hline
\end{tabular}




\begin{tabular}{|c|c|c|c|}
\hline $14: 25$ & $\begin{array}{l}\text { Artificial Lighting Design } \\
\text { for Paintings in Indoor } \\
\text { Settings with selected } \\
\text { Nanyang Paintings as a } \\
\text { case study. }\end{array}$ & $\begin{array}{l}\text { Nicholas Ong } \\
\text { Thian Chai }\end{array}$ & $\begin{array}{l}\text { MA Student, } \\
\text { Nanyang } \\
\text { Technological } \\
\text { University }\end{array}$ \\
\hline $14: 50$ & $\begin{array}{l}\text { Light and colour: } \\
\text { Assessing the effects of } \\
\text { illumination on } \\
\text { perceptual constancy of } \\
\text { and aesthetic response to } \\
\text { paintings }\end{array}$ & $\begin{array}{l}\text { Anya } \\
\text { Hurlbert }\end{array}$ & $\begin{array}{l}\text { Prof of Visual } \\
\text { Neuroscience, } \\
\text { Newcastle University } \\
\text { Scientific Trustee, } \\
\text { National Gallery, } \\
\text { London } \\
\end{array}$ \\
\hline $15: 15$ & \multicolumn{3}{|l|}{ Poster Session } \\
\hline \multicolumn{4}{|c|}{ Light, colour and vision (Part II) } \\
\hline $16: 45$ & $\begin{array}{l}\text { Colour preference and } \\
\text { naturalness of paintings } \\
\text { under multi-LED spectra } \\
\text { with different correlated } \\
\text { colour temperatures and } \\
\text { object saturation levels }\end{array}$ & Peter Bodrogi & $\begin{array}{l}\text { - Senior research } \\
\text { fellow, Laboratory of } \\
\text { Lighting Technology } \\
\text { of the TU Darmstadt } \\
\text { in Darmstadt }\end{array}$ \\
\hline $17: 10$ & $\begin{array}{l}\text { Influence of cultural } \\
\text { factors in preferred } \\
\text { illumination for } \\
\text { paintings }\end{array}$ & $\begin{array}{l}\text { Sergio } \\
\text { Nascimento }\end{array}$ & $\begin{array}{l}\text { Associate Professor, } \\
\text { University of Minho }\end{array}$ \\
\hline $17: 35$ & $\begin{array}{l}\text { The Preferred Conditions } \\
\text { of LED Lighting for Fine } \\
\text { Art Paintings: The } \\
\text { Influence of Illuminance } \\
\text { Level and Correlated } \\
\text { Colour Temperature }\end{array}$ & Ferenc Szabó & $\begin{array}{l}\text { Assistant Professor, } \\
\text { University of } \\
\text { Pannonia }\end{array}$ \\
\hline $18: 00$ & \multicolumn{3}{|l|}{ End of Day } \\
\hline $18: 30$ & \multicolumn{3}{|l|}{ Drinks Reception } \\
\hline \multicolumn{4}{|l|}{ DAY 2} \\
\hline \multicolumn{4}{|c|}{ Light Damage } \\
\hline 9:00 & $\begin{array}{l}\text { Mitigating Light Damage } \\
\text { in a New Exhibition } \\
\text { Space at the Getty } \\
\text { Research Institute }\end{array}$ & Mark Benson & $\begin{array}{l}\text { - Assistant } \\
\text { Conservator, Getty } \\
\text { Research Institute }\end{array}$ \\
\hline $9: 25$ & $\begin{array}{l}\text { A microfading survey of } \\
\text { the lightfastness of blue, } \\
\text { black and red ballpoint } \\
\text { pen inks in ambient and } \\
\text { modified environments }\end{array}$ & Bruce Ford & $\begin{array}{l}\text { - } \text { Researcher, } \\
\text { National Museum of } \\
\text { Australia } \\
\text { - independent } \\
\text { conservation science } \\
\text { consultant } \\
\end{array}$ \\
\hline $9: 50$ & $\begin{array}{l}\text { Keynote: Museum } \\
\text { lighting - } 30 \text { years of } \\
\text { developments and } \\
\text { lessons for the future }\end{array}$ & $\begin{array}{l}\text { Stefan } \\
\text { Michalski }\end{array}$ & $\begin{array}{l}\text { Senior conservation } \\
\text { scientist, Canadian } \\
\text { Conservation } \\
\text { Institute (CCI) } \\
\end{array}$ \\
\hline
\end{tabular}

9 | P a g e 


\begin{tabular}{|c|c|c|c|c|c|c|}
\hline $10: 40$ & \multicolumn{6}{|l|}{ Tea Break } \\
\hline \multicolumn{7}{|c|}{ Workshops } \\
\hline $11: 10$ & $\begin{array}{l}\text { Workshop A } \\
\text { in association } \\
\text { with Xicato \& } \\
\text { MSL }\end{array}$ & \multicolumn{2}{|c|}{$\begin{array}{l}\text { Workshop B in } \\
\text { association with } \\
\text { eldoLED }\end{array}$} & \multicolumn{2}{|c|}{$\begin{array}{l}\text { Workshop C in } \\
\text { association with } \\
\text { Zumtobel }\end{array}$} & $\begin{array}{l}\text { Workshop D in } \\
\text { association with } \\
\text { Coco Lighting \& } \\
\text { Soraa }\end{array}$ \\
\hline $12: 10$ & $\begin{array}{l}\text { Workshop A } \\
\text { in association } \\
\text { with Xicato \& } \\
\text { MSL }\end{array}$ & \multicolumn{2}{|c|}{$\begin{array}{l}\text { Workshop B in } \\
\text { association with } \\
\text { eldoLED }\end{array}$} & \multicolumn{2}{|c|}{$\begin{array}{l}\text { Workshop C in } \\
\text { association with } \\
\text { Zumtobel }\end{array}$} & $\begin{array}{l}\text { Workshop D in } \\
\text { association with } \\
\text { Coco Lighting \& } \\
\text { Soraa }\end{array}$ \\
\hline $13: 10$ & \multicolumn{6}{|l|}{ Lunch } \\
\hline \multicolumn{7}{|c|}{ Collection Care and Policy } \\
\hline $14: 10$ & \multicolumn{2}{|c|}{$\begin{array}{l}\text { Wavelength dependence } \\
\text { and relative damage } \\
\text { factors: an overview }\end{array}$} & \multicolumn{2}{|c|}{$\begin{array}{l}\text { David } \\
\text { Saunders }\end{array}$} & \multicolumn{2}{|c|}{$\begin{array}{l}\text { - Getty/Rothschild } \\
\text { Fellow } \\
\text { - Honorary research } \\
\text { fellow at the British } \\
\text { Museum } \\
\text { - Vice president of the } \\
\text { International } \\
\text { Institute for } \\
\text { Conservation }\end{array}$} \\
\hline $14: 35$ & \multicolumn{2}{|c|}{$\begin{array}{l}\text { Are we being too easily } \\
\text { LED? Assessing the } \\
\text { impact of LED lighting } \\
\text { on pigments and paper in } \\
\text { heritage collections }\end{array}$} & \multicolumn{2}{|c|}{$\begin{array}{l}\text { Emma } \\
\text { Richardson }\end{array}$} & \multicolumn{2}{|c|}{$\begin{array}{l}\text { - Lecturer in Material } \\
\text { Studies, UCL }\end{array}$} \\
\hline $15: 00$ & \multicolumn{2}{|c|}{$\begin{array}{l}\text { Implementing fully } \\
\text { tuneable spectrum LED } \\
\text { light sources at the Art } \\
\text { Institute of Chicago: } \\
\text { perspectives from } \\
\text { lighting design and } \\
\text { conservation }\end{array}$} & \multicolumn{2}{|c|}{$\begin{array}{l}\text { Kerri } \\
\text { Callahan }\end{array}$} & \multicolumn{2}{|c|}{ 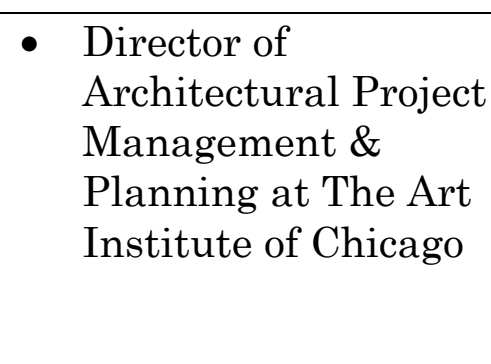 } \\
\hline $15: 25$ & \multicolumn{2}{|c|}{$\begin{array}{l}\text { Object-Specific Lighting } \\
\text { Design for Mark Rothko's } \\
\text { Green on Blue, a } \\
\text { Collaboration between } \\
\text { The University of } \\
\text { Arizona Museum of Art } \\
\text { and College of Optical } \\
\text { Sciences }\end{array}$} & \multicolumn{2}{|l|}{$\begin{array}{l}\text { Ross D. } \\
\text { Uthoff }\end{array}$} & \multicolumn{2}{|c|}{$\begin{array}{l}\text { Doctoral researcher } \\
\text { in the Applied } \\
\text { Optics Lab at the } \\
\text { College of Optical } \\
\text { Sciences at the } \\
\text { University of } \\
\text { Arizona }\end{array}$} \\
\hline $15: 50$ & \multicolumn{6}{|l|}{ Tea break } \\
\hline $16: 20$ & \multicolumn{2}{|c|}{$\begin{array}{l}\text { Fading colours and the } \\
\text { necessity for a new high- } \\
\text { quality LED-museum } \\
\text { lighting system }\end{array}$} & \multicolumn{2}{|c|}{$\begin{array}{l}\text { Kees van den } \\
\text { Meiracker }\end{array}$} & \multicolumn{2}{|c|}{$\begin{array}{l}\text { Head of Collection } \\
\text { and Conservation, } \\
\text { Van Gogh Museum }\end{array}$} \\
\hline
\end{tabular}




\begin{tabular}{|c|c|c|c|}
\hline $16: 55$ & $\begin{array}{l}\text { Upgrading Standards } \\
\text { and Guidelines for the } \\
\text { museum lighting: how to } \\
\text { include new research } \\
\text { results within an } \\
\text { outdated model? }\end{array}$ & $\begin{array}{l}\text { Costanza } \\
\text { Cucci }\end{array}$ & $\begin{array}{l}\text { Researcher, } \\
\text { Institute of Applied } \\
\text { Physics "Nello } \\
\text { Carrara", Italian } \\
\text { National Research } \\
\text { Council (IFAC-CNR) }\end{array}$ \\
\hline $17: 20$ & $\begin{array}{l}\text { Towards the new } \\
\text { standard for museum } \\
\text { lighting in Japan }\end{array}$ & $\begin{array}{l}\text { Nozomu } \\
\text { Yoshizawa } \\
\text { and Yoko } \\
\text { Mizokami }\end{array}$ & $\begin{array}{l}\text { - } \\
\text { Urofessor, Tokyo } \\
\text { University of Science } \\
\text { Associate Professor } \\
\text { in Department of } \\
\text { Imaging Sciences, } \\
\text { Graduate School of } \\
\text { Engineering, Chiba } \\
\text { University } \\
\end{array}$ \\
\hline $17: 55$ & Closing Remarks & $\begin{array}{l}\text { Panos } \\
\text { Andrikopoulos }\end{array}$ & $\begin{array}{ll}\text { - } & \text { Chair, Organising } \\
\text { Committee }\end{array}$ \\
\hline $18: 00$ & \multicolumn{3}{|l|}{ End of Day } \\
\hline
\end{tabular}




\section{Contents}

Keynote Speakers 16

Lighting the New Acropolis Museum (Florence Lam) ..... 16

Museum lighting - 30 years of developments and lessons for the future. (Stefan

Michalski). 18

Presenters.

Podium Presentations. 30

Case Studies. 30

Museum Lighting - Daylight Autonomy and Application of Novel Artificial Lighting

Technologies in Museums (Prof. Dipl.-Ing. Andreas Schulz) 30

Climate based daylight modelling for light management in historic house showrooms (Nigel Blades, Katy Lithgow, John Mardaljevic, Stephen Cannon-Brookes and Lisa McCullough)...... 32

Illuminating Artwork - different project examples in cooperation with the Vatican Museums (Dipl.-Phys. M. Boulouednine and Dipl.-Ing. Carlo Bogani)

Light, Colour and Vision (Part I).

In Praise of Spotlighting (Scott Rosenfeld)

Evaluation of colour quality of LED illumination for Museum Applications (Ming Ronnier Luo and Kangjun Liu)

Artificial Lighting Design for Paintings in Indoor Settings with selected Nanyang Paintings as a case study (Ong Thian Chai Nicholas, Martin Reiser (†), Assoc. Prof. Cesare Soci, Dr. Sarita Silveira, Assoc. Prof. Andrea Nanetti).

Light and colour: Assessing the effects of illumination on perceptual constancy of and aesthetic response to paintings (Anya Hurlbert and Joseph Padfield) ....................... 44

Light, Colour and Vision (Part II)..... 45 
Colour preference and naturalness of paintings under multi-LED spectra with different correlated colour temperatures and object saturation levels (P. Bodrogi, T. Q. Khanh, Q. T. Vinh, X. Guo).

Influence of cultural factors in preferred illumination for paintings (Sérgio NC Nascimento, João M.M. Linhares, Catarina F. M. Herdeiro, Taisei Kondo, Yukinori Misaki, Shigeki Nakauchi)

The Preferred Conditions of LED Lighting for Fine Art Paintings: The Influence of Illuminance Level and Correlated Colour Temperature (Ferenc Szabó, Renáta Kéri, Péter Csuti) .50

Light Damage 53

Mitigating Light Damage in a New Exhibition Space at the Getty Research Institute (Mark Benson).

A microfading survey of the lightfastness of blue, black and red ballpoint pen inks in ambient and modified environments.(Bruce Ford) .58

Collection Care and Policy. 61

Wavelength dependence and relative damage factors: an overview (David Saunders)61

Are we being too easily LED? Assessing the impact of LED lighting on pigments and paper in heritage collections (Emma Richardson, Elizabeth Woolley, Asya Yurchenko, Dave Thickett) 63

Implementing fully tuneable spectrum LED light sources at the Art Institute of Chicago: perspectives from lighting design and conservation (Kerri Callahan, Francesca Casadio, Sarah Casto, Sylvie Penichon, Antoinette Owen, Frank Zuccari) 66 Object-Specific Lighting Design for Mark Rothko's Green on Blue, a Collaboration between The University of Arizona Museum of Art and College of Optical Sciences (Ross D. Uthoff, Nathan W. Saxton, Rachel N. Ulanch, Kaitlyn E. Williams, Page King, Liliana Ruiz Diaz, R. John Koshel).....

Fading colours and the necessity for a new high-quality LED-museum lighting system with a clear formulated light policy for the paintings by Vincent van Gogh (Kees van den Meiracker)...... 
Upgrading Standards and Guidelines for the museum lighting: how to include new research results within an outdated model? (Costanza Cucci and Marcello Picollo)... 75

Towards the new standard for museum lighting in Japan (Nozomu Yoshizawa, Yoko Mizokami, Chie Sano, Naoto Yoshida) .77

Posters.

A status quo about the LED Lighting applications in the Chinese Museums and Galleries (Jing Ai). 79

Focus on Art by avoiding distracting color differences in the illumination - Revolution of the LED white binning (Alexander Wilm and Carolin Horst) 81

Assessment of the photo-stability of plastics found in heritage collections to visible light (Anna Pokorska, Lindsay MacDonald, Elise Talgorn, Stuart Robson, Katherine Curran, Boris Pretzel)

Natural Light Matters: surveying illumination at the Museum of Modern Art

(B. Campbell, H. Murata, J. Hickey, L.A. Daffner, E. Mosier, A. Martins)

Let LED Respect your ART Or How to Define State of the Art LED Systems for Art Galleries - A Field Report. (Claude Hidber)

Evaluation of Colour Rendition Methods Through Museum Lighting Investigations and Determination of Preferred Conditions for Fine Art Paintings (Péter Csuti, Ferenc Szabó, Renáta Kéri) 86

Take deLIGHT in Colours (Francesca Feltrin, Francesco Leccese, Peter Hanselaer, Kevin Smet) 88

LED lighting quality in museum showcases: results of an experimental case study (Gabriele Piccablotto, Anna Pellegrino, Chiara Aghemo)

The Interactions between Museum Lighting and Optically Coated Glazing (Jennifer Booth)

Moths to the flame: An investigation of the influence of lighting on museum visitor behaviour (Jessica Glaisher)..... 
Light and Art - LED and the new possibilities in object lighting (Kay-Uwe Dingeldein, Dario Maccheroni, Ralf Maller) 105

Lighting in museums, visitors' experience and satisfaction in a heritage context. Study cases in Northwest Argentina (L.N. Bazán, R.F. Ajmat, J.D. Sandoval) 108

The role of light on visitors' experience of the Parthenon Marbles in the Acropolis Museum (Panos Andrikopoulos, Kalliopi Fouseki, Panos Mavros, Andy Hudson-Smith, Frangiskos Topalis) 115

Replicating Blue Wool Testing for Art Conservation Using a Smartphone Spectrometer (Rachel N. Ulanch and R. John Koshel).

Lighting preference of artworks under multiple correlated colour temperatures condition (Qiang Liu, Rui Peng, QingMing Li, Yang Tang, MeiHua Tang, KaiDa Xiao, Ming Ronnier Luo).

Preference of Paintings under LED Lightings with Variations of CCT, Colour Fidelity and Colour Gamut (Qiyan Zhai, Ming Ronnier Luo, Ching-Ju Chou, Hung-Shing Chen)

Senses and thoughts: The light in the Kunsthaus Bregenz designed by Peter Zumthor (Seda Kaçel and Benson Lau). 128

Influence of LED lighting on the stability of modern paint materials (Valentina Pintus, Ferenc Szabo, Peter Csuti, Federica Cappa, Carlotta Salvadori, Renata Kari, David Noel That, Rita Wiesinger, Marta Anghelone, Zafia Nyari). 131

Lighting beyond art: choreographing views and appearances for the perceptive body (Veronika Mayerboeck, Elke Oberthaler, Sabine Penot, Alison Ritter). 133

Workshops. .130

Workshop A: Relighting the Petrie Museum: Smart Lighting and Proximity Aware

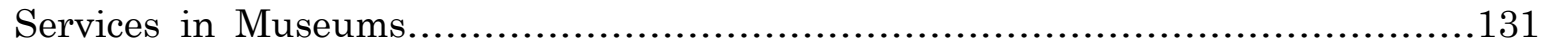

Workshop B: Precision LED drivers for viewing and digital imaging...................132

Workshop C: Neuropsychological methods for lighting design and research...........133

Workshop D: Modern Colour Science for Museum Lighting...........................134 


\title{
Keynote Speakers
}

\section{Lighting the New Acropolis Museum}

\author{
Florence Lam \\ BA(Cantab.) MA(Cantab.) MSc CEng FIET FCIBSE FSLL Fellow,
}

Global Lighting Design Leader, Arup

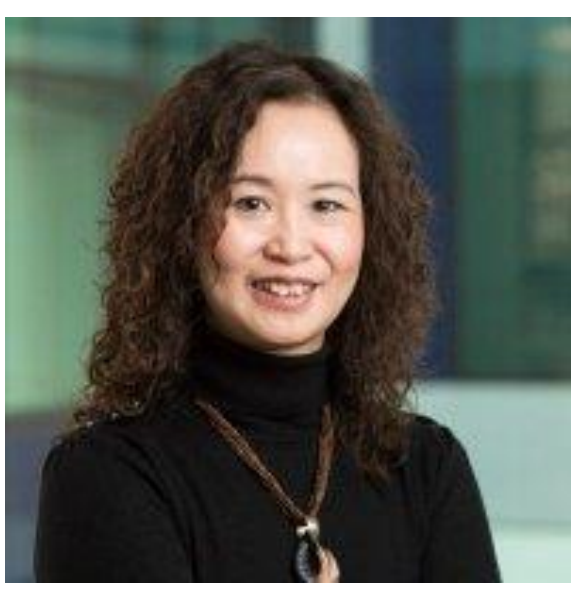

Florence is Fellow and Director at the international design, engineering and business consulting firm, Arup. She leads Arup's global lighting design practice. Her particular expertise include daylight, visual perception and holistic lighting approach, which play a key role when illuminating museums all over the world. Museum projects of significance include the New Acropolis Museum in Athens, Rijksmuseum in Amsterdam, Museo Picasso in Malaga, California Academy of Sciences in San Francisco, Nasher Sculpture Center in Dallas, Royal Ontario Museum in Toronto, British Museum World Conservation Centre and Tate Modern in London, the Hepworth in Wakefield and the V\&A Museum of Design in Dundee. She has co-authored in the publication of the RIBA Technical Review series on Lighting and a book called Space Craft on Developments in the Architectural Computing. Florence was named the Lighting Designer of the Year at the UK Lighting Design Awards in 2013. She is also the recipient of the Lighting Award from the Society of Light and Lighting in 2014. At the Museum Lighting Symposium, Florence will be discussing lighting in the New Acropolis Museum.

\section{$\underline{\text { ABSTRACT }}$}

The New Acropolis Museum is amongst the most important public projects in Greece of the 21st century. 1,000ft southeast of the Parthenon, the New Acropolis Museum stands on more than 100 concrete pillars suspended over an excavation site. Glass filled holes in the floor reveal ancient ruins and the glass walls of the Parthenon Gallery provide visitors with a panoramic view of the Acropolis and modern Athens. The sky-lit space is rotated to sit in alignment with the Parthenon. At its centre, a rectangular concrete core hosts a Parthenon frieze, placed in the exact same orientation as when it adorned the monument. Nearly 4,000 objects most coming from Acropolis are exhibited over an area of 14,000 sqm. The museum opened to the public in June 2009 and in the first two months; it was visited by 523,540 people (an average of 9,200 a day).

Arup began the journey of choreographing the light, museology and spatial experience in close collaboration with Professor Dimitrios Pandermalis (president of the Acropolis Museum) and 16 I P a g e 
Bernard Tschumi Architects after the architectural competition was won in 2001. The lighting team in London, led by Florence Lam, were appointed by OCNAM (Organisation for the Construction of the New Acropolis Museum) to provide daylighting and architectural lighting design, following the project through the opening exhibition.

More than any other quality, daylight is the theme of the New Acropolis Museum and a central requirement of the exhibition lighting design. Daylight is used to achieve a qualitative ambience for the galleries and optimum display conditions for the artefacts. The architectural lighting is minimal yet plays a complimentary role. Light is used as a tool to replicate, as far as possible, the outdoor conditions under which many of the architectural sculptures were originally seen.

In the Archaic Gallery, the glass treatment on the north facing facades and the skylight profiles have been designed to optimise the light quality of the Attican sky. On the glazed façade, diffuse screen print treatment is used on the lower panels while overlapping dim-out blinds are applied on the upper panels for optimum solar screening. The asymmetry of the daylight distribution contributes to soft modelling and atmospheric light for the sculptures allows all electric lighting to be switched off during the day, making this a truly sustainable lighting approach. Fluorescent lamps concealed within the skylights supplement the daylight as it gets dark. A layer of accent lighting for enhancing individual sculptures is provided by an array of track-mounted spotlights carefully integrated in troughs either side of the skylights.

The Caryatid Gallery is an internal gallery where natural light filters through the space through the glass floor above. The ceiling spotlights capture the main body of the statues from different angles and accentuate the hair details at the back. The track-mounted directional spotlights on the side walls frame the face of the Caryatids softening the shadowing effect caused by the downlighting of the statue capital. Layers of light are applied like brush strokes on a painting refining the Caryatid forms and revealing their modelling details. The lighting effect is theatrical yet subtle.

The highlight of all galleries is the Parthenon Gallery at the top of the museum where the Parthenon marbles are appreciated under daylight with the Acropolis seen in the background. The gallery's facades are double-glazed and treated with varying density of screen-printed technology to keep out the intense sun and sky glare while retaining the visual connection with the Parthenon. Adopting principles more commonly practiced in the theatre, the daylighting strategy configures linear continuous skylights in the roof allowing daylight from above to graze down both the friezes and the metopes thus enhancing the modelling effect of the sculptures.

As dusk falls, the architectural lighting builds up forming a key narrative element of the set, transforming the glass museum into a giant display case. The New Acropolis Museum received the Award of Excellence at the 27th annual International Association of Lighting Designers (IALD) Awards. It also attracted the Sustainability Award, the only project granted such award in 2010. 


\title{
Museum lighting - 30 years of developments and lessons for the future.
}

\author{
Stefan Michalski
}

Senior conservation scientist, Canadian Conservation Institute (CCI)

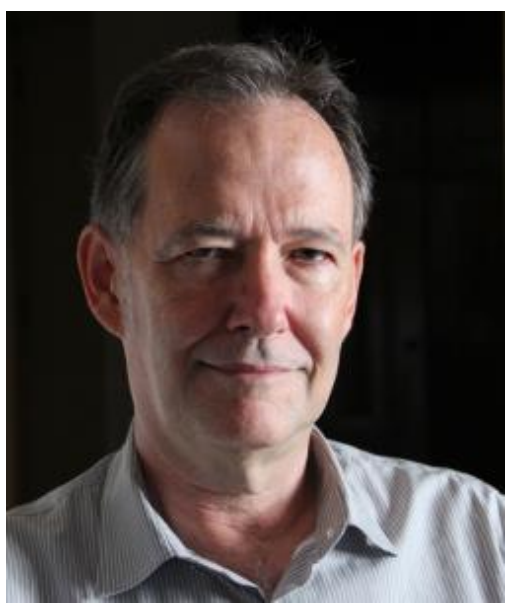

Stefan is senior conservation scientist at the Canadian Conservation Institute (CCI). For over 35 years, he has carried out research and provided advice on preservation for museums, galleries and archives, particularly on the topics of lighting and climate control. He has authored over 80 publications which have accumulated over 900 citations.

In 1987, for the conference Lighting in museums, galleries and historic houses (Museums Association, UKIC, and the Group of Designers and Interpreters for Museums) Stefan was asked to provide a critical review of the literature on light damage and its implications for museums. He is pleased to be able to present a retrospective on thirty years of developments, lack of developments, and lessons for the future.

In 1989, he developed the CCI Light Damage Slide Rule, and twenty years later, developed its web based replacement, the CCI Light Damage Calculator. In 1990, he proposed that lighting exposure guidelines be based on explicit consideration of an object's purpose, its required lifetime, and its specific vulnerability, not on fixed rules and not on false generalizations across media, e.g., all paper objects, all paintings, etc.) In 1997, he applied the CIE model of visual performance to the museum visitor's task, and showed that Thomson's guesstimate of a 50 lux benchmark could be derived explicitly for a task of moderate difficulty on an object of moderate reflectivity, moderate contrast, moderate detail, but only for a young observer. He derived rules of thumb for adjusting the intensity for older viewers, darker objects, softer contrast. He is the author of CCI's current web pages on light and UV, as well as those on incorrect relative humidity and incorrect temperature. His data tables on the sensitivity of various materials to light, developed for CCI training workshops, were used in the publications Museum and Gallery Lighting (IESNA RP-3096) and in Control of Damage to Museum Objects by Optical Radiation Publication, CIE 157:2004. He co-organized workshops on museum lighting in 1997 and 2007 for the American Institute for Conservation, and in 2011 for CCI, with Kit Cuttle and Jim Druzik. For that workshop, Jim and Stefan developed a text on solid state lighting for museums, which has been widely distributed. In 2014 the US Department of Energy surveyed 979 museums who had obtained the report and analyzed their experience of LED lighting. Completely revised guidelines are currently in preparation for the CCI web page. 
Stefan's other work has been in climate control and risk management. He was lead author for the humidity and temperature specifications in the "Museums, Libraries, and Archives" chapter of the ASHRAE Applications Handbook, (editions 1999, 2003, 2007, 2011, 2015) and author of the CCI Technical Bulletin \# 23 Guidelines for Humidity and Temperature for Canadian Archives. At the invitation of ICOM and UNESCO he wrote the chapter on "Collection Preservation" in Running a museum: a practical handbook, 2005, ed. P. Boylan, p. 51-90. (available in 5 languages on the UNESCO site). In partnership with ICCROM and Instituut Collectie Nederland (ICN, now RCE), he developed and taught the course Reducing Risks to Collections (Ottawa 2003, Rome 2005, Ottawa 2006, Sibiu 2007, Beijing and Quito 2009, Istanbul 2011, Tianjin 2014).

\section{ABSTRACT}

In 1987, the Museums Association, the United Kingdom Institute for Conservation, and the Group of Designers and Interpreters, organized a conference called Lighting: A Conference on Lighting in Museums, Galleries, and Historic Houses. I was asked to provide a review of the literature on damage caused by light and ultraviolet (UV). Both Peter Boyce and David Loe spoke about vision. Kit Cuttle spoke about damage factors for lamps. Today, thirty years later, I will present an overview of what we already knew then, what we have learned since then, and where I hope we will learn more in the future.

This presentation will touch on all three issues of museum lighting - damage to the artifacts, visual perception, and lighting technology. Although I am primarily an expert on the issue of damage, in my role as a practical advisor to Canadian heritage institutions making lighting decisions, it has been essential to place the advice on damage within the context of perception issues and lighting technology.

By 1987, damage by light was well understood. Large quantities of industrial data had quantified colour change (usually fading) in terms of a lightfastness standard (the blue wools) and a growing number of museum oriented studies provided data in colourimetric terms as well as the blue wools. In 1994 Whitmore invented the microfader, which opened the door to direct measurement of the blue wool rating of objects in question, thus by-passing the need for colourant identification. The problem remained, however, of translating Blue Wool ratings into estimates of damage per unit exposure. Several years ago, the Canadian Conservation Institute (CCI) created an online tool to provide such estimates, based on fits to existing data and the assumption of reciprocity. A very recent study of reciprocity, and the first to examine many traditional colourants, has shown that while most remained within one blue wool step error for extrapolations from near daylight intensities to almost gallery conditions, a few deviated significantly, for reasons unknown. (Lerwill et al 2015) Reciprocity can deviate even further between MFT intensities and museum intensities. Fortunately, Ford \& Smith (2017) have confirmed by several case studies of object fading in the museum compared to subsequent microfader measurements of undamaged portions that the 
correlations hold well enough to confirm not just the reliability of the blue wool assignment by MFT but also the approximations derived for absolute fading rate at museum intensities.

I think that the transformations we have seen since 1987 in our knowledge of damage, vision, lighting design, or indeed any other field of science and engineering, has been the progression of what Jim Gray called the four paradigms of science. The first was systematic observation, the second was modelling with mathematics and computations that human beings could achieve before computers. What we knew in 1987 about light damage, about vision, about lighting design, came through these two paradigms. The last thirty years saw the rise of the third paradigm computational power that allowed models to become elaborate simulations. Most of the advances in museum lighting have depended on this paradigm - the CCI light damage calculator, the new colour difference calculations, real-time colorimetry output from the micro-faders, colour fidelity based on 99 samples rather than a restricted set of eight, lighting design software, etc. The fourth paradigm is the mining of "big data" to find subtle patterns we cannot see otherwise. This is currently practiced by business and big physics but is gradually entering the sciences in general. The problem is the "curation" of legacy data into a form that allows digital mining. Pooling datasets such as fading data, together with the data on artifact materials collected by museums worldwide, is a small step in that direction.

What specific issues do I think are priorities to solve for museum lighting in the future? For light damage, we need 1) to pool the microfader data; 2) reconcile it with legacy data on lightfastness; 3) make it available to users in a meaningful form for decision-making; and 4) find the absolute calibration of such data in terms of dose. Yes, this calibration will remain uncertain, but it should be a quantified and minimized uncertainty, with known confounding factors controlled $(\mathrm{RH}$, extreme intensity, etc.). For vision issues, we need to 1) refine our understanding of visual acuity in the museum and gallery context, its change with viewer's age, and its role in preference studies of lighting; 2) make this knowledge available to users in a meaningful form; 3) develop ethical and practical protocols for providing equal access to aging populations. We need to address the lack of intergenerational ethics in the common practice of rotating sensitive collections - should we not "archive" a few reference artifacts away from exposure, gifts to inform future generations of their original appearance, rather than damage everything evenly, albeit more slowly. For lighting issues, I hope that within a few years the LED manufacturers can produce high colour rendering lamps that are stable as the norm for all consumers rather than the expensive rarity they are today. I hope that fixture designers and architectural hardware designers integrate their ideas better to produce clutter-free ceilings. I hope that visual studies separate clearly our all-too-human preferences for intensification from our core preference for fidelity, and make this knowledge available to users in a meaningful form. 


\section{$\underline{\text { Presenters }}$}

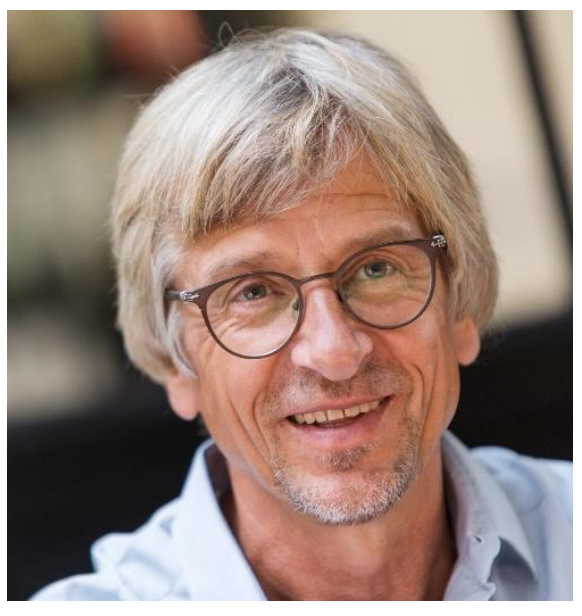

Andreas Schulz has over 30 years in lighting design experience. In 1991, he founded Licht Kunst Licht in Bonn and Berlin simultaneously. Since then, the office has participated in over 700 projects throughout Europe and overseas. It has more than 350 publications and has received numerous internationally recognized lighting design awards. $\mathrm{Mr}$ Schulz is a frequent lecturer at professional conferences and University programs. He is the founding professor for lighting design at the HAWK in Hildesheim. Mr Schulz is a Lighting and Energy related consultant for the Federal Republic of Germany, a member of the Berlin Lichtbeirat Lighting Advisory Council, and consultant to the building works senator within the German senatorial administrative office for urban development. In 2010, he was appointed Director of the International Association of Lighting Designers (IALD) and is currently Chair of the IALD Europe Steering Committee.

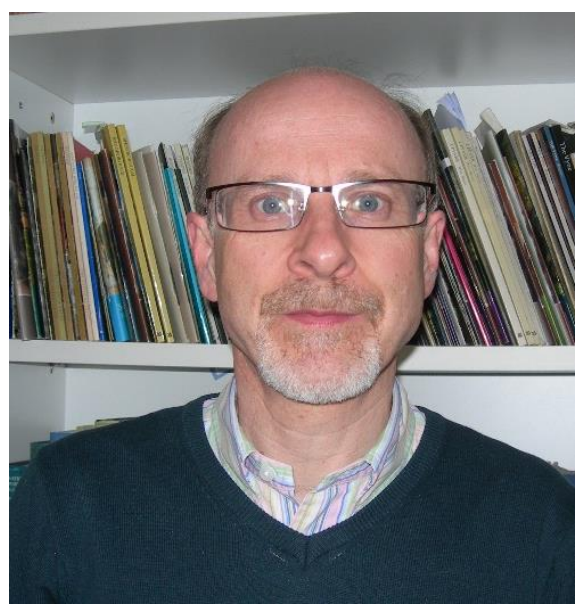

Dr Nigel Blades is Preventive Conservation Adviser (Environment) for the National Trust, where his work includes advising on environmental control solutions and preventive conservation for the care of collections; and overseeing temperature, humidity and light exposure data collection and interpretation for the Trust's historic properties. Dr Blades is closely involved with the Trust's conservation science research, which included participation in the EC Integrated project 'Climate for Culture' (2009-14) and ongoing collaborative research on mould growth in historic collections and daylighting of historic house rooms. Before joining the National Trust in 2008 Dr Blades was Lecturer at the UCL Centre for Sustainable Heritage, where he was joint course director for the MSc Sustainable Heritage and undertook research into preventive conservation. He has a PhD in Archaeological Science and a BSc in Industrial and Natural Resource Chemistry. 


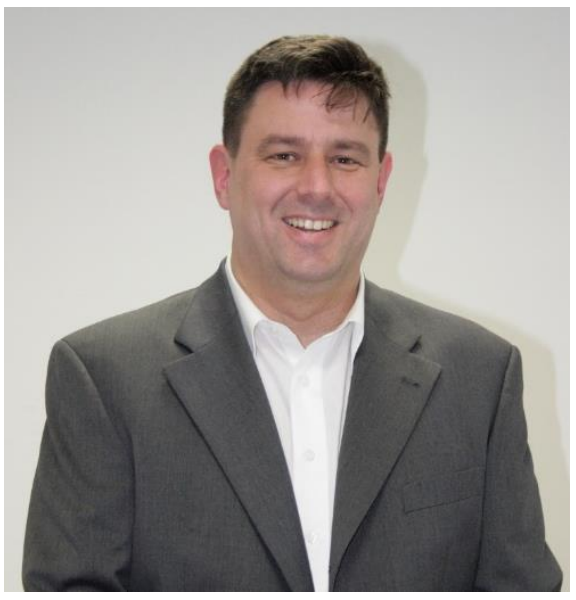

Mourad Boulouednine gained his diploma in Technical Physics at the Technical University of Munich in 1992 and then joined the project department of OSRAM. He gained extensive knowledge on illumination and application of new lighting technologies by work on many projects concerning all major traditional light sources, fibre optic light sources, inductive lamps, analogue and digital controls and LED as well as OLED technologies. In 2001, he initiated OSRAM's activities for energy auditing concepts and software tools proving the reduction of the carbon footprint in refurbishing projects. After two years in Dubai and experience in many large and international commercially successful projects, he is today responsible for OSRAM's activities in high quality illumination of art work and many projects of highest attention like the Sistine Chapel in Vatican State.

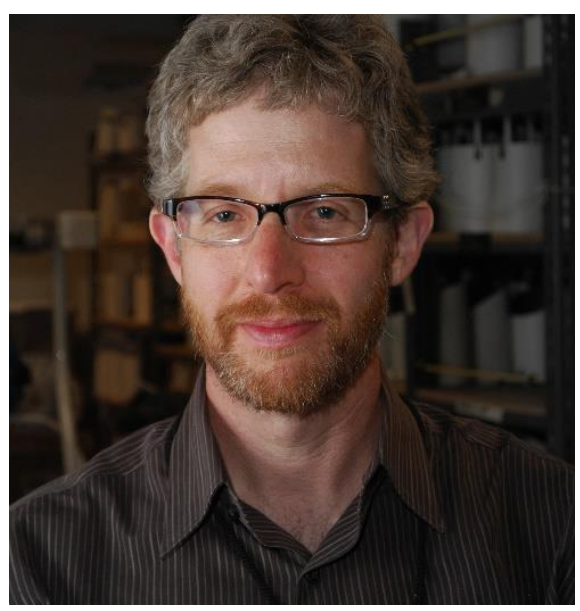

Scott Rosenfeld LC, IES is the lighting designer at the Smithsonian American Art Museum and Renwick Gallery. For over twenty years, Scott has worked on lighting art collections so they can be better seen, experienced, and preserved. The advent of energy efficient LED lighting has led him to research new possibilities for manipulating the spectrum of light to enhance vision and slow the degradation of light sensitive materials. He's collaborated with the US Department of Energy to field test LED products in museum applications, with the National Institute of Standards and Technology (NIST) to access the color rendering attributes of light, and with the Getty Conservation Institute (GCI) to better quantify how light damages art collections. Scott is chair of the IES Museum Committee where he led a team of experts to publish the 2017 Recommended Practice for Museum Lighting. 


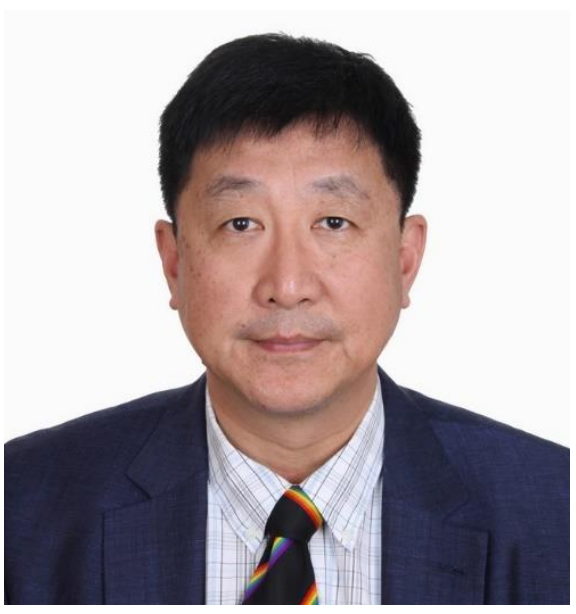

Ronnier Luo is a Professor of Colour and Imaging Science at Leeds University, a Global Expertise Professor at Zhejiang University, a Chair Professor at National Taiwan University of Science and Technology and the Vice-President of International Committee for Illumination (CIE).

He received his $\mathrm{PhD}$ in 1986 at the University of Bradford in the field of colour science. He has published over 500 scientific articles in the fields of colour science, imaging technology and LED illumination. He is a Fellow of the Society for Imaging Science and Technology, and the Society of Dyers and Colourists. He is also the Chief Editor of the Encyclopaedia of Colour Science and Technology published by Springer in December 2016.

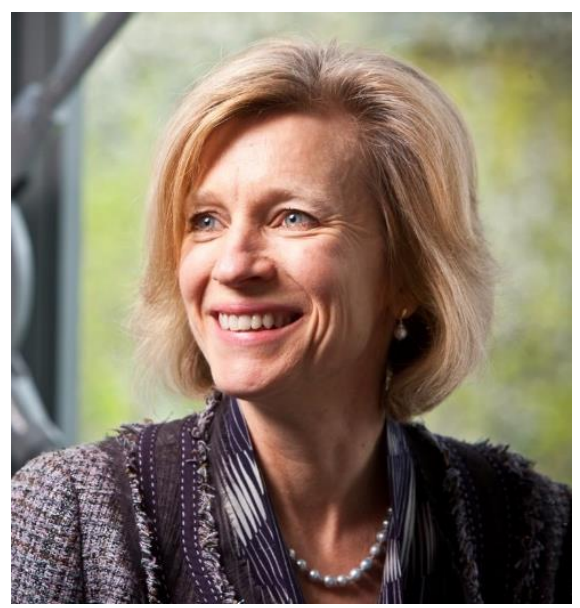

Anya Hurlbert graduated from Princeton University in 1980 with a BA in Physics, followed in 1981 by a Part III Diploma in Theoretical Physics and in 1982 an MA in Physiology from Cambridge University, where she held a Marshall Scholarship. In 1989, she received a PhD in Brain and Cognitive Sciences from MIT, where she studied with Tomaso Poggio and Peter Schiller, and in 1990, an MD from Harvard Medical School. She then held a Vision Research Fellowship at Oxford University in Andrew Parker's lab, before joining Physiological Sciences in the Faculty of Medical Sciences at Newcastle University in 1991 as a lecturer.

She has been acting Head of the Division of Psychology, Brain and Behaviour (Faculty of Science, Agriculture and Engineering) in 2003, and interim Head in 2007, helping to create the new School of Psychology in the Faculty of Medical Sciences. In 2004, she co-founded the Institute of Neuroscience with the late Professor Colin Ingram, and was co-Director of the Institute until 2014. In 2012, she established the Centre for Translational Systems Neuroscience with a Capital Award from the Wellcome Trust. 


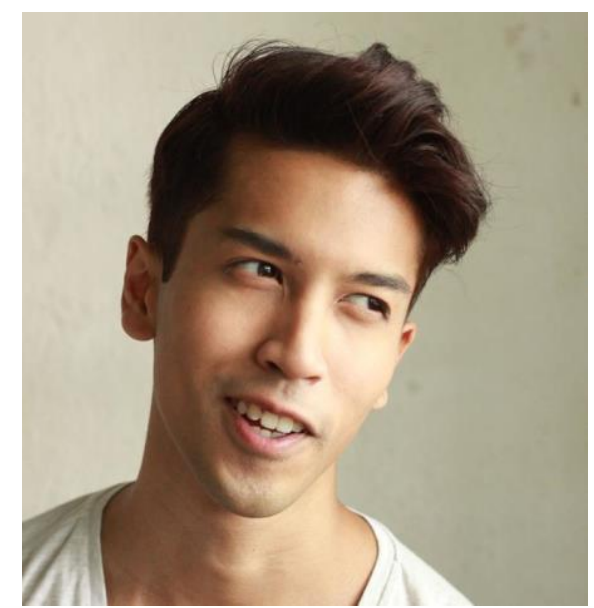

\section{Nicholas ONG THIAN CHAI}

Formally trained in industrial design, with a strong background in art history, Nicholas has, as a lighting designer lit many retail and hospitality spaces across SouthEast Asia. He is currently a Masters of Art candidate at the school of Art, Design and Media; Nanyang Technological University. Nicholas also fronts Suchart and Ong, a creative agency in Singapore and holds an adjunct lecturer position at the Singapore Polytechnic Design School.

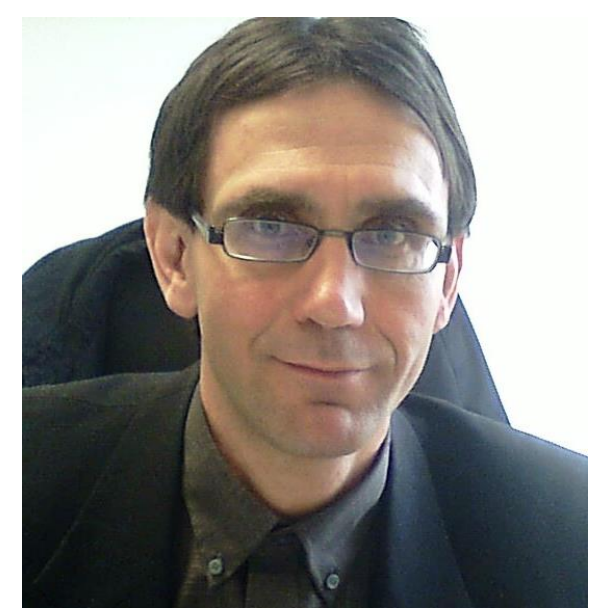

Peter Bodrogi is senior research fellow at the Laboratory of Lighting Technology of the TU Darmstadt in Darmstadt, Germany. He obtained his $\mathrm{PhD}$ degree in Information Technology from the University of Pannonia. He obtained his Degree of Lecture Qualification from the TU Darmstadt in 2010 for his thesis on the optimization of modern visual technologies. He co-authored numerous scientific publications and invented patents in the domains of self-luminous display technology and lighting technology.

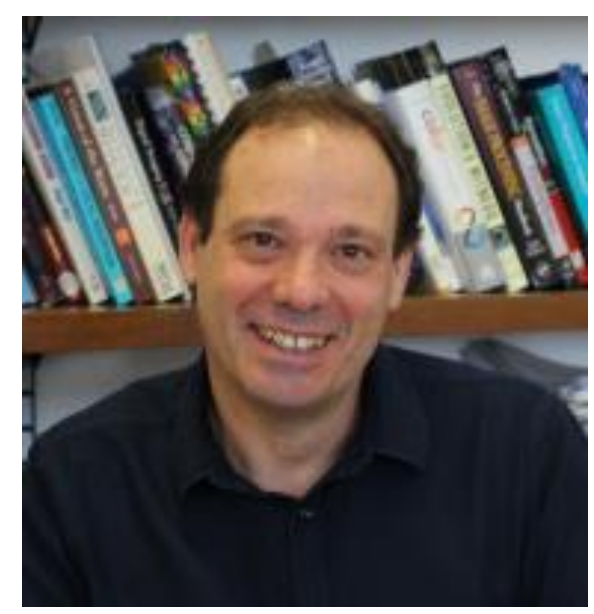

Sérgio Nascimento graduated in Physics and has a $\mathrm{PhD}$ in Color Science. He is an Associate Professor with Aggregation of Physics at Minho University, Portugal, where he teaches Optics, Vision Sciences and Color Science. His research focuses on colorimetry and color vision, in particular, applications of spectral imaging, color rendering and color in art. He has published more than 100 research articles on color vision and related topics. He is member of the Board of Directors of the International Color Vision Society and topical editor for colour vision of the Journal of the Optical Society of America A. 


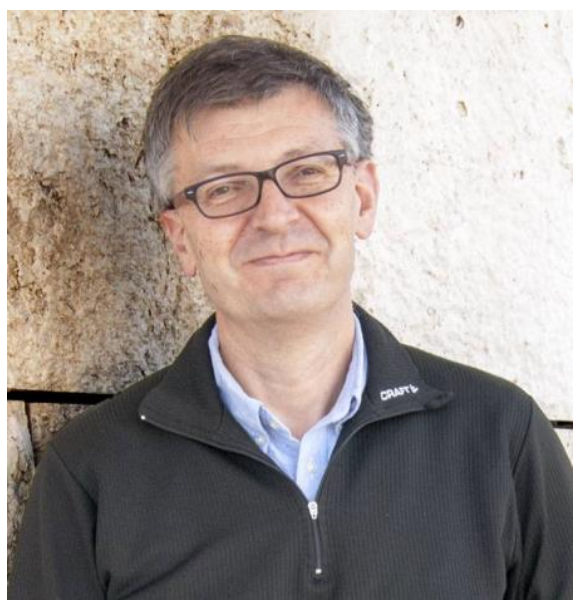

David Saunders is an honorary research fellow at the British Museum, where he was Keeper of the Department of Conservation and Scientific Research from 2005-2015, after 20 years in the Scientific Department at the National Gallery, London. His research interests include the deterioration of museum objects, particularly pigments and painted surfaces, focusing on the effect of light on the deterioration of cultural heritage objects. He has published widely on this subject, both in the specialist literature and in more general texts, including the 1994 and 2015 CIBSE guides on museum and art gallery lighting. He was a guest scholar at the Getty Conservation Institute in 2015-2016, researching a book on museum lighting. He is a syndic of the Fitzwilliam Museum, a fellow of the Society of Antiquaries of London and vice president of the International Institute for Conservation.

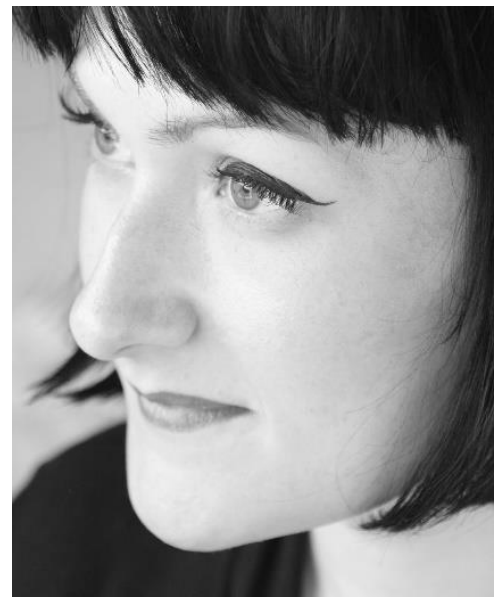

Emma Richardson is Lecturer in Material Studies at UCL and coordinator of the History of Art with Material Studies programme. She is head of the Material Studies Research Group and currently PI on projects funded by The Leverhulme Trust, the Analytical Chemistry Trust Fund and Historic England. The overarching focus of Emma's research is the study of organic polymers in heritage collections, in particular the manufacture, identification and degradation of synthetic polymers, with a view to informing contemporary conservation practice. She recently cocurated the exhibition Dangerous Diaries: Exploring Risks and Rewards in Fabrication in partnership with the Institute of Making, which studied perceptions of risk and how approaches to hands-on engagement with materials and making have changed over time. Emma's education and research has combined material science and conservation, leading to multidisciplinary collaborations with institutions such as Tate, The National Gallery, the V\&A, Hampton Court Palace, Disney Animation and SFMOMA. 


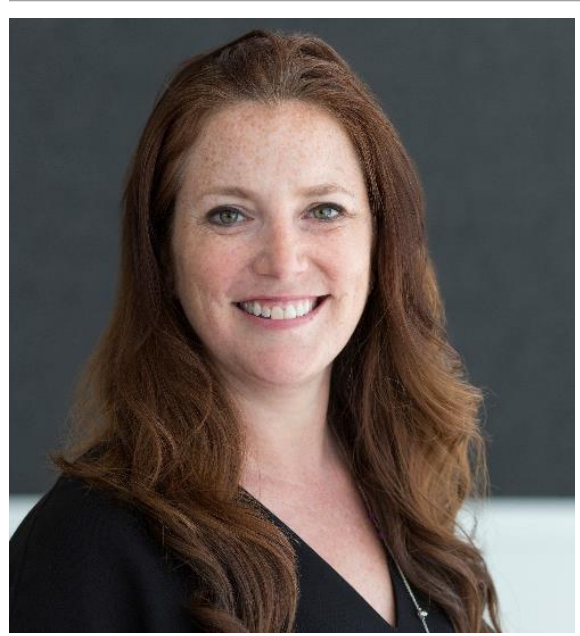

Kerri Callahan is an architect, interior designer, lighting professional, and project manager with over 20 years' experience as a design and construction professional in Chicago, Illinois. She began her career coordinating construction projects for major general contractor Pepper Construction before spending 10 years as an associate architect with LCM Architects and later the DLR Group. A keynote project in her interior design portfolio is Access Living of Metropolitan Chicago, a ground-breaking 50,000 sf office building which incorporates Universal Design concepts to meet the needs of the disabled staff and clientele of this advocacy group. Kerri next broadened her portfolio at Lightswitch Architectural, where she served as Director of Lighting Design, tackling theater spaces and residence halls with renowned firm Studio Gang before coming to the Art Institute of Chicago to lead not only the lighting design but full implementation of design \& construction for The Deering Family Galleries of Medieval, Renaissance Art, Arms and Armor. Within these new permanent collection galleries, she implemented the first all LED gallery lighting installation within the Museum, including the use of color tunable lighting throughout. Kerri currently oversees the continuing implementation of color-tunable LED lighting throughout the Museum as well as upgrades to lighting controls to accommodate ever-changing needs for the collections.

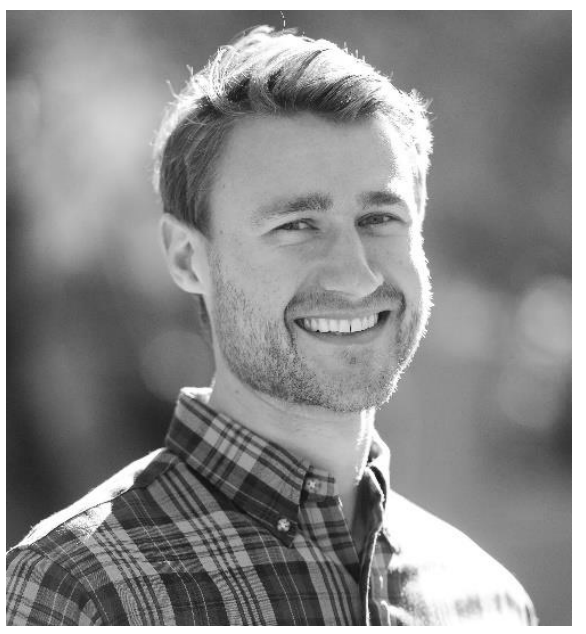

Ross Uthoff is a doctoral student in the Applied Optics Lab at the College of Optical Sciences at the University of Arizona. As part of the College's Illumination Design Interest Group, he researches the design of freeform illumination optics, and the group is currently developing a custom luminaire for Mark Rothko's Green on Blue in collaboration with the University of Arizona Museum of Art. He also works on the design and development of low-cost, smartphonebased biomedical instrumentation for low-resource communities. Applications for the technology include oral cancer detection and retinal imaging. Ross completed his undergraduate studies at Rose-Hulman Institute of Technology and has worked in industry on laser rangefinder technologies. He enjoys exploring the many mountain ranges surrounding Tucson. 


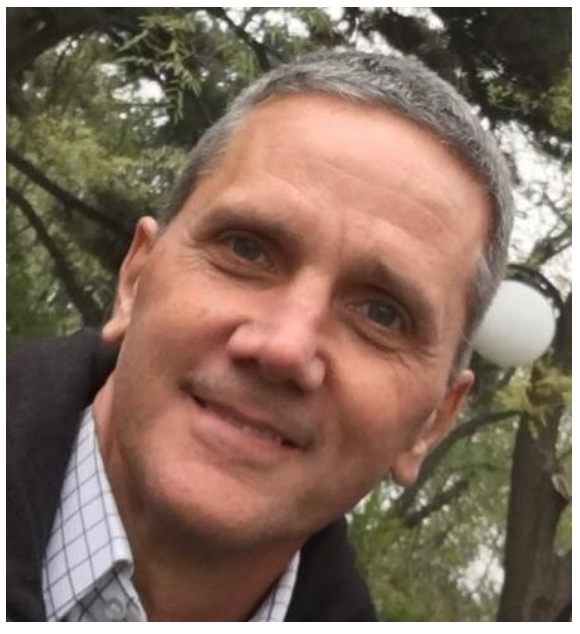

Dr. Kees van den Meiracker is Head of Collections and Preservation of the Van Gogh Museum Amsterdam. He is an anthropologist specialized in collection management.

The van Gogh Museum Amsterdam is one of Europe's most successful and innovative museums with more than 2.1 million visitors a year. The museum is housed in a relatively small building and has a relatively small collection of worldfamous fame, which is always exhibited. The collection management and restoration department is responsible for all the processes involved in the collection. Through research and innovation, we try to reduce the tension between collection care and exhibitions. In cooperation with the University of Amsterdam and several multinational we try to keep the collection for the future and show it to a worldwide audience.

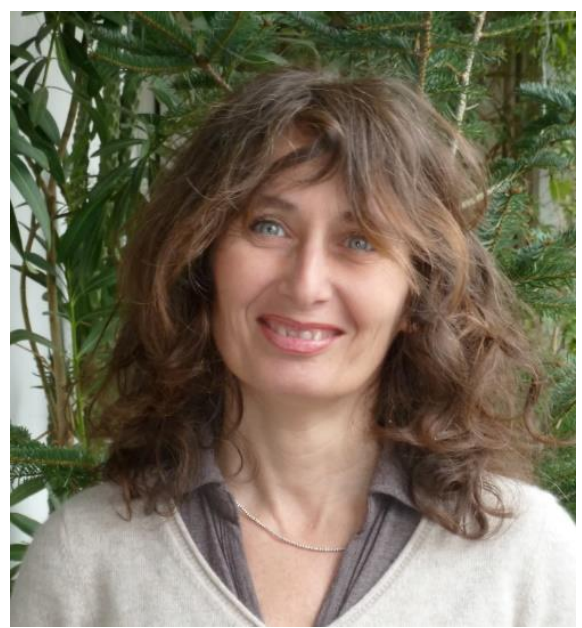

Costanza Cucci graduated in Physics and got a $\mathrm{PhD}$ in Conservation Science from the University of Florence (Italy). She is researcher at the Institute of Applied Physics "Nello Carrara" of the Italian National Research Council (IFACCNR) in Florence. Her research interests include: spectroscopic techniques for materials analysis with a focus on non-invasive methodologies, colorimetry and study of photo-induced phenomena in polychrome objects; hyperspectral imaging and multivariate data-analysis; optical sensors. Applicative fields: cultural heritage, environmental monitoring, agri-food safety/quality.

She has been involved in several international and national research projects, including the EC Project "LiDo: a LIght DOsimeter for monitoring cultural heritage (2001-2004)". She is coordinator of the 'Indoor Lighting of Cultural Heritage' Working Group of the Italian Standardization Body (UNI) and she has collaborated to the Technical Committee 346/WG6 "Exhibition lighting of cultural property" of the European Committee for Standardization (CEN). 


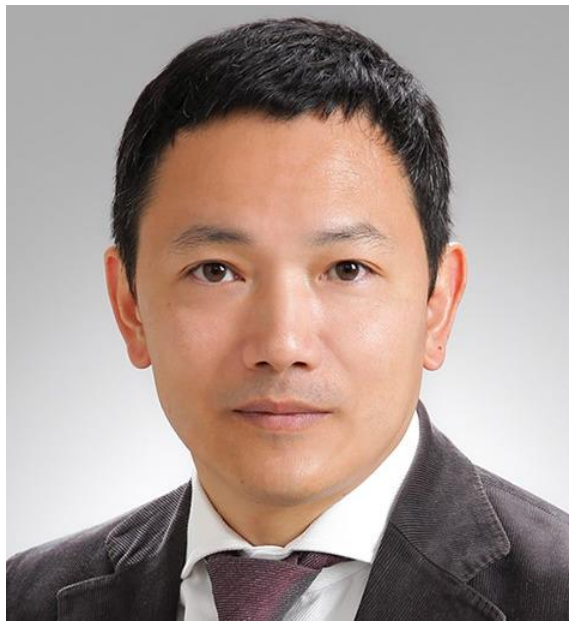

Nozomu Yoshizawa is Professor at Tokyo University of Science, received his PhD in Engineering from the University of Tokyo in 1998. He specializes in daylighting and artificial lighting in architecture, and has conducted research on the appearance of paintings and daylighting systems in museums. He serves as Vice-Chair of the Museum Lighting Committee in the Illuminating Engineering Institute of Japan, and Associate Division Director - Electric Lighting of Division 3 in CIE since 2016.

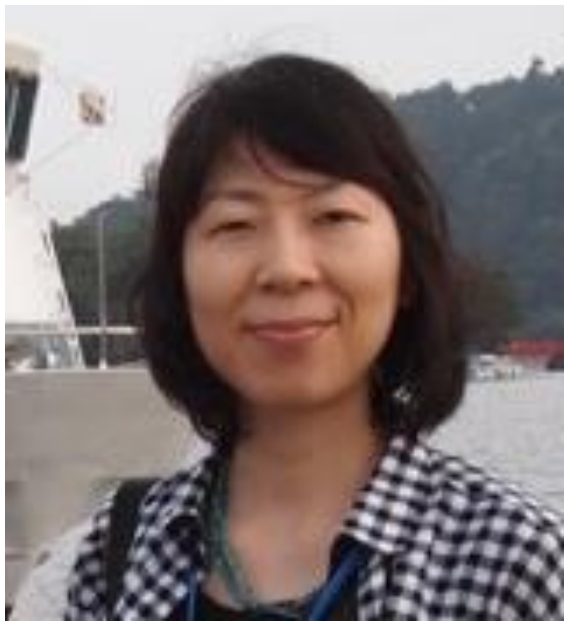

Dr. Yoko Mizokami is Associate Professor in Department of Imaging Sciences, Graduate School of Engineering, Chiba University, Japan. She received a Ph.D. in Engineering in 2002 from Ritsumeikan University, Japan. From 2002-2006 she was a postdoctoral fellow at the University of Nevada, Reno, Department of Psychology. She moved to Chiba University in 2006. Her main research fields are color vision, color science, and vision in natural environments.

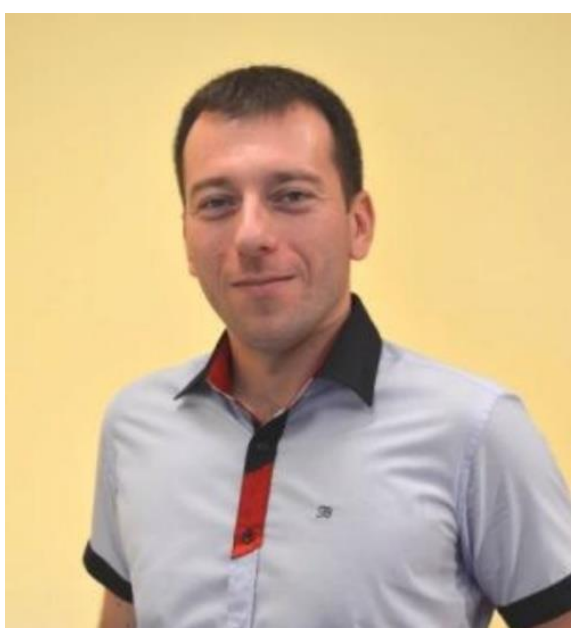

Dr. Ferenc Szabó has MSc in Information Technology and BSc in Electrical Engineering. His $\mathrm{PhD}$ thesis dealt with description of colour quality of modern light sources (LEDs). He is head of laboratory and associate professor at the "Light and Colour Science Research Laboratory" at University of Pannonia. He is author of over 100 technical papers and conference lectures. He is active in the Lighting Society of Hungary and the International Commission on Illumination, the CIE. He won prizes like the Leon Gaster award from the Society of Light and Lighting (UK, 2010) or the Exceptional Young Scientist's award from the Hungarian Academy of Science (HU, 2015). His research areas are: colour quality of light sources, colour appearance, museum lighting, mesopic vision, visual and non-visual effects of light. 


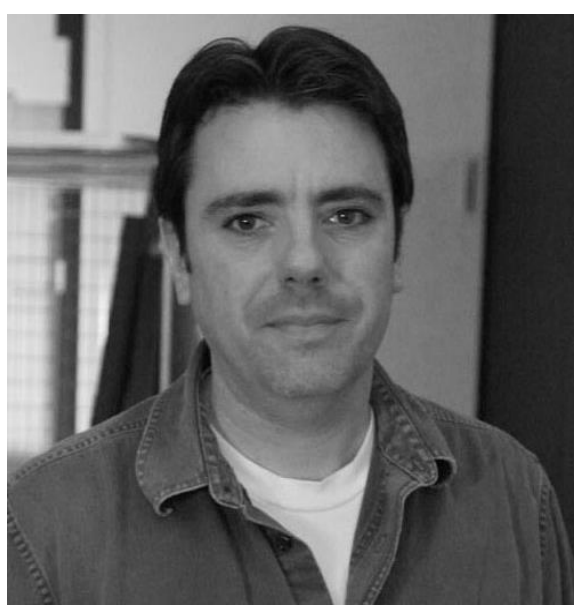

Mark Benson is an Assistant Conservator at the Getty Research Institute in Los Angeles, California. He earned an undergraduate degree in Art History from the University of California, Los Angeles and has worked in Museums and Special Collections for over ten years. Mark's primary research interest related to museum lighting is minimizing the damaging effects of light on works on paper with a minimal impact on access. Currently, Mark is working on a series of experiments utilizing Microfadeometry and color monitoring to investigate the differences between real-time color change and accelerated color change for various types of media.

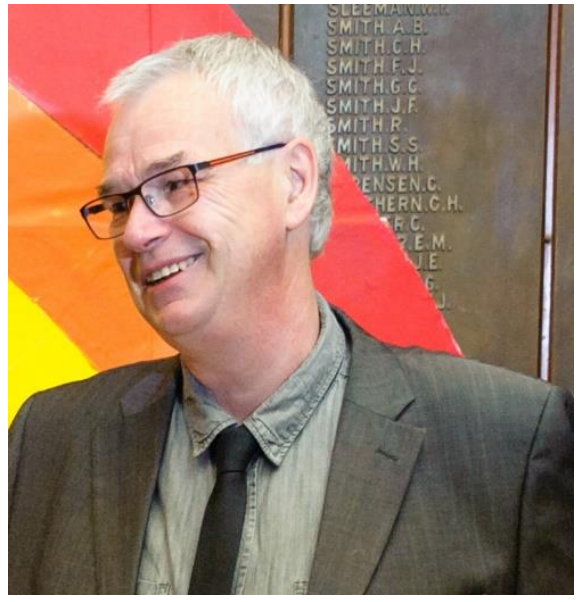

Bruce Ford is an independent Canberra based conservation science consultant and also a researcher with the National Museum of Australia, where his work focuses on the effects of light exposure on museum collections. He is also an indigenous rock art conservator and researcher, former Head of Conservation at the National Gallery of Australia and taught conservation science for many years at the University of Canberra. During the past 6 years he has worked as a Senior Researcher for the Tate Gallery in London and has provided microfade testing services, installation and training for numerous Australian and overseas museums, libraries, galleries and archives. His most recent major project concerns the response of iron gall inks to light in air and hypoxic environments. Website www.microfading.com 


\title{
Podium Presentations
}

\author{
Case Studies
}

\author{
Chaired by Panagiotis Andrikopoulos
}

\section{Museum Lighting - Daylight Autonomy and Application of Novel Artificial Lighting Technologies in Museums}

\author{
Prof. Dipl.-Ing. Andreas Schulz \\ Licht Kunst Licht AG, Bonn | Berlin \\ berlin@lichtkunstlicht.com
}

An excellent colour rendering and an availability free of charge qualifies the use of daylight for museum applications. The dynamics of daylight allow for a vivid experience of the art, at the same time however, it poses a challenge regarding the conservational requirements and the avoidance of estival overheating. In many museums, especially stringent conservational criteria have led to lighting concepts which completely exclude the use of daylight and solely focus on the use of artificial lighting. This approach seems unsatisfactory because a lighting concept using daylight may be of superior quality in comparison to artificial lighting. High quality standards concerning museum lighting result in a relatively high specific lighting power consumption. Lighting can account for up to two thirds of the primary energy consumption in a museum.

In order to integrate daylight into museums, its dynamics have to be mastered with respect to the conservational requirements and solar heat gains. Here, for overhead and sidelight illumination a variety of strategies is available.

In order to serve the principal requirement to create optimal conditions for viewing objects in a museum or exhibition context, the implementation of novel artificial lighting technologies suggests itself. Moreover, providing for a pleasurable and informative visual experience whilst avoiding damage due to light exposure, most museum applications call for unique and sensitive lighting solutions.

In collaboration with the architects of the following projects, the lighting designers and engineers from Licht Kunst Licht AG have developed lighting concepts based on various strategies to meet the purpose:

\section{Kunstmuseum Ahrenshoop (Staab Architekten, Berlin)}

New building of contemporary exhibition spaces with an ensemble of sculptural building volumes. All exhibition spaces are equipped with elongated horizontal daylight openings with integrated 
prisms in or-der to generate a virtually shadow-free light distribution. Integration of artificial light sources for general and accent lighting in the perimeter skirting of the skylight opening.

Städelsches Kunstinstitut, Frankfurt am Main (schneider+schumacher, Frankfurt am Main) New development of an underground exhibition hall, circular horizontal ceiling skylights, adjustable, flexible daylight systems, integration of artificial light sources into the skylights.

LWL Landesmuseum für Kunst und Kultur, Münster (Staab Architekten, Berlin)

New building with 51 exhibition spaces. Skylights with integrated luminous ceilings with static prismatic sun protection and electrically controlled daylight reduction layers. Identical lighting atmosphere achieved in the exhibition spaces lit by artificial lighting only. Development of a unique luminous ceiling solution implementing fluorescent tubes for uniform illumination of vertical surfaces.

The lighting systems described in the projects listed above are going to be analysed and compared concerning their function and capacity. This is going to be done by illustrating the qualitative and quantitative features of the lighting and energy concepts. 


\title{
Climate based daylight modelling for light management in historic house showrooms
}

\author{
Nigel Blades ${ }^{1}$, Katy Lithgow ${ }^{1}$, John Mardaljevic ${ }^{2}$, Stephen Cannon-Brookes ${ }^{3}$ and \\ Lisa McCullough ${ }^{1}$ \\ National Trust ${ }^{1}$; School of Architecture, Building and Civil Engineering, Loughborough \\ University ${ }^{2}$, Cannon-Brookes Lighting \& Design ${ }^{3}$ \\ nigel.blades@nationaltrust.org.uk
}

In historic house showrooms, daylight is often the main source of illumination for art works and objects displayed to the public. The changeable quality of daylight can provide interest and variety and the sense of an authentic historic house experience. However, illuminance in side-lit rooms dependent on daylight may fall by two orders of magnitude or more on objects on the back wall and in corners compared with those in the room foreground. This makes the balance that has to be struck between providing sufficient light for viewing of collections and light control for conservation, more difficult to achieve than in rooms lit solely by highly controllable electric lighting.

National Trust houses have approached this issue through the concepts of annual light dose and light planning. Fluctuating daylight conditions are managed to a maximum annual luxhour dose of 150,000 luxhours for high sensitivity objects and 600,000 luxhours for moderately light sensitivity objects. For a museum or gallery open 3000 hours a year, these luxhour doses are equivalent to the widely accepted museum conservation standards for illumination of 50 lux (high sensitivity objects) and 200 lux (moderately sensitive objects). Ultraviolet radiation is assumed to be excluded through filtration. A Light Plan is used to determine the setting of window blinds at different times of day and through the seasons to stay within annual lux hour doses; whilst enabling sufficient illumination of objects at the back of the room and avoiding excessive exposure of those in the foreground as much as possible.

Light planning has traditionally been carried out using a light meter to record the illuminance of four or five points in a room and how this varies with different blind settings under different daylight conditions, subject to the variables of time of day, season of the year and weather. It is a time-consuming and difficult exercise to construct a light plan that accounts for all these variables; with the reliability of the outcome uncertain.

This paper describes, from an end-user perspective, a new approach to understanding the fall of daylight in historic house showrooms using Climate Based Daylight Modelling (CBDM). The Radiance lighting simulation system is used as the 'engine' for the CBDM approach employed for this study. In a rigorous validation study (carried out by Mardaljevic) it was shown that illuminances predicted using the Radiance system could be within $+-10 \%$ of measured values, i.e. 32 | P a g e 
within the accuracy limits of the measuring instruments themselves. In this work, a daylight simulation model is used to predict the fall of light on a virtual representation of a historic room interior. The building orientation, window reveals and geometry of the room are modelled in precise detail and the measured reflectance characteristics of principal room surfaces incorporated. Taking a test reference year climate file as the daylight input, the model can generate both illuminance and cumulative lux hour dose data across all the modelled surfaces, as well as on other hypothetical points within the room (such as a table or chair placed in the centre of the room). The room chosen for daylight simulation in this research is the Smoking Room at Ickworth House, Suffolk. This room is typical of many of the National Trust's historic showrooms, being side lit from three sash windows on a single aspect. The Smoking Room is south-east facing, however CBDM allows the model orientation to be changed at will and the room has been simulated facing eight different compass points to understand the effect of different aspects. Daylight exposure was simulated for the windows with no daylight control and with three different blind settings, representing typical National Trust daylight management practice.

Figures 1 and 2 show the Smoking Room and its CBDM representation, with total annual illuminance output (TAI). The numbers on the paintings are the annual kluxhour light doses received by each painting if the shutters were open and the window blinds half down 12.00 $17.00 \mathrm{hrs}$ each day, with the room in blackout at all other times. The results suggest that maintaining the half down position blind position at all opening times throughout the year (assuming blackout at closed periods) is sufficient to reduce daylight exposure for all but one of the oil paintings (the exception being the painting on the far left next to the window) to below the National Trust 600 kluxhour maximum recommended light dose for moderately sensitive objects. Whilst this may be satisfactory for conservation, the TAI plot does not give any information on illuminance levels at different times through the year. Inevitably, there will be times when a fixed half-down blind position may result in too little daylight illumination for satisfactory viewing or too much for conservation. The CBDM model enables this to be assessed through the model output of metrics for hours with daylight illuminance $<50$ lux and hours $>200$ lux. CBDM data have been generated for hourly time slices through the day from 09.00 to 17.00, giving TAI, total illuminance by calendar month, hours below 50 lux, hours 200-2000 lux and hours > 2000 lux.

Using the CBDM outputs the authors are now investigating the effect of the current Smoking Room light plan on both total light dose received at reference surfaces and to see when, during opening times, illuminance falls below the 50 lux that is often taken as the minimum lux for acceptable viewing. Whilst the Smoking Room faces south-east, the simulations performed for the room at eight different compass points are being used to investigate the effect of typical light control measures on rooms with different aspects. The paper will report on this research and how CBDM is being used to optimise daylight management for improved viewing of historic collections whilst remaining within accepted light dose parameters. 


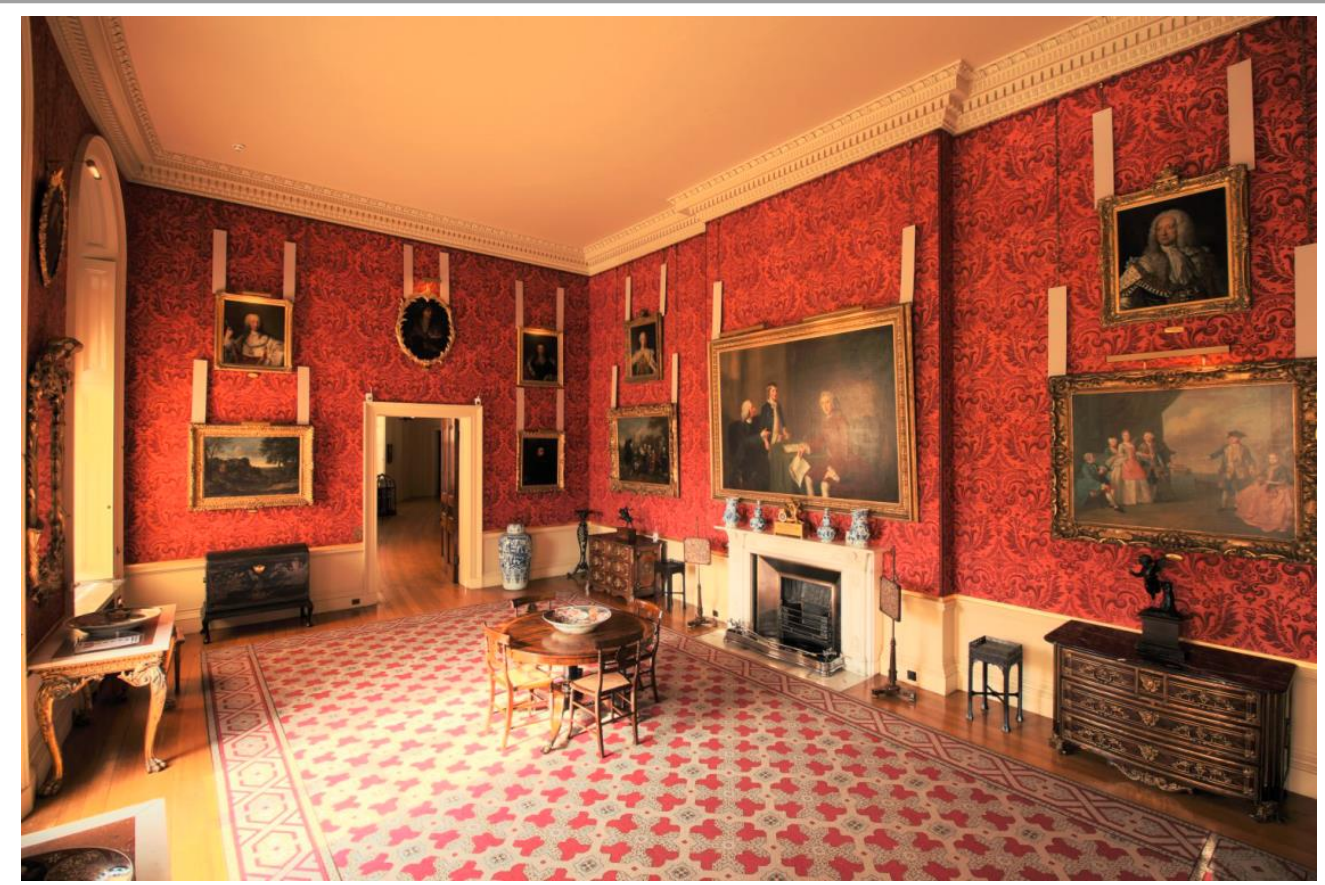

Fig. 1. Ickworth Smoking Room viewed from the south-east corner.

\section{c1-12h-17h-cont-rz348-mod02ab5 i}
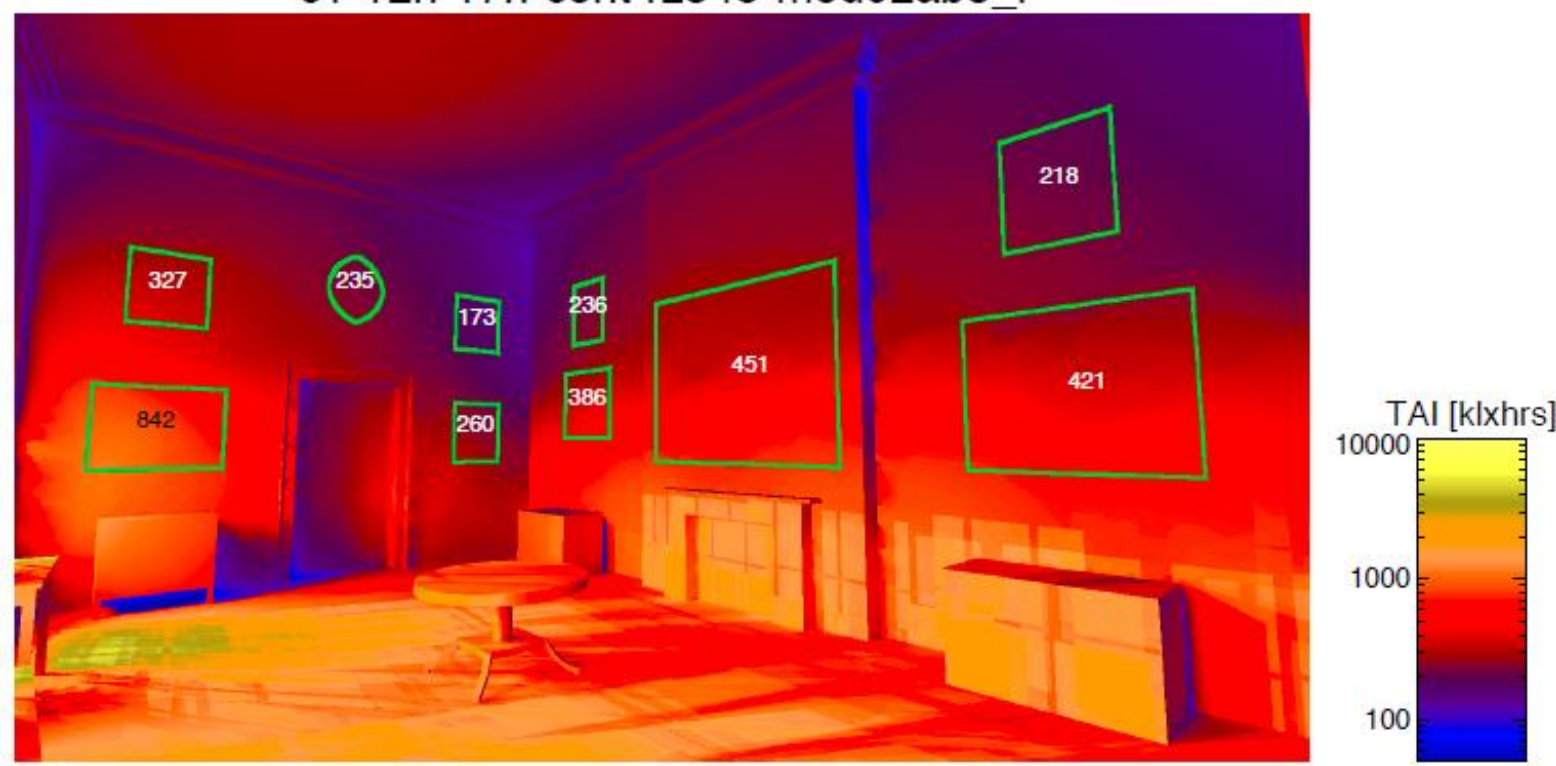

Fig. 2. CBDM representation of the total annual illuminance of the Smoking Room with shutters open and window blinds half-down every day of the year 12.00-17.00. 


\title{
Illuminating Artwork - different project examples in cooperation with the Vatican Museums
}

\author{
Dipl.-Phys. M. Boulouednine ${ }^{1}$ and Dipl.-Ing. Carlo Bogani ${ }^{2}$ \\ OSRAM GmbH' ${ }^{1}$ OSRAM SpA ${ }^{2}$ \\ m.boulouednine@osram.com
}

In the years 1508 - 1524 the Raphael rooms, four rooms in the apostolic palace have been painted by Raffael and his workshop. Illuminating such artwork has many challenges. Conservation of art or how to realize the lowest possible impact on sensitive objects is clearly the first target. Best possible appreciation of the masterpieces for the observer, may it be a museum visitor or a collector, is the next highest priority. This task has two aspects. An ideal colour rendering by selection of suitable LEDs and a strategy for the spectral distribution is crucial. If well-balanced parameters for the highest quality of light is found, the next step is to decide about the right philosophy of illuminating the artwork to enable the best viewing conditions for the observer. Commercial aspects like energy saving and maintenance cost reduction is always a focus of professional exhibitors like museums.

Together with the experts of the Vatican Museums we present in the first case study the project of the new LED illumination of the "Stanze di Raffaello" (Rafael rooms).

On request of the experts of the Vatican Museums the project was started. The different project phases executed will be introduced. First was the analysis of the existing situation of artificial and natural daylight. Second and always a difficulty in a 500 years old existing building is the evaluation of the electrical infrastructure and possible installation points. Results of the Sistine Chapel Renaissance pigment analysis have been used to achieve the best possible spectral distribution. Optical studies enabled an excellent uniformity of the illumination enabling to appreciate the many details of the artworks. Transferring the technology from a large-scale room of the Sistine Chapel into a much smaller ambience was a challenge for the engineering team. In those days, the rooms have been illuminated by candle light. But contrary to today's artificial lighting, the light source did not provide constant light but a flickering effect which the artists have respected during the design of the frescos. As a feature, the real conditions of ancient illumination can be imitated by a candle flicker program enabling the observer to see the frescoes as they were meant 500 years ago.

Not only has the concept from a large-scale room been transferred into much smaller rooms, but also was a way found to integrate the new technology as minimal invasive as possible and to deal with remarkable daylight ingress. Energy saving and 5 times longer life time eases the 
maintenance process and provides always the best viewing conditions independent from the time of the day or the day in the year.

A collaborative project funded by the European Community in the years 2012 until 2014 was the basis for the lighting concept and high colour rendering technology. In the project "New LED illumination of the Sistine Chapel", a consortium of four partners out of different European countries as well as the Institution of the Vatican Museums laid the fundament of illuminating such Renaissance frescoes.

These case studies are introducing a new approach of designing light with an unprecedented precision in the bespoke design of the right light distribution for each lighting task as well as a bespoke spectral distribution for the environment and objects to illuminate.

The case studies explain how, based on the architectural situation, the light distribution curves are being designed, calculated, evaluated and proven in mock-ups and in the final installation.

The influence of daylight will be analysed.

Furthermore, we introduce the strategy to define a project specific colour-rendering index. A stress test demonstrates the extreme protection of the artwork granted by the specific spectral distribution found. We show the results of applying the traditional CRI colour metrics as well as TM30 to the found spectral distribution.

We intend to introduce further project concepts like the new illumination of the St. Peter's Basilica in Rome to the public for the first time. 


\title{
Light, Colour and Vision (Part I)
}

\author{
Chaired by Prof. Lindsay MacDonald and Daniel Garside
}

\section{In Praise of Spotlighting}

\author{
Scott Rosenfeld \\ Smithsonian American Art Museum \\ rosenfelds@si.edu
}

The primary goal of lighting art museums is to optimize the qualities of light to reduce the rate of damage to lighting sensitive collections while allowing viewers to see as well as possible. Optimizing light to achieve these goals requires the installation of focused electric luminaires: no other method of illumination will allow designers access to all the controllable qualities of light. Focused electric light can take on many forms, such as spotlighting or picture frame lighting, and can be used alone or integrated as a component of daylighting or other systems that create flat, even illumination. It is common knowledge that adjustable lighting carries significant risks; poorly maintained and focused spotlights appear haphazard at best and are destructive to light sensitive collections at worst. To maximize the potential of spotlighting, museums need to make investments in both lighting equipment and skilled lighting talent: the payoff is displays that are easier to see, are more colorful, communicate with greater clarity, and incur less damage.

Lighting designers sometimes use a heuristic to describe the five controllable qualities of light: quantity, distribution, movement, spectrum, and angle of incidence.

Quantity: Despite its inherent limitations, illuminance is the primary metric museums use to measure the quantity of light and the resulting rate of damage to light sensitive materials. These illuminance levels do not represent safe levels, but are instead based on a consensus of how much light is typically required for visibility. As Gary Thompson stated, in the same chapter of his 1986 text The Museum Environment where he codified the 50 to 250 lux standard for conservation, "by judgment rather than by scientific formula, two incommensurables — the amount of light needed for looking at exhibits against the damage which it causes-we are now in the realms of controversy" (p.22).

Focused lighting systems provide tools to allow designers, curators, and conservators to exercise this judgment and determine the proper degree of visible access versus the rate of damage for individual collection items. Focused lighting is a particularly powerful tool for creating a balanced composition of equal luminances within an exhibit environment by allowing each artwork to be illuminated at a different level depending on its reflectance value. 
Distribution: This refers to the size and shape of each light beam (photometric solid) and how these individual beams are distributed throughout the museum to paint the collections and the built environment with light. Ideally, the size of the light can be hand-crafted to match the size of the artworks and the light beam's edge can be tailored to fall off at a specified rate. The smallest beams of light commonly found on the market are 4 degrees and the widest are 50 degrees. Cool beam LEDs provide opportunities to integrate plastic holographic lenses; this combination provides access to a whole new vocabulary of precise spotlighting and floodlighting that was not previously available in an architectural-scale fixture (as opposed to large theatrical spotlights).

Carefully controlling the distribution of light is more important to my designs than any other controllable quality; focused lighting possesses the unique ability to make artworks the brightest elements in the room rather than direct glare from luminaires or white walls.

Movement: The dynamic movement of light is a powerful tool for creating noticeable changes in color and atmosphere. But, perhaps the most important museum example is the use of occupancy sensors. Focused lighting, especially when connected to a sophisticated control system with integrated sensors, provides the opportunity to stop light-induced damage to individual objects.

Spectrum: Choices range from what shade of "white light" is desired to the color rendering properties of the lighting source. LEDs provide phenomenal new opportunities to customize spectra for specific exhibitions; the selection of color rendering attributes is especially important in lighting designs that use even levels of illumination since other qualities of light are not being fully utilized. For example, independent of the color rendering attributes of a lighting source perceived colorfulness will change via the following methods: increased illuminance (the Hunt Effect), spotlighting, the choice of wall color and the reduction of veiling reflections.

Electric light, especially from blue pump phosphor LEDs over 4000K, has the advantage of providing a lower spectral damage potential than UV filtered daylight (Royer, Michael P. TRUE COLORS. Pacific Northwest National Laboratory (PNNL), Richland, WA (US), 2014. Web. 28 Jan. 2017.) Focused lighting systems allow museums to go even further by implementing experimental concepts on individual artworks. For example, a spotlight's spectrum can be tailored to reduce damage potential given an artwork's specific action spectra, or the Hunt Effect at low illuminances might be mitigated by increasing the color gamut given an artwork's specific set of colorants.

Angle: This is the only quality that is not inherent to the light; it is instead determined by the designer's choice of where to position the luminaires. The angle of incidence has a significant impact on the distribution of the light and may impact color perception of artworks (via geometric metamerism). Narrow, focused beams of light provide designers with unique opportunities to both reduce direct glare from lighting sources and to reduce veiling reflections off of artworks. A designer's selection of the proper angle of incidence is a powerful tool for revealing the threedimensional appearance of sculptures: as Jun'ichirō Tanizaki writes in his seminal book In Praise 
of Shadows, "Were it not for shadows, there would be no beauty." Focused lighting allows designers to use everything in our power to assist viewers to see the wonders museums have to offer. Perhaps the benefits of flexible lighting systems are obvious; certainly, track lighting systems are a common feature of many museums. However, there is a great need for more education on how to use track lighting with precision and sophistication. 


\title{
Evaluation of colour quality of LED illumination for Museum Applications
}

\author{
Ming Ronnier Luo ${ }^{1}$ and Kangjun Liu ${ }^{2}$ \\ State Key Laboratory of Modern Optical Instrumentation, Zhejiang University and \\ School of Design, University of Leeds ${ }^{1}$; UnrealLight, Shanghai ${ }^{2}$ \\ M.R.Luo@leeds.ac.uk
}

\section{Introduction}

This paper is to describe what modern LED illumination can bring to museum applications. It is well known that the main tasks for museum include display, conservation and education. LED lights can serve particularly well for the former two tasks, because of their properties of low energy consumption, long life, low UV and IR contents, small size and high intensity. Furthermore, modern LED lightings are spectrum tuneable to provide the desired colour quality for a given application.

This paper includes two parts: colour quality metrics and colour quality realisation. Firstly, CIE has recently provided 10 research strategies for the LED illumination. The very first one is on colour quality. Secondly, a concept of lighting design cycle will be introduced to realise art works in real environment. Also, new technology such as virtual reality is underdevelopment to pave the way for achieving accurate light rendering.

\section{Colour quality metrics}

The conventional quality metrics used in lighting industry including illuminance, correlated colour temperature (CCT), luminance efficacy ratio (LER), light uniformity, glare, flickering, etc. Most of them are only associated with luminous efficiency function, $V(\square)$. With the arrival of LED lightings, the conventional metrics are not capable of accurate quantifying the colour quality of light. New colour quality metrics will be based on spectrum of illuminant. The followings will be introduced, CIE TC1-90 recommendation on colour fidelity index, $R_{\mathrm{f}}$ which are to be reported hand in hand with the present $R_{a}$. Furthermore, IES TM30 colour gamut index $R_{g}$ will also be introduced. Recent research works on whiteness index, neutral locus and natural white locus, etc. will be covered. In addition, the CIE 2006 colorimetry will be introduced for the computation of the above measures. Some work to study the colour quality of museum lighting will be introduced. Finally, a generic CQ metric as a function of CCT, Duv, Lux, colour fidelity, colour gamut will be proposed.

\section{Colour Quality Realisation}

A three-elements colour design cycle will be introduced to realize the colour quality. It includes a design engine, a spectrum tuneable lighting system (STLS) and a testing environment. A design 40 | P a g e 
engine is for the computation of a spectrum to meet desired colour quality requirements as described in the last section. Element 2 is an illumination system, typically including a number of LEDs having different spectrum, which are tuneable to match the SPD obtained from Element 1. Element 3 is a dedicated test environment. It can be a room installed an STLS with a desired set of furniture to simulate a real environment. The design process will be an iterative cycle, designers and clients are able to experience the light quality together and to decide the final atmosphere, or quality of lighting. Some earlier experimental results will be briefly introduced such as museum lighting, food lighting, surgical lighting, skin lighting.

Finally, new digital display technology based on virtual reality will be introduced for museum applications. Examples will be given to show how a design system can be used to design the components in an exhibition room such as wall paper colour, frame and illumination for a variety of artefacts.

\section{Conclusion}

This paper raises the awareness of the new technology for the design of future museum lighting. It will have more variability to achieve different criteria including atmosphere measures (such as cool/warm, visibility, comfort) and scientific measures (such as colour fidelity, visibility, texture, gloss). 


\title{
Artificial Lighting Design for Paintings in Indoor Settings with selected Nanyang Paintings as a case study
}

\author{
Ong Thian Chai Nicholas ${ }^{1}$, Martin Reiser ${ }^{2}(\dagger)$, Assoc. Prof. Cesare Soci ${ }^{1}$, \\ Dr. Sarita Silveira ${ }^{3}$, Assoc. Prof. Andrea Nanetti ${ }^{1}$ \\ Nanyang Technological University Singapore ${ }^{1}$, University of Cologne ${ }^{2}$, Ludwig-Maximilians- \\ Universität München ${ }^{3}$ \\ ongt0039@e.ntu.edu.sg
}

Lighting design for paintings in indoor settings, after having cleared conservation issues, is taking more and more into consideration the illumination parameters related to artist's intentions, curatorial practices, and viewer experiences. Till recently, natural daylight and incandescent lighting served as the most common lighting means for paintings with significant conservation issues. Today, Solid State Lighting (SSL) has close to no UV radiation resulting in a shift to newer LED lighting for museum use. Thus, lighting designers need to have a specific training to specialize in lighting design for paintings. This paper presents the results of an interdisciplinary research project (Physics of Light and Psychology, Art History and Aesthetic,) that began in 2015 in the School of Art, Design and Media at NTU Singapore. The aims of the research on LED lighting conditions for paintings in a museum environment (as a key showcase for indoor settings) was to examine how changing values in spectral distribution curves within a fixed intensity and correlated colour temperature can affect preference ratings and perception of a painting under various lighting conditions. This research started with an empirical investigation of the so called "Monza Method". It consists of a checklist for lighting design of painted surfaces developed in 2008 by Arch. Francesco Iannone and Arch. Serena Tellini (Consuline Architetti Associati, Milan, Italy) after an experimental lighting of the cycle of frescoes made by the Zavattari Workshop in the Chapel of Teodolinda of the Monza Duomo. The lighting design was positively validated by the general audience. However, the "Monza Method" is far more subject to the practitioner's "instinctive appreciation of light conditions" rather than to a cogent methodology for standards of illumination related to the interpretation of the audience's appreciation. Physics of light set the stage to identify and isolate variables: prior studies have already examined human responses to variables in lighting for paintings such as the physical intensity of light (brightness in lux) and preferred colour temperatures (Zhai et al. 2015, 2016). Psychology was used to both define the questions to ask to the audience and to interpret their responses (Flynn et al., 1979). On this basis,

Nanyang paintings were chosen as a case study, not only because of their accessibility in Singapore museums, but mostly due to the concurrency that they were painted and exhibited in the same geographical and cultural environment, in which the surveys would have been conducted on the audience. Last, but not least, Art History provided the necessary knowledge about the paintings 42 | P a g e 
and the painters, and Aesthetic gave an understanding of the sets of principles used by the painters to make them (Low 2010, Teo 2011). Initial surveys are conducted in Singapore, in collaboration with and endorsed by the Asian Civilizations Museum (ACM) and the National Gallery of Singapore (NGS), to

1. identify preference with relation to changing relative spectral distribution curves and

2. categorize specific variables that influence the viewers' perceptive impression.

Observers are asked to evaluate their preferred lighting conditions for selected Nanyang (or Nanyang related) paintings ( 2 oil on canvas and 2 ink on paper). The paintings are presented to the audience under 8 lighting conditions, which have constant correlated colour temperatures and constant intensity, but have varied spectral distribution curves. The observers' preferences are measured on a Likert scale from -2 (very dissatisfied) to 2 (very satisfied). Concomitantly, we test the audience using word-pairs recommended by the Illuminating Engineering Society's methodology for studying psychological and related subjective effects of illumination.

The results of the preliminary interpretation of the data generated by these surveys have shown that:

1. individual paintings are viewed best under specific lighting conditions that are related to the painting's medium, i.e. both the type of paint used (e.g., oil, ink) and the base to which it is applied (e.g., canvas, paper);

2. increases in the "Red" wavelengths of the spectral distribution curve correlate with a significant higher chance of altering preference for viewing the paintings as compared to increases in the "Blue" and "Green" wavelengths;

3. despite keeping physical brightness at a constant, perceived brightness changes drastically with the altering of spectral distribution curves (it is an example of a frequently discussed, but not often documented case of how the perception of brightness is not simply proportional to the intensity of the light). These research findings of human visual perceptions of change in spectral distribution curves, and the related interpretation of audience behaviour, constitute a proof of concept for the need of a new approach to the standards of illumination in the lighting design for paintings in indoor settings. The lighting designer can be trained to explore more dynamic and science-driven ways to better enhance the empathic relationship of the audience with the paintings, and show paintings "in new light". 


\title{
Light and colour: Assessing the effects of illumination on perceptual constancy of and aesthetic response to paintings
}

\author{
Anya Hurlbert ${ }^{1}$ and Joseph Padfield ${ }^{2}$ \\ Institute of Neuroscience, Newcastle University ${ }^{1}$, The National Gallery, London ${ }^{2}$ \\ anya.hurlbert@newcastle.ac.uk
}

Colour constancy -- the perceptual stability of object colour under changes in the illumination spectrum -- is central to human colour perception. As the light shining on a bowl of lemons changes from tungsten to bluish daylight, the light reflected from the lemons changes, becoming "bluer", yet the lemons continue to appear yellow. Qualitatively, colour constancy is a reliable feature of everyday vision, and enables people to use colour as a reliable signal of object identity. Quantitatively, as measured in the laboratory, colour constancy is imperfect, with colour constancy indices (CCI) ranging from 10 to 90\%. Methods of quantifying colour constancy include tasks requiring people to adjust, match or name the colour appearance of surfaces under different illuminations or to identify the cause of changes in colour appearance as illumination vs. material change. It is clear that the extent of colour constancy depends on the experimental conditions and the participant. The metrological study of colour appearance, on the other hand, acknowledges that object colour depends on lighting conditions and scene configuration, as well as other contextual factors. The correlated colour temperature (CCT), lux and colour rendering index (CRI) of the illumination are taken into account when choosing the appropriate illumination for particular settings. For museum settings, illuminations with "warm" CCTs (traditionally around 3200K), low lux (to minimise phototoxicity), and the highest possible CRI have typically been selected. The advent of new spectrally tuneable lighting technologies have enabled studies which directly test whether these typical illumination choices are indeed optimal in terms of the viewer's response. The main question I address here is what is the best method and measure for determining whether an illumination is optimal, particularly for viewing a painting in a museum setting. This subsumes other questions: what is the relationship between the colour constancy index (CCI) and the CRI? Does the latter predict the viewer's experience of colour constancy in a real-world setting? Do any of these quantitative measures predict the viewer's aesthetic or emotional response to the painting, or are qualitative assessments the most appropriate? I will address the hypothesis that the most aesthetically preferred illuminations will be those which preserve the highest colour constancy relative to the presumed illumination under which the artist painted. In addressing these questions, I will describe three sets of experiments: (1) a mass experiment in a public setting (the 2014 summer exhibition at the National Gallery); (2) laboratory experiments using forced-choice and user-adjustment methods to select optimal illuminations for different paintings; (3) free-choice descriptions of illumination quality by museum professionals and naïve viewers. 


\title{
Light, Colour and Vision (Part II)
}

Chaired by Prof. Lindsay MacDonald and Daniel Garside

\section{Colour preference and naturalness of paintings under multi-LED spectra with different correlated colour temperatures and object saturation levels}

\author{
P. Bodrogi, T. Q. Khanh, Q. T. Vinh, X. Guo \\ Laboratory of Lighting Technology, Technische Universität Darmstadt \\ bodrogi@lichttechnik.tu-darmstadt.de
}

\section{Introduction: objectives}

Multi-channel LED light sources provide flexible spectral power distributions which are adjustable in terms of their correlated colour temperature (CCT: warm white, neutral white or cool white) and the saturation level they cause on the illuminated coloured objects (e.g. if the red LED channel has a high intensity then reddish objects become more saturated). In museum lighting (more specifically, in the lighting of coloured artistic paintings), this spectral flexibility should be utilised to enhance the colour quality of the paintings. To this aim, in this paper results of a visual experiment on two aspects of colour quality (colour preference and colour naturalness) will be reported and a model will be described.

In the experiment, a still life arrangement with two artistic paintings and some additional coloured objects were illuminated at $750 \mathrm{~lx}$ by a four-channel multi-LED engine at four CCTs $(3100 \mathrm{~K}, 4100$ $\mathrm{K}, 5000 \mathrm{~K}$ and $5600 \mathrm{~K}$ ) with nine different oversaturation levels (measured in terms of $\Delta \mathrm{C}^{*}$ ) of the coloured objects at each CCT. The symbol $\Delta C^{*}$ is the CIELAB chroma difference (chroma shift) for a given coloured object between its colour appearances under the light source used in the experiment and its reference light source. $\Delta C^{*}$ was computed as a mean value of the individual $\Delta C^{*}$ values of the 15 CQS test colour samples VS1-VS15.

The colour preference and naturalness of the still life arrangement was scaled visually by viewing them in a real room with immersive viewing. Visual scale results of the observers were analysed to find out 1. if colour preference and naturalness assessments depend on the CCT of the multiLED spectra; and 2. if there is a CCT dependent maximum oversaturation level $\left(\Delta C^{*}\right)$ at which the colour preference and naturalness judgements begin to diminish due to the oversaturation of the coloured objects. 
A further objective is to develop a CCT dependent model of the mean preference and naturalness assessments in terms of the colour fidelity index IES $R \mathrm{f}$ (here its modified version was used as suggested by CIE TC 1-90) and $\Delta C^{*}$.

\section{Experimental method}

A set of 36 white spectra was generated at $750 \mathrm{~lx}$ at the above mentioned four CCTs. There were 9 spectra at each CCT providing different $\Delta C^{*}$ values ranging between -1 and 10 . The two paintings (and the additional coloured objects below the paintings) were viewed from a viewing distance of about 2 meters (see Figure 1).

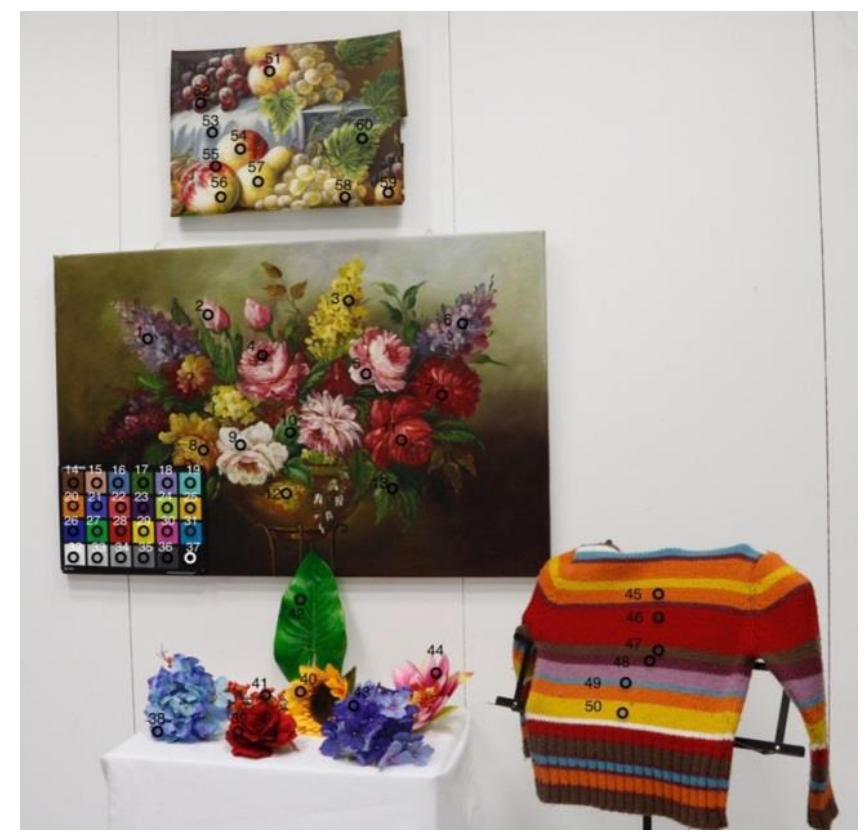

Figure 1. Two artistic paintings and some additional coloured objects

The panel of observers included 20 men and 10 women (20 - 46 years of age) with good or corrected visual acuity and normal colour vision. Observers were grouped into two clusters: the standard deviation (SD) of all "colour preference" answers of every observer were computed, and, if the SD of a specific observer was greater than the mean SD of all 30 observers then this observer, a socalled "responsive" observer, belonged to Cluster-1. The other subjects belonged to Cluster-2. Ten subjects belonged to Cluster-1 and only these results will be analysed here.

Observers adapted one and a half minute to each one of the 36 LED spectra shown in a fixed random order. Then, observers assessed their colour preference and naturalness impression about the colour appearance of the two paintings and the additional coloured objects. Colour preference was defined by the "subjective extent of how the observer likes the colour appearance of the coloured objects on the table under the current light source taking all coloured objects into consideration". Colour naturalness was defined by the "subjective extent of how natural the colour appearance of an identified object is under the current light source compared to the ideal colour 
appearance in the subject's memory in the way the subject remembers that object". Assessments were done by putting a cross on an interval scale labelled by rating categories, see Figure 2 .

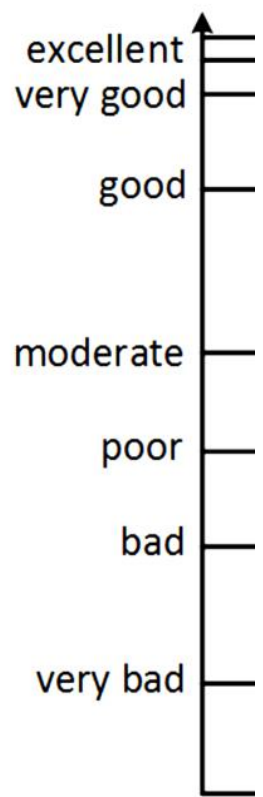

Figure 2. Rating scale labelled by the categories 'excellent' 97.9; 'very good' 91.6; 'good' 79.6; 'moderate' 52.9; 'poor' 41.2; 'bad' 26.5; and 'very bad' 12.8)

\section{Results and discussion}

The effect of both CCT and $\Delta C^{*}$ on preference and naturalness was significant at the $1 \%$ level. The variable $\Delta C^{*}$ could not describe visual preference and naturalness data as a standalone metric due to the decreasing branch of the mean visual ratings with increasing $\Delta C^{*}$ values after a critical $\Delta C^{*}$ value because observers did not prefer too much oversaturation. An example (colour preference, $3100 \mathrm{~K}$ ) is shown in Figure 3. The colour fidelity index $R \mathrm{f}$ was not a good enough standalone measure, either. $R$ f was combined with $\Delta C^{*}$ according to Eq. (1) to obtain a new model (CQ; shown in Figure 3 as a thick black model curve fitted to the visual results).

$\mathrm{CQ}=a+b \Delta C^{*} 2+c \Delta C^{*}+d R \mathrm{f}(1)$

As Eq. (1) was fitted to the visual data obtained by using the scale shown in Figure 2, Eq. (1) is able to predict the absolute magnitude of preference and naturalness ratings in terms of semantic categories. E.g. CQ $=79.6$ is associated with the semantic category "good" i.e. "good colour preference" or "good naturalness" and this value can be used as a criterion value to be exceeded during the optimisation of the multi-LED spectra.

As can be seen from Figure 3, observers do need a certain moderate level of oversaturation for best colour preference (about $\Delta C^{*}=2$ ). Eq. (1) shows that the model has a constant term $(a)$ in order to help adjust the absolute level of the predicted visual scales across the different CCTs. There are quadratic and linear $\Delta C^{*}$ terms (with the coefficients $b$ and $c$ ). Optimum model coefficients and the fit of the model in case of every one of the four CCTs will be shown in the final paper. The absolute 
maxima of the mean visual scales which are achievable in case of a given CCT will also be described. Latter issue is very important in order to select a CCT for the highest achievable colour preference or naturalness.

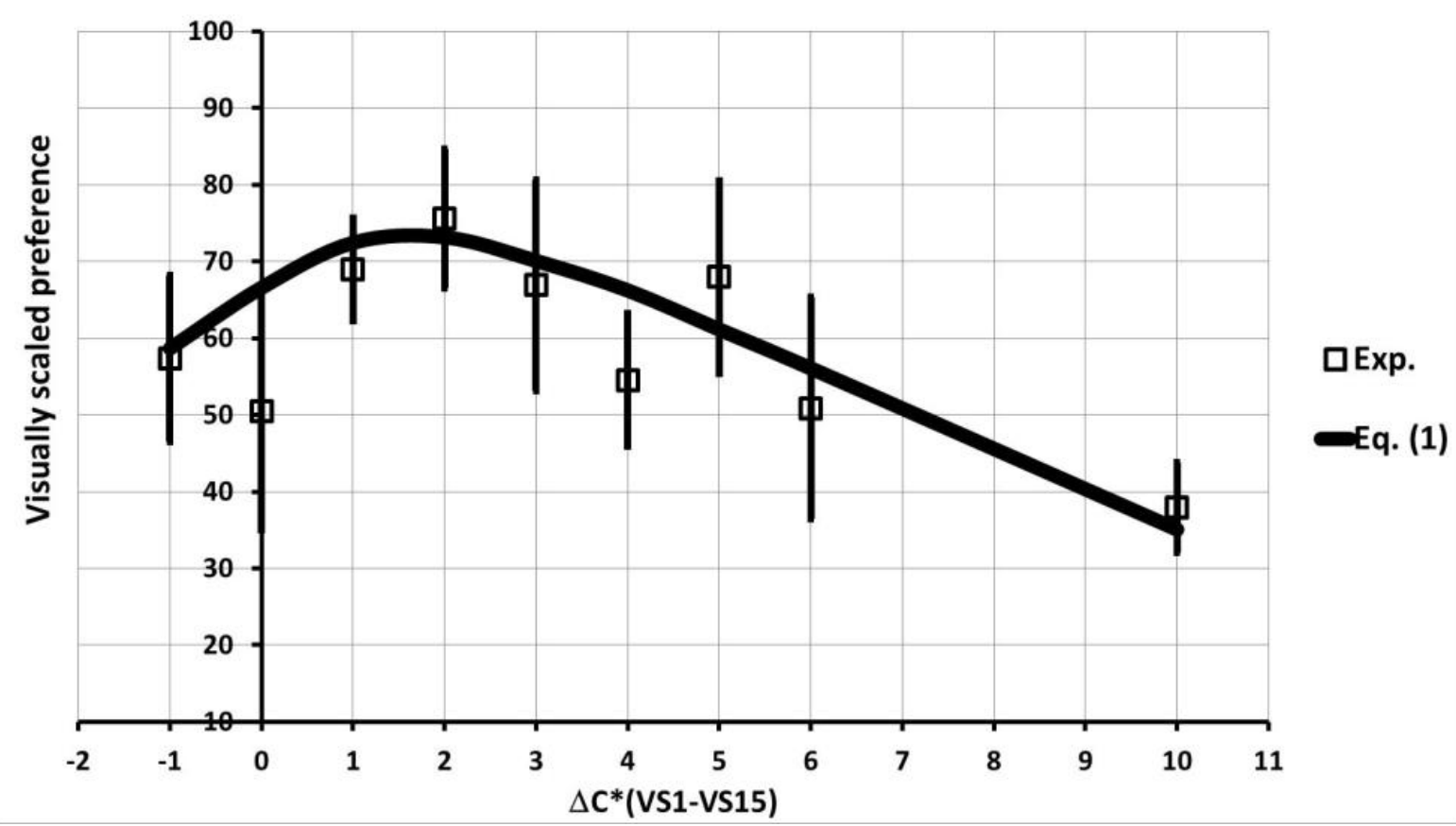

Figure 3. Mean scaled visual colour preference (with $95 \%$ confidence intervals) as a function of $\Delta C^{*}$ for $3100 \mathrm{~K}$. The model curve of Eq. (1) is also shown

\section{References}

Khanh TQ, Bodrogi P, Vinh QT, Stojanovic D. Colour preference, naturalness, vividness and colour quality metrics - Part 1: Experiments in a real room. Lighting Research and Technology First published 7 April 2016, doi 1477153516643359

Khanh TQ, Bodrogi P, Vinh QT, Stojanovic D. Colour preference, naturalness, vividness and colour quality metrics - Part 2: Experiments in a viewing booth and analysis of the combined dataset. Lighting Research and Technology First published 7 April 2016. doi 1477153516643570

Khanh TQ, Bodrogi P. Colour preference, naturalness, vividness and colour quality metrics - Part 3: Experiments with makeup products and analysis of the complete warm white dataset. Lighting Research and Technology First published September 16, 2016.

Davis W, Ohno Y. Colour quality scale. Optical Engineering 2010; 49: 033602.

David A, Fini PT, Houser KW, Whitehead L. Development of the IES method for evaluating the colour rendition of light sources. Optics Express 2015; 23: 15888-15906.

Bodrogi P, Brückner S, Krause N, Khanh TQ. Semantic interpretation of colour differences and colour-rendering indices. Color Research and Application 2014; 39: 252-262. 


\title{
Influence of cultural factors in preferred illumination for paintings
}

\author{
Sérgio NC Nascimentoํㅡㄹ João M.M. Linhares ${ }^{1}$, Catarina F. M. Herdeiro ${ }^{1}$, Taisei \\ Kondo ${ }^{2}$, Yukinori Misaki ${ }^{2}$, Shigeki Nakauchi ${ }^{2}$ \\ Centre of Physics, University of Minho'; Toyohashi University of Technology, Department of \\ Computer Science \& Engineering ${ }^{2}$ \\ smcn@fisica.uminho.pt
}

The spectrum of the light to illuminate paintings in museums dramatically influences the visual impression they produce in the viewers. In selecting adequate lighting, the intent of the artist should be considered but, unfortunately, this is often unknown and museum curators need solid guidance to select the best option, not only for energy efficiency and safety, but also for optimal visualization. Although there are some studies suggesting that for occidental viewers a correlated colour temperature (CCT) of about $5000 \mathrm{~K}$ is optimal for visual appreciation there is not yet general agreement in the museum community about this issue. Moreover, cultural aspects influence colour preference and may also influence optimal lighting. The aim of this work was to test whether the best lighting for appreciation of paintings is influenced by cultural factors by comparing preference for occidental and Japanese viewers using occidental and Japanese artworks. The stimuli for the experiment were images of the paintings synthetized from hyperspectral imaging data acquired in Portuguese and Japanese museums. Of the 42 paintings tested 32 were from occidental painters and 10 from Japanese painters. Paintings were both of abstract and figurative nature. They were simulated illuminated by daylights with correlated colour temperature (CCT) in the range 3,600 K - 25,000 K. In the experiment, observers could change the $\mathrm{CCT}$ of the illumination using a joy-pad and their task was to select the one producing the best visual impression of the painting. The adjusting parameter was made circular to prevent observers to use other references for their selections. Stimuli were displayed on calibrated CRT monitors controlled by a video board in 24-bits-per-pixel true-colour mode. There were 5 experimental sessions. In the first session 10 paintings were selected at random from the set of 42 . In each of the subsequent sessions 10 paintings were also tested but to control for changing criterion two were repeated from the first session. In each session, each painting was tested three times. Ten Japanese observers carried out the experiment in Japan and 11 Portuguese observers carried out the experiment in Portugal. All observers were naïve to the purpose of the experiment and both groups were tested with all 42 paintings. It was confirmed that for Portuguese observers the preferred CCT was about $5000 \mathrm{~K}$. Moreover, the Japanese observers systematically required a CCT larger by about $1000 \mathrm{~K}$ regardless of the origin of the paintings. The data suggests that cultural factors influence the optimal lighting conditions for paintings and therefore spectrally tunable light sources may be necessary to optimize for all viewers. 


\title{
The Preferred Conditions of LED Lighting for Fine Art Paintings: The Influence of Illuminance Level and Correlated Colour Temperature
}

\author{
Ferenc Szabó, Renáta Kéri, Péter Csuti \\ University of Pannonia, Veszprém \\ szabof@szafeonline.hu
}

The aim of the investigation was to provide recommendations for optimal lighting conditions in museum environment. The main aspects of the investigation were to elaborate the optimal illuminance level and correlated colour temperature (CCT) for the lighting of paintings and test Kruithof's rule ${ }^{1}$ in order to define the range which provides a pleasant lighting for fine art paintings. The method of factor analysis was used to the evaluation of the visual results.

\section{Environment}

The visual experiments were conducted at the University of Pannonia, in Hungary. In the experimental room three paintings on wood were hung on a wall with white background. The illumination was provided with special museum lighting prototype luminaires of our HI-LED project. The luminaires were multi-channel systems which were fully controllable to reach light stimuli with specific illuminance levels and correlated colour temperature values.

\section{$\underline{\text { Settings }}$}

During the visual experiments, the influence of illuminance level and CCT was investigated. Six illuminance levels (30 lx, $50 \mathrm{~lx}, 100 \mathrm{~lx}, 200 \mathrm{~lx}, 400 \mathrm{~lx}$ and $600 \mathrm{~lx}$ ) and four CCT values (2850K, $4000 \mathrm{~K}, 5000 \mathrm{~K}$ and $6500 \mathrm{~K}$ ) were selected, which resulted 24 different scenarios of the viewing conditions.

\section{$\underline{\text { Testing process and evaluation }}$}

During the testing process ten-word pairs were used for evaluating the paintings' appearance under each lighting conditions. Five of the scales were associated with appearance of the painting (low contrast - high contrast, cold - warm, dark - bright, pale - colourful, moist - dry) while five others were associated with atmosphere (artificial - natural, soft details - crisp details, unpleasant - pleasant, depressing - relaxing, boring - lively). Each scale was evaluated by using a four-point categorical scale. The word with negative meaning was recorded with the scores of 1 or 2 and the word with positive meaning was recorded with scores 3 or 4 . The visual experiment resulted 34 observations, which could be evaluated statistically.

Impact of CCT and illuminance level on the visual results

According to our results the CCT has the highest effect in case of most of the variables. When CCT increases, the trend of variables of 'Natural', 'Pleasant', 'Relaxing' and 'Lively' increase more 50 I P a g e 
steeply. In case of the light compositions having warm white output light (2850K), the atmosphere becomes rather unpleasant. This involves an optimization of the blue content of spectrum in order to control damage potential of museum lighting. The trend of 'High Contrast', 'Bright' and 'Crisp Details' shows growth with increased CCT as well, but this is not significant. In case of these variables rather the illuminance level has a greater impact. With increased illuminance level the contrast and brightness perception increases, and the details are crisper. The observers' feeling on warmness-coolness correlates very well with the CCT of light.

\section{Factor analysis}

In order to reduce the number of variables into fewer independent factors, the analytical method of factor analysis was carried out. Principal component analysis with Kaiser-method and orthogonal rotation were applied in the factor analysis.

Two main factors were identified in the factor analysis. The first associates with the atmosphere perception of the museum lighting and the second refers to the appearance of the paintings. Factor \#1 includes the variables of 'Natural', 'Relaxing', 'Lively', 'Pleasant' and 'Warm' and according to this analysis this group seem to be highly related to CCT, similarly to the results of the first investigation. Based on this analysis, warm has an opposite effect to 'High Contrast' - 'Bright' 'Natural' - 'Crisp Details' - 'Pleasant' - 'Relaxing' and 'Lively' variables and to the Factor \#1

('Comfort'). Factor \#2 includes the variables of 'Colourful' - 'Crisp Details' - 'Bright' - 'High Contrast' and this group seem to be highly related to illuminance level. The variable of 'Dry' has opposite effect to all of the other aspects except the 'Warm' variable.

\section{$\underline{\text { Comfort zone for museum lighting }}$}

In order to choose suitable combinations of illuminance level and CCT, the Kruithof curve can be used. Based on the results of the score of Pleasant/Unpleasant the comfort zone for museum lighting was defined. Accordingly, the observers perceived the illuminance level of $200 \mathrm{~lx}, 400 \mathrm{~lx}$ and $600 \mathrm{~lx}$ more pleasant than the illuminance level of $30 \mathrm{~lx}$ and $50 \mathrm{~lx}$. The latter were perceived clearly uncomfortable for museum lighting. In case of the investigated CCT range the settings with $\mathrm{CCT}$ of $4000 \mathrm{~K}$ and $5000 \mathrm{~K}$ were perceived the most pleasant and the CCT value of $2850 \mathrm{~K}$ was evaluated as uncomfortable. This suggests that a higher CCT value (around $4000 \mathrm{~K}-5000 \mathrm{~K}$ ) and a higher illuminance level (200 lx - $600 \mathrm{~lx}$ ) will be perceived as the most comfortable. The present results are not fully in accordance with Kruithof's rule, because the area of high CCT values (between $4000 \mathrm{~K}$ and $5000 \mathrm{~K}$ ) and higher illuminance levels (between $200 \mathrm{~lx}$ and $350 \mathrm{~lx}$ ) is uncomfortable according to the Kruithof curve.

\section{Conclusion}

During the visual experiment, the impact of CCT and illuminance level on visual perceptions was investigated. It was found that the variables which are related to the atmosphere show rather CCT 
dependence and the variables which associate with the paintings appearance show rather the dependence of illuminance.

Factor analysis revealed that there are two visual factors: 'comfort' and 'vividness'. The result of the factor analysis confirms the result of the visual experiment: in case of light mixtures having warm white output light (2850K) the atmosphere becomes rather unpleasant and uncomfortable.

The present results showed some disagreements with the Kruithof's rule. According to our study, lighting within the CCT range of 4000K - 5000K and a higher illuminance level of $200 \mathrm{~lx}-600 \mathrm{~lx}$ is considered to be pleasing for LED lighting of fine art paintings in museums.

\section{Funding}

The authors would like to express thanks for the financial support of the HI-LED EU FP7 project (grant number: 619912) in producing the above research.

\section{References}

Kruithof AA. Tubular luminescence lamps for general illumination. Philips Technical Review 1941; 6: $65-96$. 


\title{
Light Damage
}

\author{
Chaired by Joseph Padfield
}

\section{Mitigating Light Damage in a New Exhibition Space at the Getty Research Institute}

\author{
Mark Benson
}

Getty Research Institute

mbenson@getty.edu

In 2013 The Getty Research Institute (GRI) in Los Angeles opened its newly expanded exhibition space. The goal was to create a larger gallery that was more suitable for exhibiting the Institute's vast collection of rare books, prints, drawings, photographs, manuscripts and archives. The design converted almost 2000 square feet ( 185 SQM) of an existing area into a second, two-level gallery. Due to the inherent challenges of converting an existing space, a significant amount of natural light was getting into the gallery. The resulting lighting conditions were a combination of natural and electric light, the combined level of which was not controllable. The natural light levels would fluctuate during the day and throughout the year so the overall exposure of artwork could not be known. Stable, controllable light levels are crucial to minimizing light damage to works on paper but as in this situation, circumstances are not always ideal.

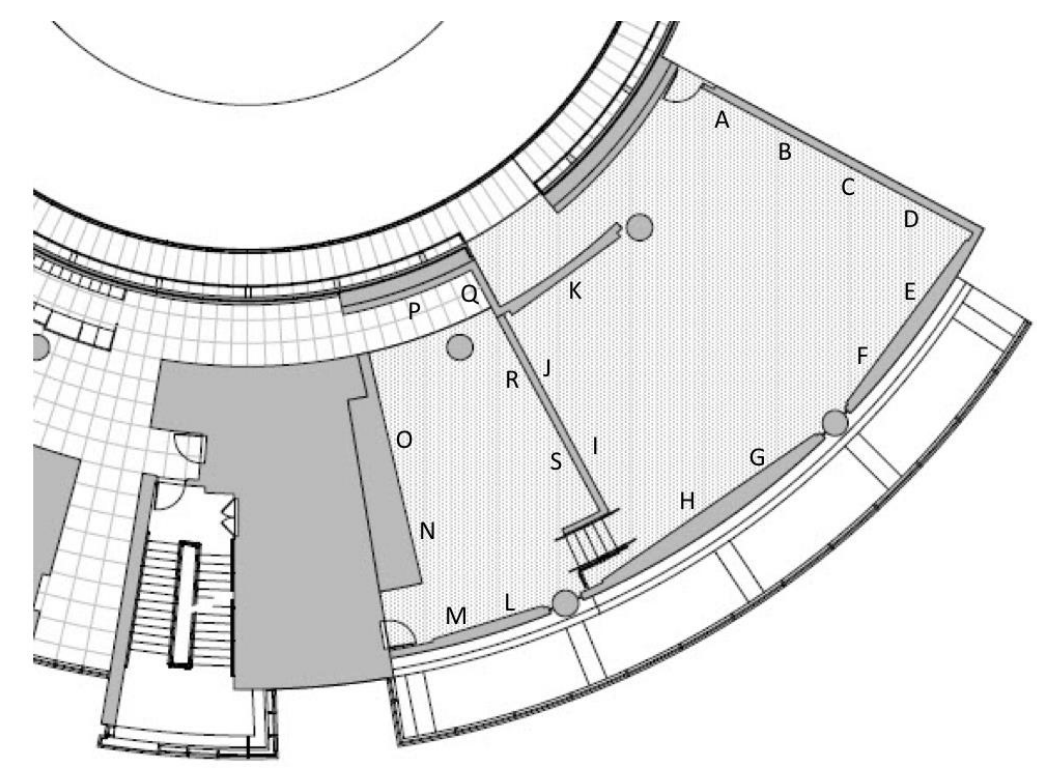

Figure 1. GRI Gallery 1 with natural light level survey locations A-S. 
This presentation will feature an overview of the lighting challenges in the GRI's new gallery. Although the gallery has no exterior walls or windows, fire code restrictions required a four-foot gap between the top of the northern, southern and western walls and the ceiling. On the other side of those walls are large windows and the white interior walls of the Institute. These windows and white walls resulted a large amount of diffused light that was making its way through the gap between the top of the walls and the ceiling. Inside the gallery, the white ceiling was further diffusing the light and spreading it throughout the space. Despite hanging a curtain outside of the walls to bridge the gap, a significant amount of light still made its way into the gallery. Additionally, the same light was infiltrating the gallery through the large open passageways used to enter and exit the gallery, further contributing to the fluctuating light levels. More information was needed to understand these lighting conditions.

A survey of the natural light levels was undertaken in June of 2014. Natural light levels were recorded with no electric light in nineteen locations (Figure 1), horizontally and vertically, once per week, four times per day. The horizontal and vertical readings were taken to more accurately reflect light levels for items in table cases and those mounted on the walls. While data loggers would have been ideal, the survey, as it was designed, allowed us to start immediately with no expense and get excellent coverage. The survey made it apparent that light levels were changing throughout the day, month and year. Figure 2 shows the significant increase in natural light for location "F" on March 2, 2015. At 9am the natural light level was 0.8 foot candles, by 3pm the level had increased to 10.4 foot candles. The light levels also differed depending on the location in the gallery (Table 1) and the design of the exhibition. For example, exhibitions incorporating more colors on the wall saw a reduction in natural light levels compared to exhibitions with white walls. The weather was also a contributing factor; overcast days saw significantly lower natural light levels compared to clear sunny days.

\begin{tabular}{|c|c|c|c|c|c|c|c|c|c|c|c|c|c|c|c|c|c|c|c|c|}
\hline Time & Position & A & B & C & D & E & $\mathbf{F}$ & G & H & 1 & $J$ & K & L & $M$ & $\mathbf{N}$ & 0 & $\mathbf{P}$ & $\mathbf{Q}$ & $\mathbf{R}$ & $S$ \\
\hline \multirow[t]{2}{*}{$9 A M$} & Wall & 2.0 & 2.0 & 2.0 & 2.0 & 2.0 & 2.0 & 2.0 & 2.0 & 2.0 & 2.0 & 2.0 & 2.0 & 2.0 & 2.0 & 2.0 & 2.0 & 2.0 & 2.0 & 2.0 \\
\hline & Table & 2.3 & 1.2 & 1.1 & 1.6 & 2.0 & 2.0 & 2.0 & 1.9 & 1.2 & 1.3 & 1.6 & 3.3 & 3.6 & 1.1 & 1.0 & 3.3 & 3.4 & 1.2 & 1.1 \\
\hline \multirow[t]{2}{*}{$11 \mathrm{AM}$} & Wall & 4.4 & 2.6 & 2.2 & 2.4 & 2.4 & 2.4 & 2.7 & 2.6 & 2.3 & 3.3 & 2.7 & 2.7 & 3.2 & 2.2 & 2.4 & 5.2 & 9.0 & 2.6 & 1.8 \\
\hline & Table & 5.1 & 2.5 & 2.0 & 2.6 & 3.1 & 3.3 & 3.3 & 3.4 & 2.5 & 4.2 & 4.4 & 4.6 & 5.4 & 2.1 & 2.1 & 8.8 & 8.6 & 3.1 & 2.0 \\
\hline \multirow[t]{2}{*}{$1 \mathrm{PM}$} & Wall & 4.2 & 2.9 & 2.9 & 3.8 & 2.7 & 2.8 & 2.9 & 3.0 & 2.9 & 2.8 & 2.8 & 3.9 & 5.4 & 2.9 & 2.6 & 4.4 & 7.5 & 2.5 & 2.8 \\
\hline & Table & 4.7 & 2.4 & 2.7 & 3.6 & 5.3 & 5.8 & 5.8 & 5.6 & 3.1 & 3.2 & 3.1 & 8.0 & 9.4 & 3.0 & 2.1 & 6.5 & 6.6 & 2.7 & 2.4 \\
\hline \multirow[t]{2}{*}{ 3PM } & Wall & 3.3 & 3.2 & 4.2 & 5.1 & 4.2 & 3.7 & 3.7 & 3.5 & 3.4 & 3.3 & 3.2 & 4.3 & 5.8 & 3.9 & 2.5 & 3.2 & 5.5 & 2.3 & 2.9 \\
\hline & Table & 3.5 & 2.5 & 3.5 & 6.0 & 8.6 & 8.7 & 8.1 & 7.6 & 3.6 & 3.3 & 3.0 & 11.1 & 12.9 & 3.6 & 1.8 & 3.6 & 3.8 & 2.2 & 3.0 \\
\hline Average & Wall & 3.5 & 2.7 & 2.8 & 3.3 & 2.8 & 2.7 & 2.8 & 2.8 & 2.7 & 2.9 & 2.7 & 3.2 & 4.1 & 2.8 & 2.4 & 3.7 & 6.0 & 2.4 & 2.4 \\
\hline Average & Table & 3.9 & 2.2 & 2.3 & 3.5 & 4.8 & 5.0 & 4.8 & 4.6 & 2.6 & 3.0 & 3.0 & 6.8 & 7.8 & 2.5 & 1.8 & 5.6 & 5.6 & 2.3 & 2.1 \\
\hline
\end{tabular}

Table 1. Natural light level survey data for July 28,2014, prior to any action taken to reduce light levels. All values in foot candles.

As possible long-term solutions were discussed the data from the light level survey was applied immediately to assist with lighting exhibitions. For example, areas with higher levels of natural light throughout the day would be lit with less electric light to keep the overall levels closer to what was required for the artwork. Additionally, the data from the light level survey helped us to 54 I P a g e 
determine if we could maintain the light levels required by lenders. When the new gallery was opened, the exhibitions involved a lot more loans. With the data from the survey we could be much more confident assuring lenders we could maintain required light levels. Further, we could prevent sensitive artwork from being displayed in areas with the highest natural light levels by alerting curators and designers during the exhibition design phase.

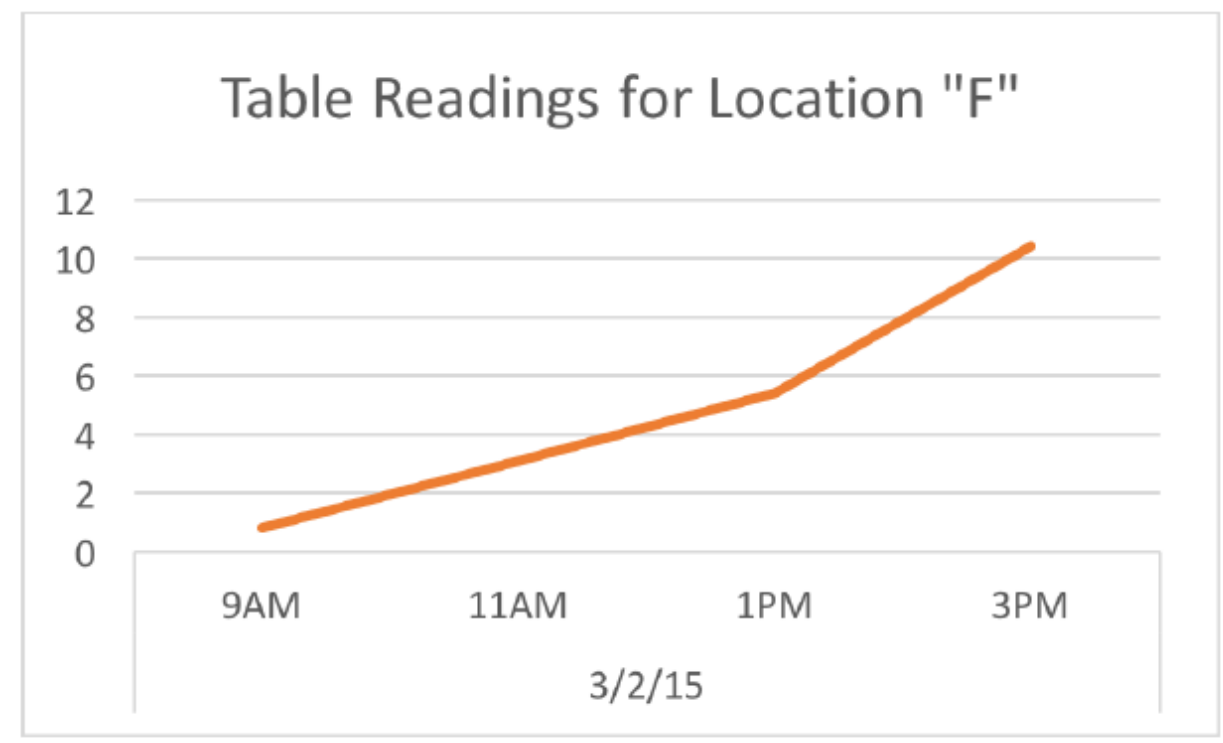

Figure 2. Natural light level change for location "F" on March 2, 2015 prior to any action taken to reduce light levels. All values in foot candles.

After 10 months of surveying the natural light levels four measures were taken to improve the lighting conditions and protect items on display:

1. The ceiling was painted a middle grey.

2. Displaying art near the entrance and exit of the gallery was restricted. Only facsimiles, graphics and artwork not susceptible to light damage would be displayed in these areas.

3. Designers were encouraged to incorporate more color into the design of GRI exhibitions.

4. Conservators would begin using Microfadometry to assess light sensitivity of selected items.

Looking at light levels before and after these measures were taken shows a dramatic change. For example, comparing July 28, 2014 before the ceiling was painted and July 27, 2015 after the ceiling was painted, both with similar weather conditions, the natural light levels in some locations dropped as much as $90 \%$ (Figure $3 \& 4$ ). The vast majority of locations, wall and table, were now well below 1 foot candle of natural light. While these measures did not result in $100 \%$ control over the lighting conditions they were a dramatic improvement (Figures $5 \& 6$ ). 


\section{Wall Light Level Averages}

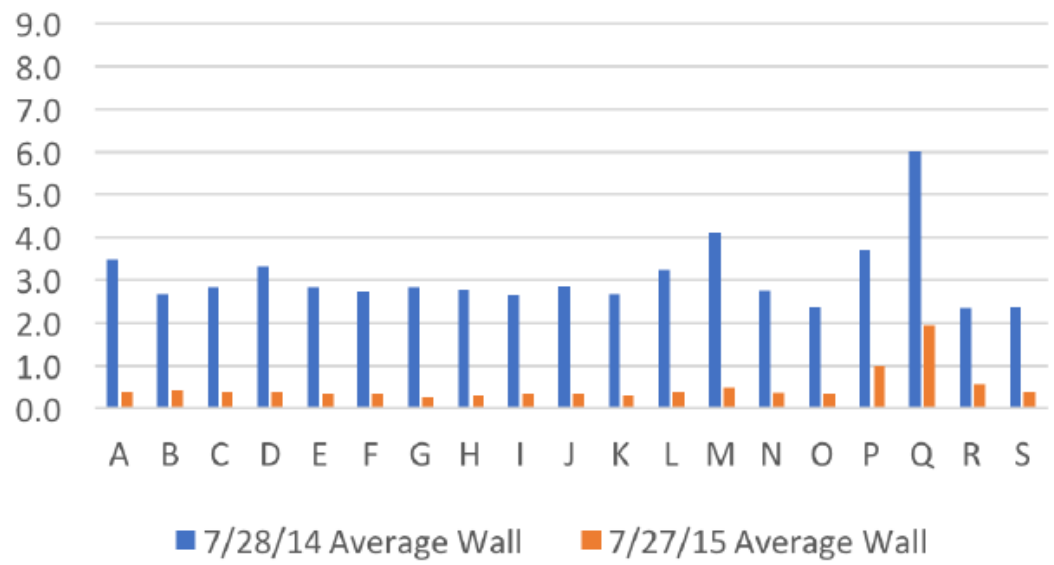

Figure 3. Natural light level on the wall for all survey locations on 7/28/14 (before) and 7/27/15 (after) action was taken to reduce light levels. All values in fc.

\section{Table Light Levels Averages}

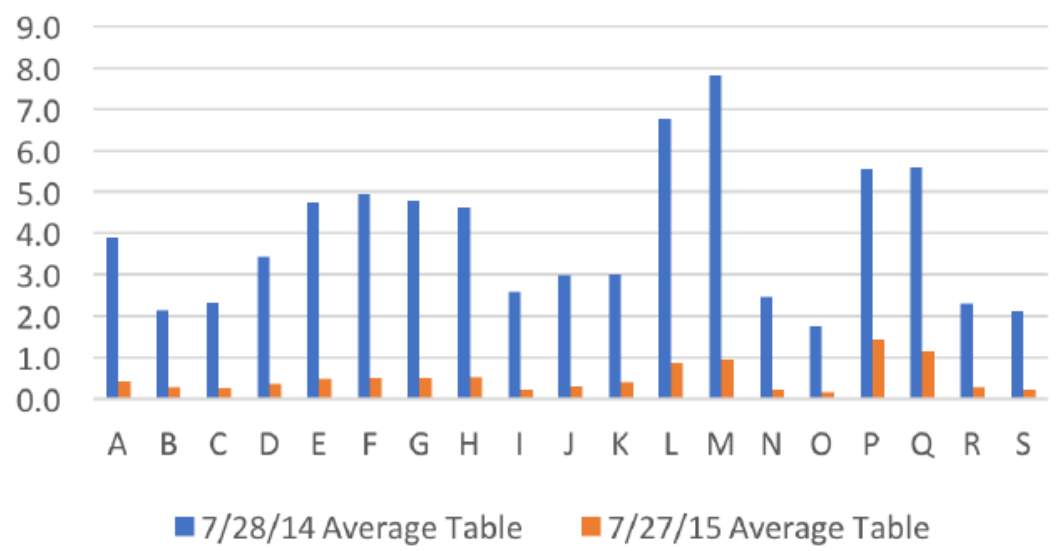

Figure 4. Natural light level in a table case for all survey locations on 7/28/14 (before) and 7/27/15 (after) action was taken to reduce light levels. All values in fc.

To further limit unnecessary exposure of items on display GRI Conservators were trained to use a portable Microfadometer (MFT) designed by the Getty Conservation Institute. Introduced around the time the new gallery was being built, the portable MFT uses a high dose of light over a small area for a short period of time. The color change is measured and compared to that of ISO BWS 1,2 and 3 tested under the same conditions. The GRI had been color monitoring with a Spectrodensitometer since 1997 but the addition of the MFT greatly increased our ability to predict how materials would behave when exposed to light. This informed decision-making about how, or 56 | P a g e 
even if, something should be displayed. Considering the lighting conditions when the new gallery was opened, this instrument was extremely helpful in the solution phase. Currently, the Conservation Dept. is coupling Microfadometry with color monitoring. This presentation will conclude with the results of a real-time test that compares the results of MFT and color monitoring data of an item currently on display in the new gallery as well ISO BWS 1,2 and 3.

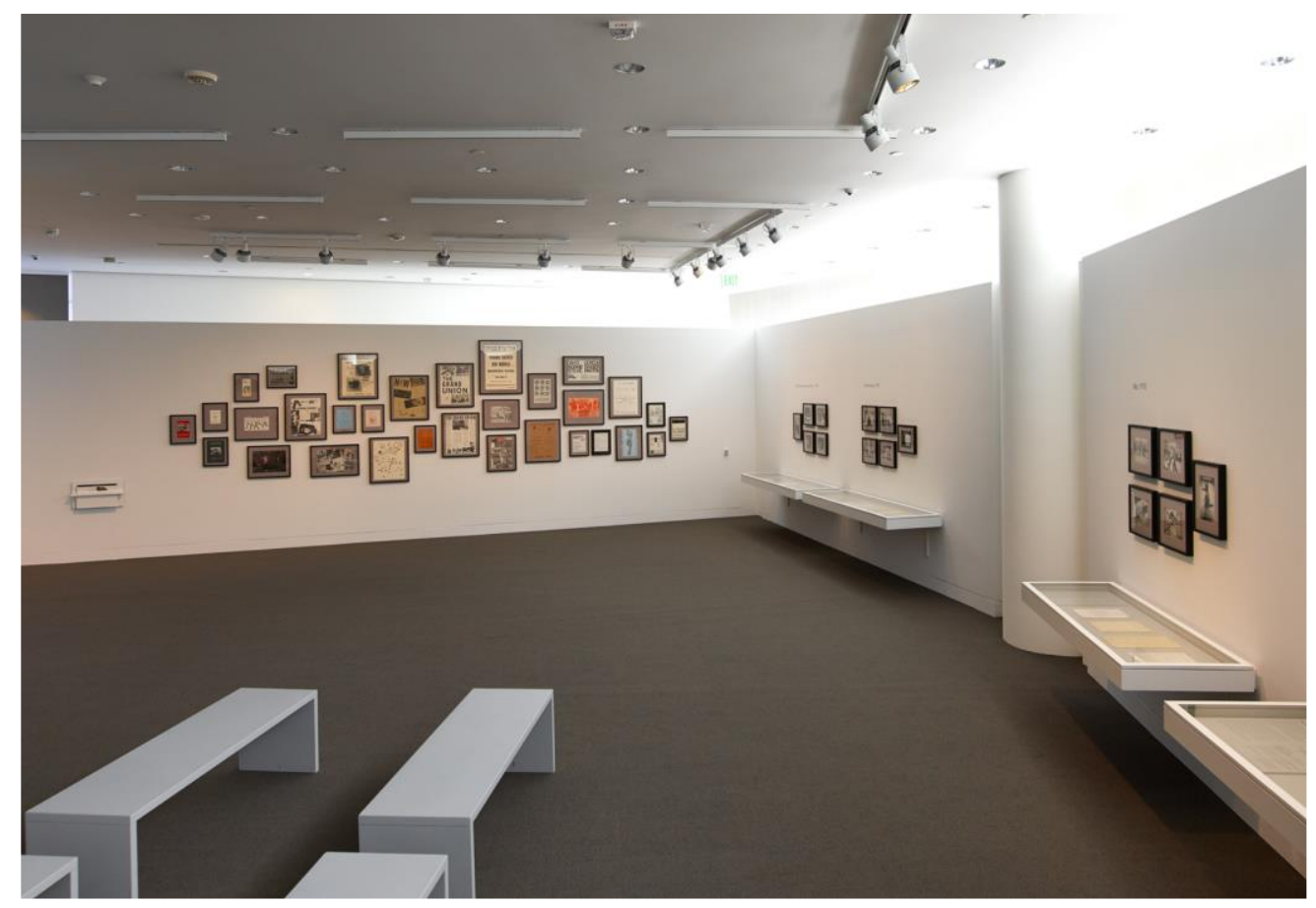

Figure 5. Gallery lighting conditions before steps were taken to reduce light levels.

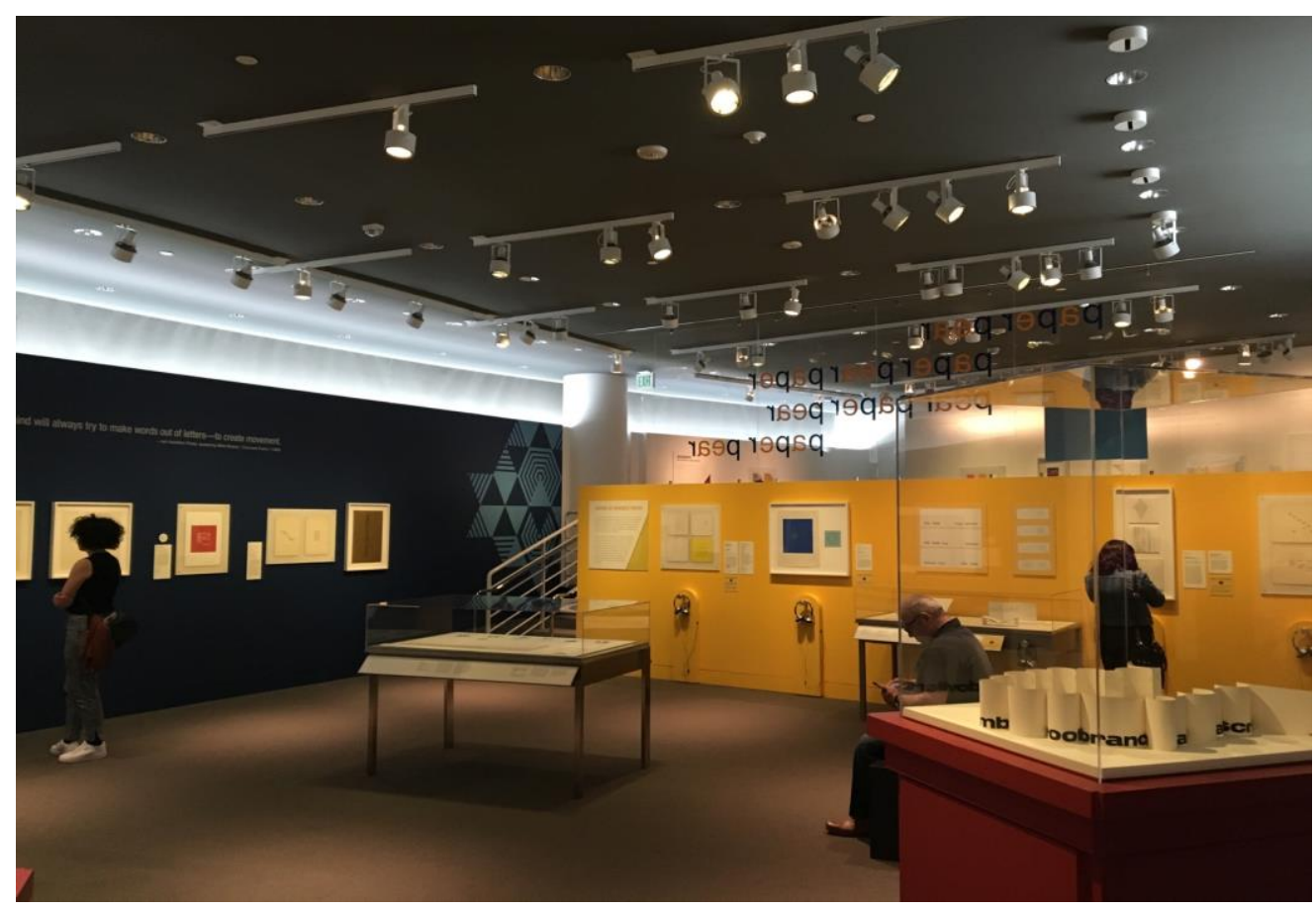

Figure 6. Gallery lighting conditions after steps were taken to reduce light levels. 


\title{
A microfading survey of the lightfastness of blue, black and red ballpoint pen inks in ambient and modified environments.
}

\author{
Bruce Ford \\ National Museum of Australia \& Microfading.com \\ bford@microfading.com
}

Documents and artworks containing ball point pen inks are increasingly encountered by conservators, and because it is well known that because some contain very light-sensitive such as methyl violet, rhodamine and eosin, it is typically recommended that their display should be highly restricted. This project set out to survey the light-sensitivity of approximately 100 randomly selected red, black and blue ballpoint pen inks, in part to evaluate published display recommendations such as CIE157:2004 (CIE 2004), the Victoria \& Albert Museum's lighting policy (Ashley-Smith et al.2002) and an AIC standard (AIC 2004).

Forty brand-name and generic blue, 35 black and 17 red ballpoint pen inks were drawn onto Whatmans filter paper and allowed to dry in the dark under ambient conditions for 18 months. They were subsequently exposed to 6 Mlux UV and IR-free illumination through a transparent window in a modified-environmental chamber using the accelerated micro fade-testing (MFT) apparatus described by Whitmore et al. (1999). Colour difference ( $\left.\mathrm{DE}_{00}\right)$ was calculated from $L^{*} a^{*} b^{*}$ values derived from visible reflectance spectra acquired at 1 minute intervals over 10 minutes. The projected $300 \mu \mathrm{m}$ diameter illuminated test area fitted within most ink lines. ISO Blue Wool Fading Standards 1-3 (in air) were used as internal standards. The ink light-sensitivity tests were carried out at 50\% and 1\% RH in air, and an "anoxic" environment ( $<10 \mathrm{ppm} \mathrm{O2)}$ at 50\% $\mathrm{RH}$.

In air, the light-sensitivity of individual inks of all three colours ranged from negligible to much worse than Blue Wool 1 (BW1) (Fig.1 for blue inks). Overall light-sensitivity (DE 00 ) usually decreased substantially in anoxia, with the notable exception of a quarter of the red inks and one blue ink which responded more rapidly. The effects of oxygen restriction, however, were complex: for example, the inks whose overall light sensitivity increased either lightened (DL*) less rapidly in anoxia or actually darkened (-DL*), better maintaining legibility than in air. For these inks, anoxic display might be a positive for an archive primarily concerned about legibility, but a negative for an art gallery for whom colour has significant aesthetic value. Contrary to expectations (e.g. Giles et al. 1976) low RH failed reliably suppress fading, sometimes having the opposite effect. Lightfastness was not associated with "quality" brands, appearance, or probable year of manufacture and an attempt to correlate lightfastness with characteristic spectral features was only moderately successful because some inks with apparently identical spectra responded differently, probably because colourless ink components, contaminants and even photochemical 
reaction products may be photo-catalytic (Favaro et al. 2012). Such autocatalysis may explain the increasing-rate curves in Figure1.

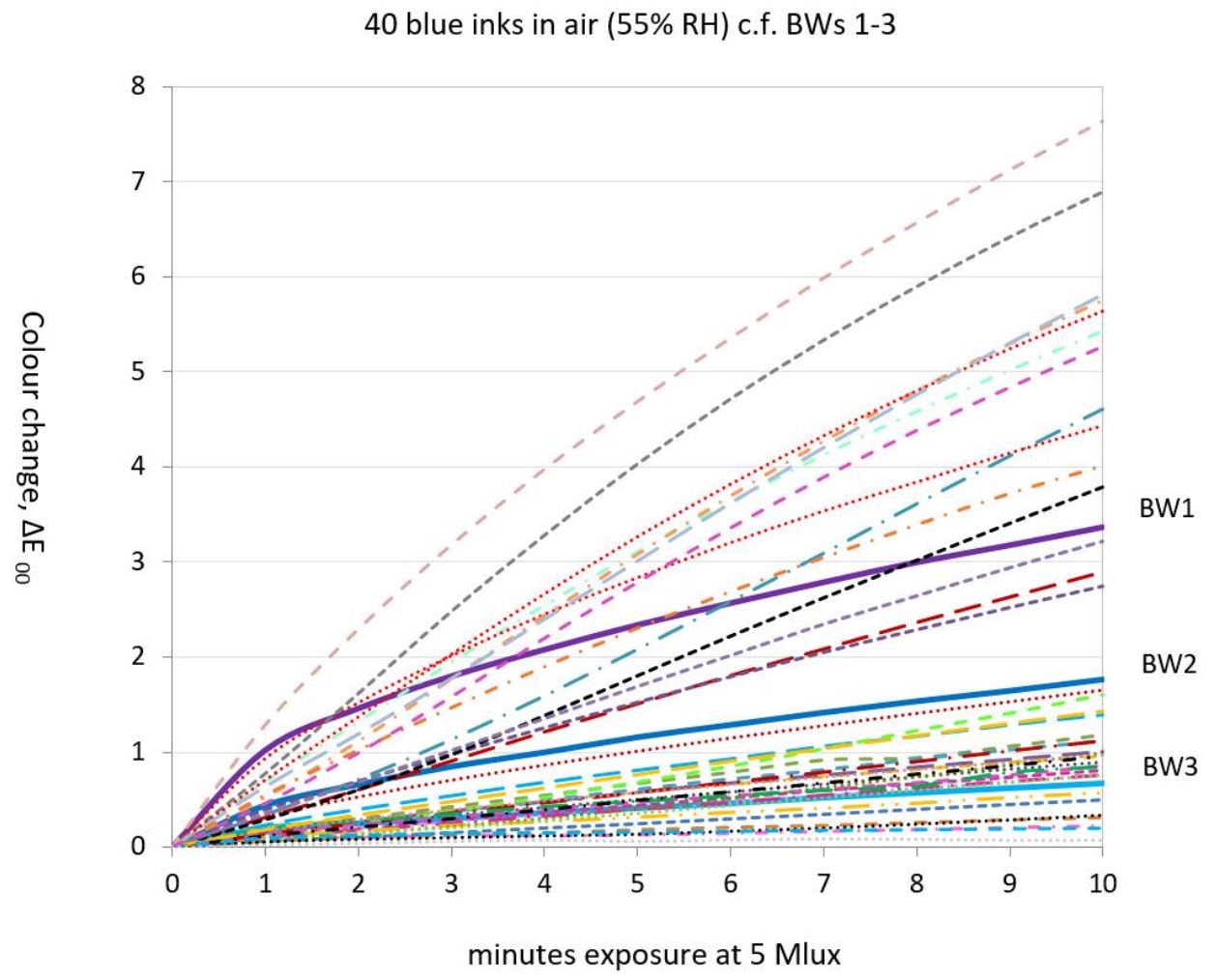

Figure 1. Microfading rates of 40 blue ballpoint pen inks compared to ISO Blue Wool Fading Standards 1-3. Black and red inks spanned similar lightfastness ranges.

Except for BW1, the following calculations are based on UV-free BW lightfastness values in CIE157:2004 (Table 3.3, 2004). Recent unpublished results (Druzik 2016, Tse 2016), suggest BW1's lightfastness is 0.1-0.2 Mlux h/JND (Just Noticeable Difference $=1.6 \mathrm{DE}$ ), much less responsive than some inks at $0.05 \mathrm{Mlux}$ h/JND or worse (Fig.1). The V\&A's policy, predicated on limiting lightfading to no more than $2 \mathrm{JND} / 100$ years, restricts the display of colourants less lightfast than BW4 (3 Mlux h/JND) to 2 years/decade at 50 lux ( 0.3 Mlux h). This would seriously fade the many inks more fugitive than BW1 (2-6 JND) during their very first exhibition. CIE157:2004's 10\% exhibition/storage ratio for similarly (assumed) "high-responsivity" colourants would cause half as much - but still serious - damage, and even the AIC's very conservative 0.05 Mlux h (4 month) limit would cause gross fading within a few exhibition cycles. The substantial proportion of inks more lightfast than BW2 (1 Mlux h/JND), however, could be displayed under the same conditions for at least 7 years without causing a single perceptible colour difference, and BW3 (3 Mlux h/JND) for 20 years or more. 
The results demonstrate that there can be no reliable general exhibition recommendations for ballpoint pen inks, either in terms of cumulative exposure or modified environments. Even if the heuristic exposure guidelines cited above were successful in protecting the most vulnerable inks and other potentially fugitive colourants, it would be unrealistic to expect museums to restrict access to a significant proportion of their collections to 1 or 2 years per decade or less - in most cases unnecessarily and at great expense according one study which also, however, demonstrated practical ways to make them more workable (Ford \& Smith 2010).

\section{References}

AIC Photographic Media Group. 2004. PMG Section 1.4.1 Standards, Guidelines, and Recommendations for Light Levels During Exhibition. http://www.conservationwiki.com/wiki/PMG_Section_1.4.1_Standards,_Guidelines,_and_Recommendations_for_Light_Le vels_During_Exhibition (Accessed 18 th Aug. 2017).

Ashley-Smith, J., Derbyshire, A., and B. Pretzel. 2002. The continuing development of a practical lighting policy for works of art on paper and other object types at the Victoria and Albert Museum', Preprints of the 13th triennial meeting of the ICOM Committee for Conservation in Rio de Janeiro, vol. 1 , pp. $3-8$.

CIE. 2004. Control of damage to museum objects by optical radiation: CIE157-2004. Vienna: Bureau Central de la Commission Internationale de l'Éclairage.

Favaro, G., Confortin, D., Pastore, P., and M. Brustolon. 2012. Application of LC-MS and LC-MSMS to the analysis of photo-decomposed crystal violet in the investigation of cultural heritage materials aging. Journal of Mass Spectrometry 47: 1660-1670.

Druzik, J.M., Getty Conservation Institute, personal communication, email 18/11/16.

Ford. B., and N. Smith. 2010. Protecting the most important, most exhibited and most fugitive museum objects from light-fading, American Institute of Conservation 38th Annual Meeting in Milwaukee, WI: The Textile Specialty Group Postprints, vol. 20, pp.156-166.

Giles C.H., Haslam R., and G.D. Duff. 1976. An examination of the cause of the humidity sensitivity of the lightfastness of dyed materials. Textile Research Journal 46 (1): 51-54.

Tse, S., Canadian Conservation Institute, personal communication, email 23/11/16

Whitmore, P.M., Pan, X., and C. Bailie. 1999. Predicting the fading of objects: identification of fugitive colorants through direct nondestructive light-fastness measurements, Journal of the American Institute for Conservation 38: 395-409. 


\title{
Collection Care and Policy
}

\author{
Chaired by Kalliopi Fouseki and Carolien Coon
}

\section{Wavelength dependence and relative damage factors: an overview}

\author{
David Saunders \\ Honorary Research Fellow, The British Museum \\ d@saunders-online.net
}

Basic physics tells us that not all radiation has the same energy; the shorter the wavelength, the higher the energy. Accordingly, when we consider lighting in a museum context we pay particular attention to the shorter wavelengths emitted by those sources commonly used to light objects, avoiding ultraviolet exposure wherever possible. Of course, it helps that with very few exceptions, ultraviolet radiation plays no part in the way we see objects. Once we have eliminated ultraviolet, we usually focus on reducing total visible light exposure by limiting light levels and minimizing the time objects are lit - bearing in mind the needs of those who will view our collections. But having blocked ultraviolet are there ways in which we can reduce damage further by modifying the visible spectrum emitted by sources? Seen purely as an exercise in reducing light-induced damage the answer is 'yes'. But if we ask the question whether we can achieve this without also either reducing the visibility of the objects we are lighting or illuminating them with strongly 'coloured' light - or both - the answer is more difficult. This contribution looks at over a century of research into the effect of wavelength on damage potential, starting with the now-famous investigations conducted by J.R. Russell and W. de W. Abney in London in the late 1880s and ending - for now at least - with current experiments to compare the damage potential of LED light sources with the incandescent and fluorescent lamps they are rapidly replacing. Two types of experimental study can be identified. First, those that investigate the relationship between wavelength and damage by exposing materials to different parts of the spectrum. A series of such experiments in the second half of the twentieth century established the sensitivity of materials at different wavelengths and the effect that selective absorption of radiation by those materials plays in determining the damage that results. The second type of experiment makes direct comparisons of two or more light sources so the damage they cause relative to each other can be compared. In some investigations, a reference source is included against which comparisons are made. Alongside these studies, attempts have been made to calculate a damage function that would then allow us to determine a relative damage factor for any light source for which we have the spectral power distribution, without the need for experimental testing. These calculations take 
as their basis the results from investigations of wavelength dependent damage. The $2004 \mathrm{CIE}$ publication on Control of Damage to Museum Objects by Optical Radiation, presents a set of such functions for different classes of material commonly found in museum objects. These functions have been used in two significant applications. First, to estimate the damage potential of new light sources as they come on the market, often taking the existing light source used in the museum as the reference point for relative damage factor calculations. Second, to help design new light sources that have a lower damage potential for the same level of illumination as existing light sources. In some cases, the results from these theoretical studies of damage are tested by exposing test samples to the light sources under investigation, providing a good test of the relationship between theory and practice - particularly when general assumptions about material sensitivity are contrasted with the behaviour of real objects. The survey of this field will end with a review of the current state of research into, and application of, wavelength dependency. How well are the relationships between damage and wavelength that were used to formulate the damage functions holding up in the light of new research? How useful are relative damage factors when making decisions about suitable light sources - are they simply a rule of thumb? Are there better, simpler ways of reducing damage? Where might future research most usefully be directed? 


\title{
Are we being too easily LED? Assessing the impact of LED lighting on pigments and paper in heritage collections
}

\author{
Emma Richardson ${ }^{1}$, Elizabeth Woolley ${ }^{2}$, Asya Yurchenko ${ }^{1}$, Dave Thickett ${ }^{3}$ \\ University College London ${ }^{1}$, The Courtauld Institute of Art ${ }^{2}$, English Heritage ${ }^{3}$ \\ e.richardson@ucl.ac.uk
}

Solid-State Lighting systems, commonly known as Light Emitting Diodes (LED), are steadily finding application in an increasing number of museum and heritage institutions, providing energy efficient solutions for collection display. Spurred on by the increased risk of obsolescence of tungsten halogen lamps, and the large outlay of money required for the migration of English Heritage's current lighting systems, our research is directed towards assessing whether particular paper, pigments and pigment/binder compositions are vulnerable to chemical alterations, enhanced fading and discolouration when subject to solid-state lighting.

With LED lighting technology still in its infancy, there can be large differences in properties between lighting systems, which may pose problem for collections management and display [1]. One of the major concerns regarding the move from tungsten lighting to LEDs relates to the spectral power distribution output from the latter, with some lamps emitting a significant intensity of light at wavelengths nearing the ultraviolet region of the spectrum. For museum and gallery applications white LEDs that contain violet chips are not deemed appropriate as these have an intense emission peak at $405 \mathrm{~nm}$, close to the demarcation of UV radiation [1,2]. Where LEDs have been installed in museums and galleries white LEDs containing a blue chip are favoured. This is due to their primary emission being centred at approximately $450 \mathrm{~nm}$ and concomitant broad phosphorescent emissions at longer wavelengths [1-3]. Although the intensity of short wavelength emissions $(405 \mathrm{~nm})$ are greatly reduced when compared to violet chip LEDs, the presence of emission peaks in the $450 \mathrm{~nm}$ region of the spectrum has raised concerns within the conservation profession. In a recent survey on museum lighting selection [4] it was suggested that the peak at $450 \mathrm{~nm}$ should not exceed three times the height of the broad phosphorescent emission. Current U.S Government guidelines for the display of works of art suggest that the peak at 450 $\mathrm{nm}$ should not exceed $50 \%$ of the maximum power in the spectral power distribution [5].

It is acknowledged that historic house environments routinely display works under UV-filtered daylight conditions, with relative spectral power distribution below the $500 \mathrm{~nm}$ region being higher than in blue chip LEDs. However, photosensitive objects are restricted to locations where daylight penetration factors often approach zero. In such cases local lighting often relies on tungsten to illuminate such objects. Although dyes and photographs have been assessed and are not adversely affected compared to tungsten, previous work indicates some papers and certain pigments may be at risk [6,7]. Material selection is generally based on reflectance spectra exhibiting strong 
absorption around the $450 \mathrm{~nm}$ region, however this does not necessarily indicate a reaction.

This collaborative project aligns with English Heritage's policy for Climate Change and the Historic House [8] through studying the impact of different options for climate change mitigation and adaptation. Through the investigation of energy efficient lighting alternatives for the historic house environment a significant contribution can be made towards national and international targets for climate change [9, 10]. Based on estimated annual reductions in energy costs per equivalent lamp, moving from tungsten lighting to LED lighting could theoretically establish an energy and monitory saving in the region of $85 \%$, to be offset against the cost per unit of replacement. However, the aged electrical systems within historic houses, coupled with the limitations on controlling temperatures, will reduce the expected operational life of the lamps. Additionally, many historic interiors have much lower artificial lighting density than museums and galleries, therefore total potential savings may prove less significant.

Nonetheless a move to LED lighting could provide financially beneficial, coupled with a significant reduction in $\mathrm{CO} 2$ emissions. Although there is a business case to be made for moving towards LED lighting within English Heritage properties, the safe display of objects must also be ensured. Identifying vulnerable pigments and papers will enable future preservation strategies to be put in place, avoiding acerbation of damage and reducing the need for conservation.

With this in mind our research consists of an accelerated ageing study to assess the impact of blue chip LED lighting on the stability of a number of artists' pigments, paints and papers. It is a comparative study focusing on four different lighting environments, 13 pigments, three binder compositions, in addition to representative paper samples used for watercolours. The aim being to establish what extent LED lighting differs, in paint stability terms, relative to tungsten lighting currently employed within English Heritage historic house environments. Current English Heritage guidelines restrict the use of LEDs with a $450 \mathrm{~nm}$ emission greater than $33 \%$ of the broad phosphoresce and with a full width at half height greater than $20 \mathrm{~nm}$. The two LED lighting systems were therefore selected to interrogate the importance of these guidelines.

The paint samples were prepared following traditional paint recipes and applied onto Teflon substrates (Figure 1), ensuring a uniform application of paint media for subsequent analysis by ATR-FTIR and colourimetry. Analysis was carried out on samples following six months drying, followed by periodic, exponential analysis of artificially light aged samples. Owing to the large dataset generated, a multivariate approach has been employed in order to highlight spectral alterations and colour change across the dataset. Principal component analysis (PCA) and partial least squares (PLS) has been used to decompose the data in order to map variations and correlations across the sample set.

Data interpretation is still underway, but initial results suggest comparable stability between traditional halogen lighting and the two LED systems that are the focus of our work. When accounting for sampling errors and perception thresholds for Delta E00 the samples are seen to follow similar behaviour across all pigment and binding media up to exposures of 37 Mlux hrs. At

$64 \mid \mathrm{P}$ a g e 
extremely high exposures there is a degree of divergence between the halogen lighting and the LED systems in certain watercolour pigments, namely vermillion, cochineal and sage green watercolours. The principal component analysis undertaken on the FTIR spectra for each different pigment type does not indicate systematic differences between the light sources, although this data is still to be fully interrogated.

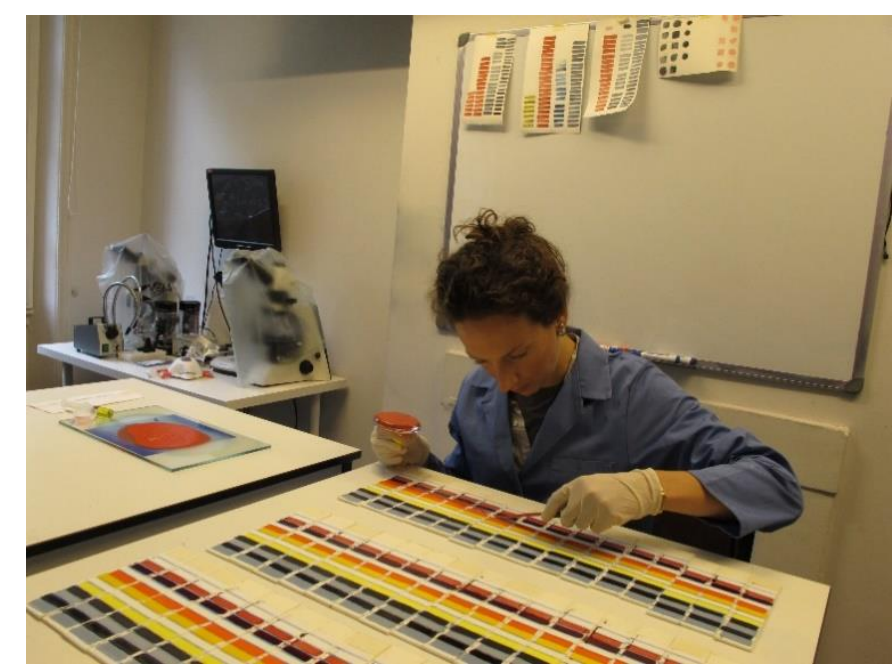

Figure 1. Preparation of oil paint samples

\section{REFERENCES}

1. Druzik, J.R. and S.W. Michalski, Guidelines for Selecting Solid-State Lighting in Museums. 2012, J. Paul Getty Trust and Canadian Conservation Institute: Los Angeles.

2. Padfield, J. Measuring and Working with Different Light Sources with The National Gallery. 2014 [cited 2014 August]; Available from: http://research.nglondon.org.uk/scientific/spd/.

3. Padfield, J., S. Vandyke, and D. Carr. Improving Our Environment. 2013; Available from: http://www.nationalgallery.org.uk/paintings/research/improving-our-environment.

4. Garside, D., et al., How is museum lighting selected? An insight into current practice in UK museums. Journal of the Institute of Conservation, 2017. 40(1): p. 3-14.

5. Demonstration Assessment of Light-Emitting Diode (LED) Retrofit Lamps, U.S.D.o. Energy, Editor. 2012, Pacific Northwest National Laboratory: Washington.

6. Lerwill, A., et al., Micro-fading spectrometry: investigating the wavelength specificity of fading. Applied Physics A, 2014. 118(2): p. 457-463.

7. Lerwill, A., et al., Photochemical colour change for traditional watercolour pigments in low oxygen levels. Studies in Conservation, 2015. 60(1): p. 15-32.

8. Heritage, E., Climate Change and the Historic Environment. 2012, English Heritage: London.

9. DECC, The Energy Efficiency Strategy: The Energy Efficiency Opportunity in the UK, DECC, Editor. 2012, Department of Energy \& Climate Change: London.

10. DTI, Meeting The Energy Challenge: A White Paper on Energy, DTI, Editor. 2007, Department of Trade and Industry: London. 


\title{
Implementing fully tuneable spectrum LED light sources at the Art Institute of Chicago: perspectives from lighting design and conservation
}

\author{
Kerri Callahan, Francesca Casadio, Sarah Casto, Sylvie Penichon, Antoinette \\ Owen, Frank Zuccari
}

The Art Institute of Chicago

kcalla1@artic.edu

In recent years, solid state light-emitting diode (LED) illumination has come to the fore as an attractive option for museum lighting. The Art Institute of Chicago (AIC) was the first fine art institution to adopt fully tunable spectrum Ketra Color Tunable LED light sources in 2015. Up until this point, AIC maintained typical incandescent light sources, dictating a $2850 \mathrm{k}$ static color temperature, which also brought along some emission in the UV, high energy usage, and short life span typical for incandescent sources. After an extensive search of static color LEDs on the market, AIC was dissatisfied by their intensity, output, stability over time, and most importantly color rendition. Utilizing Ketra tunable LED sources opened up a larger dialogue of what "color" illumination was the right choice for each work of art, rather than choosing one color or one color per gallery. LEDs also brought additional benefits, including reduction in energy use by nearly $75 \%$, with an energy use payback period of less than one year, a lengthened lifecycle, and elimination of all UV. Since then, AIC has installed over 4,000 lamps throughout various galleries: from temporary exhibitions of Southeast Asian art and of Vincent van Gogh paintings, to new permanent galleries devoted to Medieval and Renaissance art. From a lighting design perspective, these systems are desirable not only because of their longevity and lowered environmental impact, but also because of the full tunability of correlated color temperature (CCT), color calibration within one MacAdam ellipse, and color rendering index (CRI) over the life of the lamps. This means that, as the light sources age, the variation in color of the lamp over time can be offset by its tunability.

As new LED technology and luminaire designs appear on the market, it is important for lighting designers, conservators, and scientists to work together to define the perimeter of working conditions that can ensure optimal viewing in the galleries, as well as safeguard and promote preservation of collections, especially when light sensitive materials are displayed.

Recent research on solid-state lighting has shown that, on average and below 3200K, LED sources show comparable damage potential (CIE relative damage) to the accepted blackbodies or UVfiltered fluorescent lights at the same color temperature and illuminance. For collections items whose sensitivity to light is equivalent to ISO blue wool standards 1-3 or for mixed material collections, published research advises to keep the CCT within $2700 \mathrm{~K}$ and 3200K.The AIC 
Conservation Department has generally adopted such guidelines, recommending a CCT of $2850 \mathrm{~K}$ or $3000 \mathrm{~K}$ to curators and exhibition lighting designers.

A unique feature of Ketra lamps is that they offer the possibility to increase "vibrancy" at any given color temperature, and make illuminated objects appear more vividly colorful. However, the effects of such vibrancy modes on the spectral power distribution (SPD) of the lamps are still largely untested and may have considerable conservation implications.

Specifically, a Ketra emitter has four LEDs: red, green, blue (RGB), and white (W): adjusting the vibrancy of the light implies changing the ratio of RGB to $\mathrm{W}$ output. When vibrancy is set at $100 \%$, the output is dominated by the RGB LEDs; when, on the other hand, vibrancy is closer to $0 \%$, the white LED dominates. When changing the vibrancy feature, the intensity of the light source is the same, but the SPD output and the CRI change (Fig. 1). At 3000 K Ketra show a Color Rendering Index (CRI) of 95 at $0 \%$ vibrancy, and CRI of 30 at 100\% vibrancy, while the relative exposure damage at $3000 \mathrm{~K}$ and $0 \%$ or $100 \%$ vibrancy, is $51 \%$ and $59 \%$ respectively, compared to a theoretical blackbody radiation at the same CCT ${ }^{1}$. Thus, on average the Ketra tunable lights can be considered comparable or perhaps slightly less light-damaging than tungsten lamps. However, because light is emitted in discrete areas of the spectrum, rather than a continuum, specific materials may be more at risk, depending on their absorption curves in the visible. Additionally, an important consideration to be made is that by increasing the vibrancy of Ketra lamps, the perceived brilliance of the source decreases to roughly half, and consequently, the measured lux drop significantly going from 0 to $100 \%$ vibrancy at the same CCT.

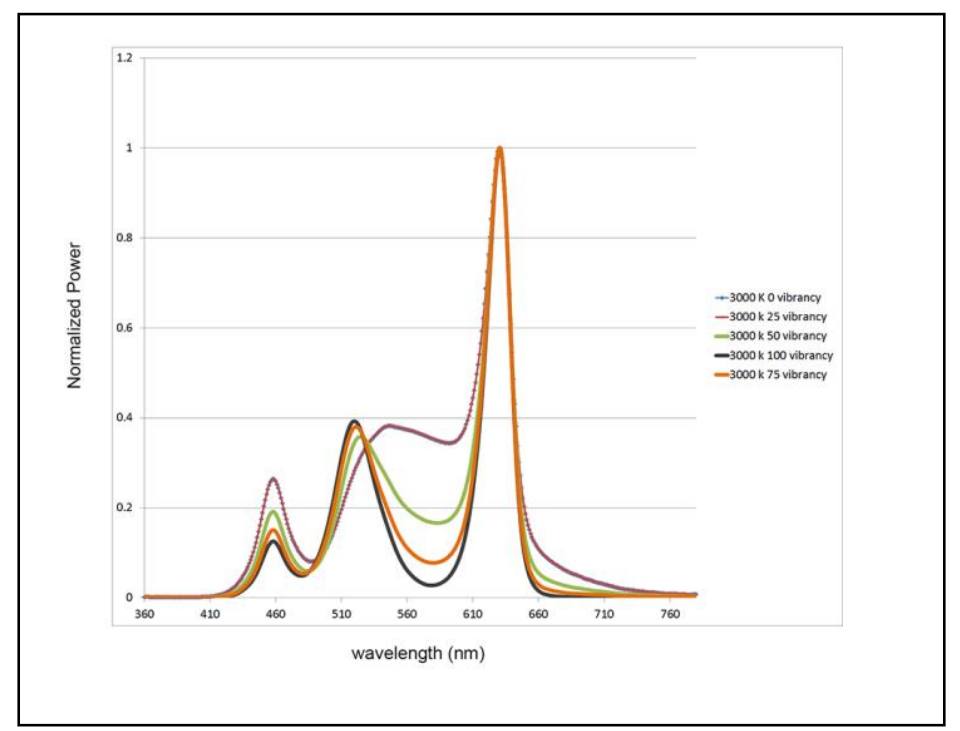

Fig. 1 - Normalized spectral power distribution curves of Ketra tunable LED lamp at a CCT of $3000 \mathrm{~K}$ and various vibrancy settings

\footnotetext{
${ }^{1}$ National Gallery: Spectral Power Distribution (SPD) Curves by Joseph Padfield
} 
This study was conducted to evaluate the changes of the SPD of Ketra color tunable LEDs caused by modification of the vibrancy setting, and its effect on a selection of light-sensitive objects. This paper reports on the measurement of the SPDs of tunable spectrum single point LED Ketra lights produced at various vibrancy settings in the 2850-4000K CCT range. It also details the results of artificial aging of chromogenic prints and washes of indigo, cochineal, and madder watercolors, as compared to blue wool standards 1-3, using Ketra lamps at fixed CCTs (2850 and $3000 \mathrm{~K}$ ) but varying vibrancy between $0 \%$ and $100 \%$. Results of this study have shown that, for example, on washes of cochineal watercolor aged at 3000k, color fading (measured as DE) at $0 \%$ vibrancy (at 16500 lux for 48 hours, totaling 816,000 lux/hour) or 100\% vibrancy (at 8100 lux for 96 hours, totaling 777,600 lux/hour; equivalent to 81 days of museum exposure at 50 lux, 8 hours a day) is in fact comparable (Fig 2.). Yet, fading is significant, with measured DE around 11.

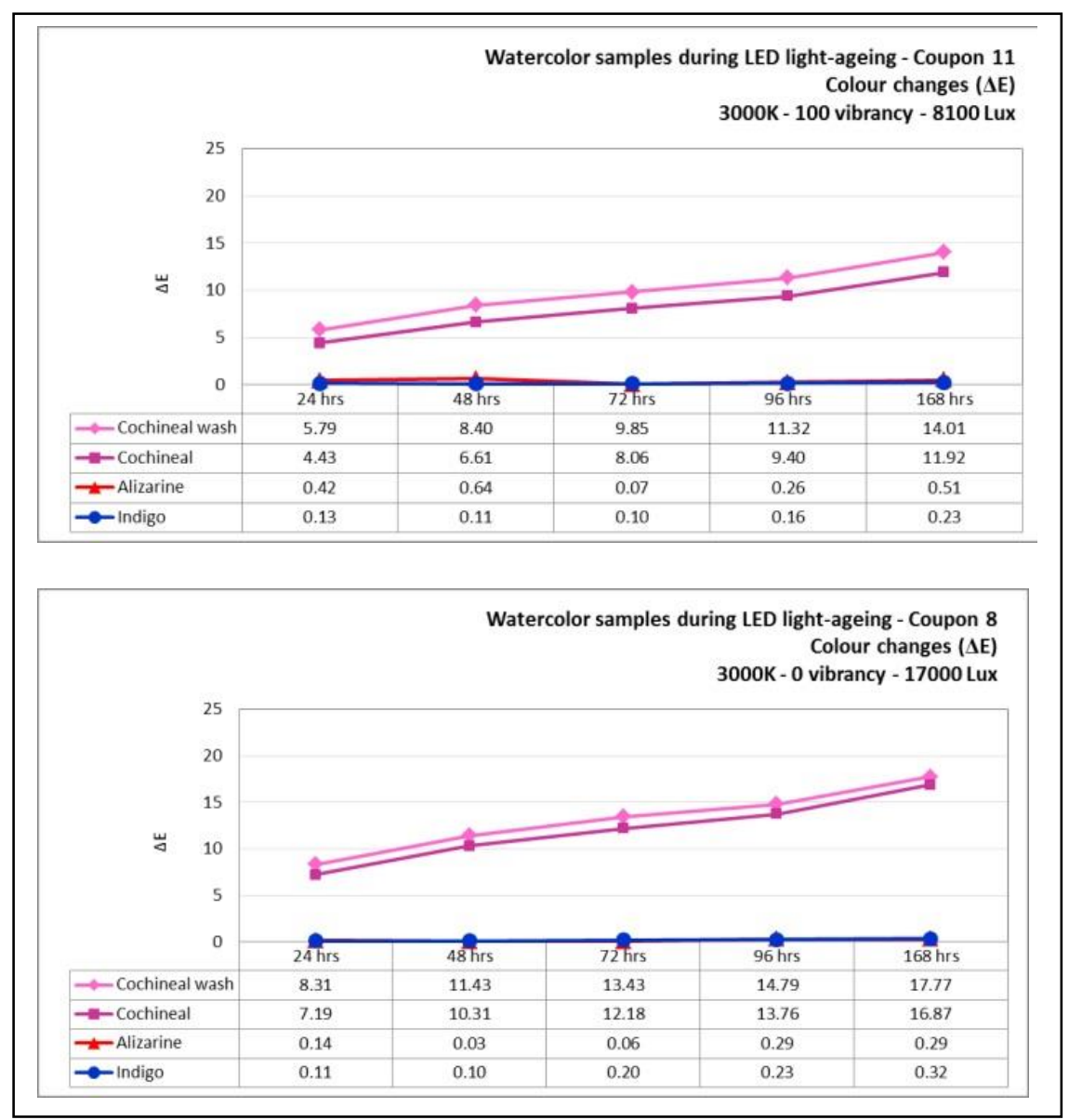

Fig. 2 - Examples of color change measured under Ketra lamps at 3000K and various vibrancy settings for reference samples of watercolor washes

This information has been used to inform the museum's internal lighting and loan illumination policies and may be useful to the wider Museum community. 


\title{
Object-Specific Lighting Design for Mark Rothko's Green on Blue, a Collaboration between The University of Arizona Museum of Art and College of Optical Sciences
}

\author{
Ross D. Uthoff ${ }^{1}$, Nathan W. Saxton ${ }^{2}$, Rachel N. Ulanch ${ }^{1}$, Kaitlyn E. Williams ${ }^{1}$, \\ Page King ${ }^{1}$, Liliana Ruiz Diaz ${ }^{1}$, R. John Koshel ${ }^{1}$
}

The University of Arizona College of Optical Sciences ${ }^{1}$, The University of Arizona Museum of Art ${ }^{2}$

rossuthoff@email.arizona.edu

Museum lighting is a balance between presentation and preservation, between the work of the lighting designer, the conservator, and the artist or curator. Quantitative factors such as illuminance, color, uniformity, shape, efficacy, and cost and qualitative factors like aesthetics, visitor experience, and artist intent must all be considered simultaneously. Increasing the difficulty, lighting designers are limited in luminaire choices due to market availability and cost, and installation locations due to existing infrastructure. In this case study, The University of Arizona Museum of Art (UAMA) and College of Optical Sciences collaborate to design a lighting solution specifically for Mark Rothko's Green on Blue (1956), UAMA's most distinguished artwork. Though tunable color-temperature light source usage is increasing, the ability to control light shape and distribution remains desirable. Object-specific lighting opens up a new technology area for designers and artists in the lighting of myriad art objects. Research into Mark Rothko's strict exhibition parameters at the Phillips Collection in Washington DC, and conversations with his son, Christopher Rothko, shaped a number of design specifications. Mark Rothko was notoriously particular about how his work was exhibited, wishing it to be hung low to the ground in a confined, diffusely lit space. The artwork was to completely command the space and the viewer, in order to create an entirely immersive experience. While the full effect of a Mark Rothko painting can be a powerful experience, that effect is also easily defeated when the lighting and display environment are not carefully designed. Rothko strongly felt the effect of his work was blunted when displayed alongside other paintings. UAMA did not have the resources to build a dedicated space as in the Phillips Collection in Washington, DC, or the Rothko Chapel in Houston, TX. Instead, the artist's wishes were honored by building partial walls to isolate and confine the painting from the rest of the gallery, allowing for further control over the illumination. Fortunately, Rothko's lighting preferences and the illuminance levels desired for preservation overlap. Rothko's paintings are very sensitive to light damage as evidenced by the Harvard murals. He desired the illuminance be set to the light level where the painting 'shimmers', possibly a result of his egg-based materials. To use Christopher Rothko's words, 'This means lighting subtly, drawing out light from the painting rather than imposing light upon it'. Testing at UAMA measured this light level to be about 20 lux, under the 50 lux level recommended by the IESNA for highly susceptible materials. 
Along with the confined and dim display environment, source color temperature greatly impacts the viewer experience. Surveys at UAMA and from the Getty Conservation Institute and Lunder Conservation Center at the Smithsonian American Art Museum and the National Portrait Gallery's Master Class on Museum Lighting found a majority of visitors to prefer a color temperature around $3000 \mathrm{~K}$. LED sources offer many correlated color temperatures with low output in the UV and infrared wavelengths, but have limited output in the $475 \mathrm{~nm}-550 \mathrm{~nm}$ range, reducing the visibility of the green content in Green on Blue. Measurement of the reflection spectrum of the painting provides additional insight to the ideal illumination spectrum. Even with these improvements, the large, rectangular painting is still illuminated by a source with a circular output at an oblique angle, causing spillover to the walls and floor and an illuminance gradient across the height of the painting. The College of Optical Sciences, experts in optical design and engineering, sought to solve this problem. To simultaneously address the shape, gradient, and uniformity of the illuminance, a freeform optical design is used. Freeform optics are not constrained by radial or plane symmetry. Typical design methods design for idealized point sources and utilize analytic methods to build a surface profile point by point by steering each ray to its desired target. While these methods have recently been applied to extended sources (such as LED sources), the output is not parameterized making it difficult to further optimize the result to correct real world issues. A new design process is developed to address these limitations. The result is a custom luminaire for Green on Blue that overcomes the cosine ${ }^{\wedge} 4$ illuminance fall-off and the Lambertian, spherical intensity distribution of the LED source to create a rectangular distribution that is perceptually uniform across the entire artwork. Based on museum lighting standards, the human visual system, and initial design results, final design specifications were developed. For the hardware of the lighting system, a single LED is used for decreased materials and operating costs. Additionally, the hardware retrofits into existing luminaires and track lighting systems for additional cost reduction to the museum. The optic has an aspect ratio reasonable for manufacturing and collects a greater than 50 degree source cone angle, leading to a high optical transfer efficiency. The target illumination requirements include illuminance less than 30 lux, peak-to-valley uniformity of greater than $75 \%$, no light past the edge of the canvas, and minimal chromatic aberrations at the edge of the pattern. Cutting the light pattern at the edge of the canvas minimizes observer distractions and confines their interactions to Rothko's work. This new technology provides unprecedented control over light shapes and distributions, letting visitors view Rothko's work the way he intended. Generalizing this design process for other art objects or historical artifacts allows the artist to be more demanding and discerning in the presentation of their work and the lighting designer to fully realize the vision of the artist and curator, further enhancing the observer experience. 


\title{
Fading colours and the necessity for a new high-quality LED-museum lighting system with a clear formulated light policy for the paintings by Vincent van Gogh
}

\author{
Kees van den Meiracker \\ Van Gogh Museum, Amsterdam \\ Vandenmeiracker@vangoghmuseum.nl
}

The Van Gogh Museum had, until recently no lighting policy, the light levels were based on the generally accepted maximum light levels for oil paintings, 150 lux, based on publications of more than 60 years ago. It is also well known that Van Gogh paintings were changing continue in colour due to light exposure and we wanted to formulate a new lighting policy for the coming thirty years. Under the leadership of the Head of Collection Management and Restoration, the Light Team was formed in 2014, with representatives from all departments of the museum. This team, after thorough research and with the help of external lighting architect Henk van der Geest and Agnes Brokerhof (Cultural Heritage Agency of the Netherlands) formulated the light policy of the museum.

\section{Introduction}

The Dutch painter Vincent van Gogh (1853-1890) was a colourist in heart and soul. He became famous in particular for the bold expressive palette of his later French works. In his paintings, Van Gogh made extensive use of bright simultaneous colour contrasts for emotive effects. Given the primary importance of colour to Van Gogh it is hardly surprising that his letters express a concern for the adverse effects of ageing and consequent colour change 'Paintings fade like flowers'. Van Gogh was dependent on his brother Theo for money to buy painting materials and the artist's letters provide ample evidence for his quest to balance price and quality when selecting the purchases. A striking example of colour change is given by The Bedroom (October 1888), the version now in Amsterdam. In his letters, Van Gogh describes how he aimed for strong contrasts of complementary colour: the yellow bed set against a purple wall and the rusty red floor against the green window.

\section{Context}

The Van Gogh Museum in Amsterdam is one of the most successful museums in the world, with more than two million visitors in 2016, the main building, which was established in 1973 as a daylight museum and was built for about 150,000 visitors a year. In 1999, the Kurokawa wing came ready for temporary exhibitions. This success has a downside, namely extending the opening hours. In addition, the museum organizes around 300 festivities outside opening hours. 
The museum holds the largest collection of Vincent van Gogh in the world, 205 paintings, 6,000 prints and drawings and 900 letters. The collection is world-renowned and widely asked throughout the world. The iconic works like the Sunflowers and Potato eaters are always visible to the public.

In addition, it is known that Vincent van Gogh's paintings, made after August 1, 1885, are very sensitive to light. In addition to the quality of the light source, it is necessary to reduce the maximum amount of light.

All this means that the pressure on this relatively small collection is huge and wants to be preserved for future generations, then a strictly formulated light policy is a prerequisite.

\section{Lighting}

The halogen lighting in the entire museum needs replacing and the expectation is that halogen will become increasingly in use in the coming years. The only alternative is LED lighting, but previous experiences and tests have not led to the museum and all its stakeholders to be enthusiastic. In particular, the colour display is considered unsatisfactory. Current technical developments in LED technology, however, offer opportunities.

\section{The future}

The visual power of the reconstruction could also be seen to foster broader awareness of the risks of continued light exposure. When the Van Gogh Museum renovated its Kurukawa Wing, it chose to take a decisive approach towards selecting a new lighting system and adjusting its lighting policy. The choice for the most suitable LED system was made on the basis of experiments conducted by a light designer in the permanent exhibition. Different fixtures and light sources were used to illuminate sets of similar paintings and opinions from staff about colour rendering and perception of atmosphere were gathered [Note 1]. Rather than simply adopting the generally agreed maximum illuminance (lux) for oil paintings, the acceptable degree of fading and hence the permissible light dose (lux-hours) over a certain period would form the foundation for the lighting policy. Since the reconstruction had literally opened the organisation's eyes to conservation concerns, the door was open to discuss acceptability of further change by visualising possible future fading. Building on past experience with a similar approach (Brokerhof et al., 2008) an experiment was designed in which simulations of future states of The Bedroom were used to solicit opinions about the acceptability of change. 


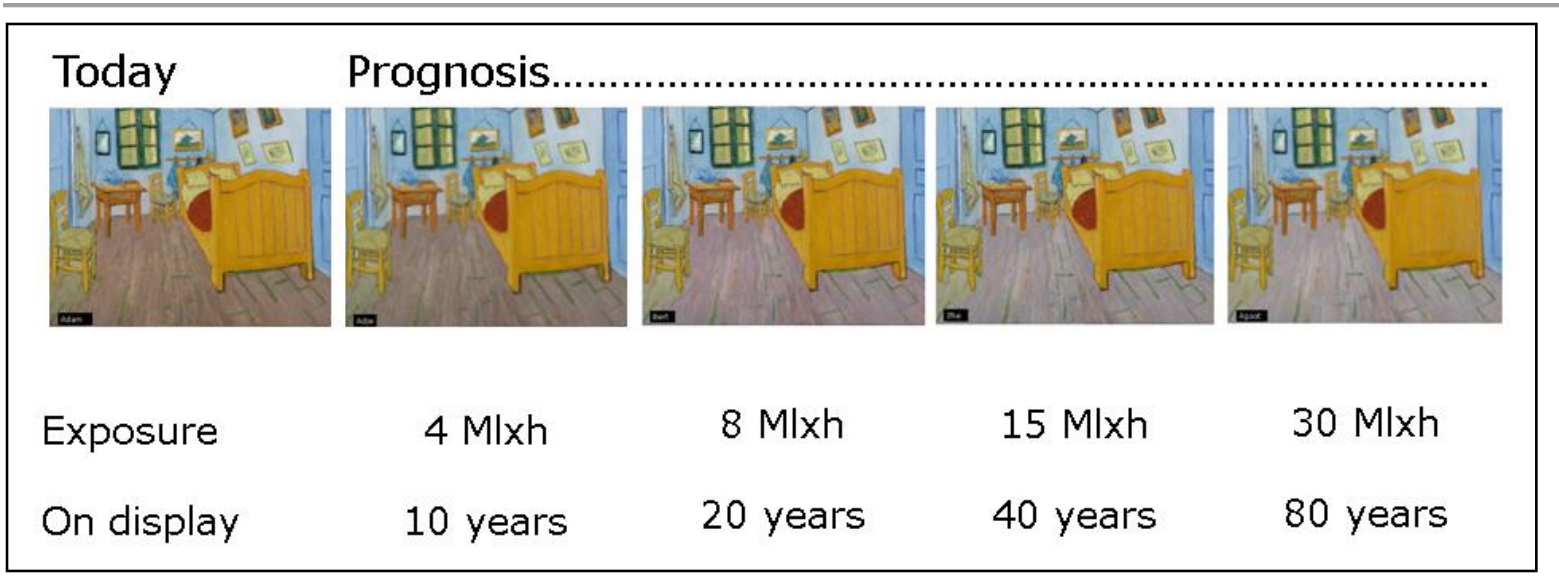

\section{The new LED}

How much light is acceptable depends on the amount of hours you will display the painting. In the case of the Van Gogh Museum the iconic works of art has to be on display every day, 365 days a year from $9.00 \mathrm{am}$. till sometimes $10.00 \mathrm{pm}$. Visitors from all over the world come especially for these objects to Amsterdam, it is not allowed to put them in storage without light. It was almost impossible to reduce lux with the old halogen lighting system, below 60 lux the colours changed to much.

\section{Conclusion}

The light team has formulated policies approved by the management for the next thirty years. New high-quality LED lighting has been purchased, which meets the highest quality requirements for color temperature, light spectrum and color rendering. This makes it possible to reduce the amount of lux on the works to a maximum of 50. The light team is an integral part of the museum in the field of consulting and realization.

\section{Notes}

1. Henk van der Geest of instituut Lichtontwerpen (iLo), Amsterdam, was responsible for the tests and installation of the new LED lighting system.

2. Colours were adjusted with masks by Roy Berns, RIT. Colour calibrated prints were made by Maurice Tromp, Van Gogh Museum.

\section{$\underline{\text { References }}$}

Berns, R. 2010. Digital rejuvenation of the bedroom,

http://slaapkamergeheimen.vangoghmuseum.nl/2010/09/digital-rejuvenation-of-the-

bedroom/?lang=en (accessed 31 October 2016)

Berns, R.S. 2013. Artistic Rejuvenation of Vincent van Gogh's "The Bedroom"

https://www.youtube.com/watch?v=HZqLVQAy8rc （accessed 31 October 2016) 
Van Bommel, M., M. Geldof, and E. Hendriks. 2005. An investigation of organic red pigments used in paintings by Vincent van Gogh (November 1885 to February 1888). Art Matters: Netherlands Technical Studies in Art 3:111-137.

Hendriks, E. 2016. 'Paintings fade like flowers': colour change in paintings by Vincent van Gogh. In Colour Change in Paintings, ed. R. Clarricoates, H, Dowding, and A. Gent, 39-51. London: Archetype Publications Ltd. in association with the ICON Paintings Group.

Van Gogh Museum. 2010. Bedroom secrets. Restoration of a masterpiece.

http://slaapkamergeheimen.vangoghmuseum.nl/the-painting/?lang=en

(accessed 31 October 2016)

Van Gogh Museum. 2012. Research in progress: Discoloration of Van Gogh's 'Bedroom'

https://www.youtube.com/watch?v=pgOm9rjEtgI ～(accessed 31 October 2016)

Van Gogh Museum. 2013. App Touch Van Gogh.

https://www.vangoghmuseum.nl/en/app-touch-van-gogh

(accessed 31 October 2016) 


\title{
Upgrading Standards and Guidelines for the museum lighting: how to include new research results within an outdated model?
}

\author{
Costanza Cucci and Marcello Picollo \\ Instituto di Fisica Applicata Nello Carrara - National Research Council (IFAC-CNR) \\ c.cucci@ifac.cnr.it
}

Since more than one decade, at the CNR-IFAC laboratories in Florence is active a research branch fully dedicated to the topics museum lighting, including the study of photo-induced phenomena on light sensitive artworks as well as the design and set-up of new tools and protocols for light monitoring in museum environment. This research activity started in 2001, with the partnership in the EC Project LiDo: A LIght Dosimeter for monitoring cultural heritage: development, testing and transfer to market (2001-2004), aimed at providing innovative light-dosimeters, based on a colorimetric principle to respond to the light exposure of highly photosensitive artworks. The outcome of the Project was marketed under the LightCheck® brand and obtained great attention by the museum community, despite its limited diffusion on the market. Apart from the commercial outcome - a new smart tool for monitoring artworks - the crucial novel contribution of this Project was the exploitation of color change - the main undesired effect on artist materials exposed by light - as working principle to monitoring light effects in museum environments and to prevent lightdamages. This was the beginning of a new generation of smart sensors for the museum environment, intended to complement the more conventional approach based on data-loggers. Along with research on new prototypes of light dosimeters, the CNR-IFAC research group proposed and developed protocols and procedures for monitoring on time light-induced colour changes in museums objects by means of non-invasive methodologies based on reflectance spectroscopy, such as Fiber Optics Reflectance Spectroscopy (FORS) and Reflectance Hyperspectral Imaging in the Visible (VIS) and Near Infrared (NIR) spectral range. Considering that the colour variation is one of the main undesired effect of light overexposure of artworks, new procedures of colour measurements are crucial for investigations and controls of photo-induced phenomena on artworks on display.

Subsequently, the experience gained by the group in the field of risk-assessment of photodegradation phenomena could be implemented with the participation to the CEN (European Committee for Standardization) TC346/WG6 Working Group Conservation of cultural property: Exhibition lighting of cultural property. At present, the authors are continuing this activity in the framework of the Italian Standardization Body (UNI), participating to the Indoor Lighting of Cultural Heritage Working Group, with the aim of drafting an updated version of the Italian Standard for lighting in museums. 
During this multi-year work on topics of measuring and controlling lighting effects on artworks, the authors encountered several contradictory aspects linked to the need of conciliating still widely accepted, yet outdated, lighting standards and recommended limits with the new concepts of light monitoring and the new generation illumination technologies. Transferring the new research results to acceptable standards and recommended practices for museums is not an easy task, and many questions remain open.

For example: which is the best way to include the most relevant and recent research outcomes (light dosimeters, passive sensors, smart tools, fadometers, etc.) in an updated version guidelines for museum lighting? How the knowledge gained in experimentation on light sensitive materials can be transferred to routine in museums and recommended practices? How the widely-accepted lighting limits have to be upgraded, taking into account the new light sources (LED) introduced in the meantime? Is the color change the most indicated parameter to assess the light damage in photosensitive materials? etc. etc.

The present contribution is not intended to present new results in the field, but is rather aimed at discussing the still open problems and sharing the possible solutions related to the challenging task of upgrading the guidelines for museum lighting within the widely accepted framework. 


\title{
Towards the new standard for museum lighting in Japan
}

\author{
Nozomu Yoshizawa ${ }^{1}$, Yoko Mizokami², Chie Sano ${ }^{3}$, Naoto Yoshida ${ }^{3}$ \\ Tokyo University of Science, Graduate School of Advanced Integration Science, Chiba \\ University2 ${ }^{2}$ Tokyo National Research Institute for Cultural Properties ${ }^{3}$ \\ yosizawa@rs.noda.tus.ac.jp
}

\section{Backgrounds and Purposes}

LED lighting systems have recently spread in museum exhibits. The characteristics of LEDs, such as lower energy consumption, longer lifetime, smaller size can be a great advantage for museum lightings. However, there is not enough information about colour rendering, long-term damage on artworks or luminous intensity distribution different from halogen/fluorescent lamps, and some curatorial and technical staffs in museums are still hesitating about whether they should introduce LEDs into their museums. In 2015, we organized a committee for establishing the new standard on museum lightings in the illuminating engineering institute of Japan (IEIJ), and started to accumulate data on retrofitting to LEDs in actual museums, to examine the experimental data on the effect of LEDs in museums, and to discuss which direction we should go for the next-generation lighting standards among committee members from various fields. At the end of fiscal 2016, we completed writing the draft for the new standard.

\section{Contents}

A questionnaire survey as to LEDs introduction situation in museums all over Japan was carried out. There were 113 valid response, and lots of comments by curators on their awareness of the problem of LEDs were collected. We tried to reflect some of them to the new standard or guidelines, to be able to relieve their concerns. The standard draft is composed of mainly five parts. The first chapter shows the purpose and the scope. Not only museum display lightings but also ambient lightings, lightings in repository or corridors will be included in this standard. The second chapter is about necessary requirements which should be satisfied in museums. The former half of them is about conservation especially when using LEDs. Based on the previous research by Sano et al. on the evaluation methods of light exposure levels, it is stated that LEDs cause almost the same damage on artworks compared with halogen/fluorescent lamps and high colour temperature has much influence on artwork damages rather than the difference of lamp types. The latter half of this chapter is about the appearance of artworks. Luminance contrast between artworks and backgrounds is stated to be the most important factor to make the artworks bright and clear, though it does not always link to preferable appearances. Assuming surfaces are uniform diffusers, luminance can break down into illuminance and reflectance, however we've decided not to present the quantitative recommendation values as to contrast in this standard, because of the lack of research data and its difficulties for the curators or staffs in actual museums. Another important 77 | P a g e 
factor is colour rendering, and we are now arguing how to deal with the new colour rendering index such as Rf. In the third chapter, quantitative recommendation values of illuminance and colour rendering index are presented. We refer to CIE 157:2004 for illuminance, and Ra 95 is recommended for exhibition lightings, though there are some discrepancies between this draft and JIS Z 9110:2011(Japanese Industrial Standards: General rules of recommended lighting levels). In the fourth chapter, concrete usages of LEDs in museums are explained, for example the methods of ambient lightings, wall washers, track lightings and cabinet lightings and so on. The last chapter is the appendix, and measurement methods of illuminance, luminance and colour rendering index are presented here.

\section{Current Discussions}

1) Illuminance/Luminance levels: We received a request that illuminance recommendation levels should be raised under new LED lightings in the symposium held at February 2017, however, we've judged it better not to change current and conventional illuminance levels in this standard. The importance of luminance contrast is emphasized, but much research on contrast effects and development of measurement instruments at reasonable prices will be necessary to include quantitative values in the standard. 2) Colour rendering index: in the current draft, traditional $\mathrm{Ra}$ is used instead of new $\mathrm{Rf}$ to show quantitative levels, however it might be necessary to continue the discussion in the future. In the summer 2017, we conducted a subjective experiment to compare the various LED museum spotlights of which Ra are 95 or more. The result shows that both indexes would be useful for the general museum lightings. 3) Daylighting: Daylighting is not always popular among curators in Japan, because of its difficulties in handling rain leaking and condensation on windows under Japanese humid temperate climate, however, some architects emphasize attraction of daylight in museums and it would be preferable to briefly add some comments on daylighting methods, taking global trends into consideration. 


\title{
$\underline{\text { Posters }}$
}

\section{A status quo about the LED Lighting applications in the Chinese Museums and Galleries}

\author{
Jing Ai \\ Exhibition Department, National Museum of China \\ 1379643238@qq.com
}

Future museums will be smart museums. Their environmental conditions, especially illuminations will be intelligently adjusted according to different types of artifact exhibited. LED lighting has been fast advanced over the last decade. It is expected to replace most of the conventional museum lamps in 2020 due to its superior characters such as low energy consumption, low UV and IR contents, long life time, green technology, small size and high intensity. The next phase of this LED evolution will be smart lighting development, i.e. to make museum LED lighting spectrum tunable for different applications.

China now has the largest number of manufacturers in the world and it increases the export more than $45 \%$ each year for the last four years. Currently, there are 4692 registered museums and art galleries in China. The number has increased each year by about 200. Most of the new ones are using LED lamp. Some leading museums such as National Palace Museum, Nanjing museum, Shanghai art museum etc. also adopted smart control technologies such as DALI.

However, there are limited studies on LED lighting usages in Chinese museums and galleries. With this in mind, a two-year project entitled "To study the present and future applications of LED lighting in Chinese museums and galleries", funded by the Ministry of Culture, China and led by the author at National Museum of China was established from April 2015, to understand the current usage of museum LED lighting by conducting a comprehensive survey in some Chinese museums. The results would help to understand the practical situation and future requirement. The technical data collected could provide future guideline for LED manufacturers to develop new lighting technologies for future Chinese museums.

The project was unique because it is the project directly supported by the Ministry of Culture, China due to its importance in the national strategic plan. It involves large number of consortium, which is truly multi-disciplinary, for which one third of the national museums (43) and half of the national galleries (15) were involved. They cover over half of the nation including 14 provinces and territories. Note that $30 \%$ of those surveyed using LED lamps. 
The project includes close collaboration between 300 experts in different universities, culture industries and illumination companies. There were 10 academics to perform research, 70 experts to conduct technology survey and 40 companies involved in the product research work.

The main outcome from the project included three areas. Firstly, the results of the LED and conventional lightings in terms of energy efficiency, colour quality including correlated colour temperature (CCT), colour rendering, illuminance and its distribution, were compared in current museums and galleries. For example, it was found that $75 \%$ of light in the exhibition rooms were ranged from $2700 \mathrm{~K}$ to $3000 \mathrm{~K}$. Only few of them used 3500K. Secondly, the optical tests were conducted to compare spectra of difference sources in UV, visible and NIR regions. Works were also carried out to study different illumination conditions for different types of artefacts. The third was to accumulate the present museum illumination data together with some data reported from overseas. It was concluded that LED lighting is a necessity for future museum lighting, the results concluded that LED technology possesses all the advantages for museum lighting. Most importantly, the parts of the conventional illumination will be unavailable in the near future. Proper training programme should be provided for illumination manufacturers to remove the problems such as poor colour rendering, glare, poor distribution. Finally, it should move into the intelligent lighting not only to produce fidelity, comfort and pleasing feeling but also to achieve energy conservation.

The overall results were published in Chinese as a book, with an English title "The change of lighting". In the book, additional to the above results, guidelines were also provided for the application of LED museum lighting in future China. 


\title{
Focus on Art by avoiding distracting color differences in the illumination - Revolution of the LED white binning
}

\author{
Alexander Wilm and Carolin Horst \\ OSRAM Opto Semiconductors \\ Carolin.Horst@osram-os.com
}

\section{DESCRIPTION OF THE PROBLEM}

The trend towards higher light quality and especially better color consistency between white LED light sources is now down to 1SDCM which should provide no visible color differences. But reality shows that even a 1 step MacAdam binning cannot prevent visible color differences in real applications of general lighting. This can cause distraction and unpleasant appearance of the illuminated objects. The problem is the CIE $19312^{\circ} \mathrm{xy}$ color space which is currently used for LED binning around the world. It is correct for a $2^{\circ}$ field of view, but most applications judge white consistency not based on a small $17 \mathrm{~mm}$ diameter spot in $0,5 \mathrm{~m}$ distance (equivalent to $2^{\circ}$ field size) but on larger surfaces with more than $90 \mathrm{~mm}$ (equivalent to at least $10^{\circ}$ field size). Therefore, a binning according to a $2^{\circ}$ field size does not reflect the reality. This is the reason, why a perfect 1SDCM binning or even light sources with exactly the same color coordinates in the $2^{\circ}$ color space but different spectral compositions cannot prevent visible color differences in real and normal application conditions.

\section{AIM OF THE PRESENTATION}

Understanding the physiological reasons for the different perception under $2^{\circ}$ and $10^{\circ}$ field of view and illustrating the effects of a narrow binning at $2^{\circ}$ and the possible color variations under a $10^{\circ}$ field size. Learn about the current standards and the impact on LED white binning.

\section{DESCRIPTION OF THE SOLUTION}

The change of the color space from the CIE $19312^{\circ}$ to the new CIE $201510^{\circ}$ enables a LED binning closer to real application conditions and provides a better color consistency for general lighting applications. This will be visualized on impressive demonstrators.

\section{LEVEL OF REALIZATION}

This is no science fiction but already implemented in existing standards and products providing better light quality. The existing CIE $201510^{\circ}$ color space provides the normative regulations and description for an independent and international specification of better color consistency. The new $\mathrm{TEN}^{\circ}$ binning feature of the Soleriq ${ }^{\circledR} \mathrm{S}$ CoB LEDs is following this new standard and provides unprecedented color consistency for excellent illumination. 


\title{
Assessment of the photo-stability of plastics found in heritage collections to visible light
}

\author{
Anna Pokorska1, Lindsay MacDonald², Elise Talgorn ${ }^{3}$, Stuart Robson², \\ Katherine Curran ${ }^{1}$, Boris Pretzel ${ }^{4}$
}

Institute for Sustainable Heritage, UCL ${ }^{1}$; Dept. of Civil, Environmental and Geomatic Engineering, UCL2; Philips, Eindhoven ${ }^{3}$; Victoria and Albert Museum, London ${ }^{4}$

anna.pokorska.15@ucl.ac.uk

Plastics have a relatively short history within heritage and research into their conservation is still limited compared to traditional materials such as wood or metal. Despite a wealth of academic and industrial literature on the subject of polymer photostabilityphoto-stability, the majority of research is focused on the effect of UV radiation and, therefore, sensitivity of plastics to visible light remains largely unexplored. The main complication lies in the complexity of plastic materials and stability of a plastic artefact encompasses both the base polymer and any colourants present. In fact, institutional guidelines for display of those artefacts can be rather vague and tend to treat different plastic materials as one. However, as more plastic objects are entering museums and galleries there is a compelling need for more research that addresses conservation requirements. The first step towards this understanding is to screen a wide range of plastics commonly found in museums to identify which categories are sensitive to visible light. In this experiment, photostability to visible light exposure of a wide rangephostability of plastic materials commonly found in museums and galleries to visible light exposure - was assessed through accelerated photodegradation over 8 weeks at two different light intensity levels (i) between 33-38 klx (116$\left.133 \mathrm{~W} / \mathrm{m}^{2}\right)$ and (ii) at $8.3 \mathrm{klx}\left(31 \mathrm{~W} / \mathrm{m}^{2}\right)$. Chemical stability was investigated with ATR-FTIR, while visual appearance was measured using reflectance spectrophotometry. In generalterms of chemical stability, three polyurethane foams and one polycarbonate sample showed chemical changes consistent with literature. In addition, some of the samples of cellulose nitrate, ABS, polyurethane, PVC and polycarbonate experienced different types of colour change. LED and fluorescent light sources were also compared for their damaging potential, with the latter causing a similar level of degradation despite a much lower overall light dose. However, the effect of spectral power distribution and different temperature fluctuations in both of those setups would have to be further investigated before firm conclusions can be drawn. This study highlights that the light sensitivity of plasticsplastic artefacts in museums is complex and needs more in-depth study in order to improve museum guidelines. In particular, the effect of colourants on the stability of plastics when exposed to visible light will be explored in future research. 


\title{
Natural Light Matters: surveying illumination at the Museum of Modern
} Art

\author{
B. Campbell1, H. Murata 2 , J. Hickey ${ }^{3}$, L.A. Daffner ${ }^{4}$, E. Mosier ${ }^{4}$, A. Martins ${ }^{4}$ \\ Princeton University ${ }^{1}$, The Better Image, Inc ${ }^{2}$, Guggenheim Museum ${ }^{3}$, Museum of Modern Art ${ }^{4}$ \\ brenna.campbell@princeton.edu
}

The Museum of Modern Art (MoMA) in New York City maintains an active program for 3 million visitors per year, including an average of 50 on-site exhibitions. As attendance climbs, the Museum has sought an expanded range of locations in which to display its collection. Spaces such as the lobby and public hallways, which were not originally designed to meet the Museum's exacting climate standards, have nonetheless been identified as potential sites for exhibiting artworks. Discussions between conservators and curators about the benefits and risks of displaying art in these spaces, and concern about the preservation implications for the collection, prompted members of MoMA's Conservation Department to devise a plan to monitor light levels, temperature, and relative humidity in non-gallery public spaces throughout the museum. Conservators from different specializations reviewed floor plans and identified locations that were both popular choices among curatorial staff and thought to have light levels in excess of standard gallery levels. Preliminary light readings were taken to identify additional areas for monitoring. The monitoring team identified sixty-three locations of interest. An inexpensive and unobtrusive model of logger, the Hobo U12-012, was chosen to collect data on light, relative humidity, and temperature. A monitoring plan was devised to rotate nine loggers among the selected locations for four fourteen-day periods: once in each season. Successful execution of this project depended upon careful planning and thorough communication with stakeholders. The project plan was unanimously approved by security, facilities, and each department's chief curator. Over the course of the year, the monitoring team rotated the loggers on a bi-weekly basis, and made minor adjustments to location as necessary to avoid unduly impacting the aesthetics of a given gallery. At the end of the survey, the data was analyzed by conservation scientists. Reports and raw data for each location are available electronically and in hard copy. Organized by location, each entry includes image and mapping documentation of the site, graphs of light levels, temperature, and relative humidity, and statistical analysis. Each location's report includes the minimum, maximum, average, and standard deviation for light, temperature, and relative humidity. One of three grades was assigned to each location and season: no risk, low risk, or significant risk. The data and analysis serve as powerful tools for identifying inappropriate locations for works that are sensitive to environmental fluctuations. The survey data has proved to be an essential resource, and a second iteration of the project, to incorporate the Museum's latest expansion, is planned for 2019. 


\title{
Let LED Respect your ART Or How to Define State of the Art LED Systems for Art Galleries - A Field Report.
}

\author{
Claude Hidber \\ mati.ch, Lichtgestaltung, Switzerland
}

claude.hidber@mati.ch

In this presentation, we will cover how to define state of the art LEDs and look at best practice when it comes to tender lighting systems for Museum projects.

For this exercise, we have taken live data from 3 on-going projects in the following Museums: Musèe Cantonal des Beaux Art in Lausanne by Barozzi Veiga Architects, tendering in Spring 2017. The Kunsthaus Extension in Zurich, by David Chipperfield Architects, tendering in summer 2017, and Fondation Beyeler Riehen, lighting system modernisation, due for completion in 2018.

A look at How it Used to be.

In the era of conventional light sources, such as halogen and fluorescent tubes, lighting designers were defining the lighting layout, distribution curves of the light fittings, the wattages, and colour temperatures (CCT). But back than it was possible to change the light sources whenever it was needed.

In the pre-LED-era, the world of lighting was a safe place as well. Everybody knew what kind of precautionary measures needed to be taken in order to maintain safety and fulfil conservational restrictions. Basically, years of experience gave lighting designers and conservators a common ground.

With the introduction of white LEDs, it seemed the salutary wonder light source was created. Everything seemed to be become better. It didn't take long however, until the first concerns were common knowledge. In late 2012 the scary news surfaced of a damaged Van-Gogh painting, a "burnt hole" caused by LED-lighting. We knew by then we had to reassess how we illuminated artworks using LEDs.

And How it is Now.

Nowadays there is no way around LEDs. Conventional light sources are either banned by law or production will cease in the near future or they are too costly to run. There is only one alternative: LEDs are the winner, but it comes with its own parameters.

It is true that LED technology has now reached a level where it surpasses any other artificial light source - if they are correctly specified. But we have experienced as well, that LEDs need to be very carefully specified in order to be able to take full advantage and not cause irreversible damage to invaluable artworks.

Great care is needed when LED technology is to be specified in a museum. The right questions need to be asked, and the right parameters have to be defined to insure safe and brilliant lighting. 
Keep in mind that once the light source and all its specification are selected you might not be able to change them for the next 15 years or so. And with LEDs you cannot simply change the light source anymore. It is an all-in-one solution. Therefore, these decisions are truly defining the way the artwork will be displayed, perceived and protected.

The Following Crucial Factors Need to be Discussed and Defined:

- What are the CCTs (colour temperature? The defined CCT in the light fixtures might not be the one that we see in the space.

- Where is the blue peak with in the spectral power distribution of a light source? What is tolerable and what is not acceptable.

- What is the damage potential of the lights?

- Is the damage potential stable over the life-time of the light source or does it get worse?

- How does the Pdm (damage potential) help us to compare and choose the right LEDs for the art work?

- What shall the maximum SDCM (Standard Deviation of Colour Matching) be?

- What LED binning do we require? According to CIE 1931 with the $2^{\circ}$ precision or CIE 2015 with accuracy of $10^{\circ}$ ? Which one is better and why might $10^{\circ}$ be better than a $2^{\circ}$ precision?

- What is the life time expectation according to LBC?

- Why are these three letters so important to lighting systems?

- What is the expected CPS (Colour Point Shift) at $6000 \mathrm{~h}, 12000 \mathrm{~h}$ and $50000 \mathrm{~h}$ ? And how to minimise it. Why do we need to keep testing the lighting tools?

- What is the CRI (Colour Rendering Index)? Is a higher always better?

- Does the colour rendition need to be defined in a new standard? Possibly the TM 30-15?

These questions were never an issue previously with conventional light sources. But we need to ask them now and define future parameters when designing the illumination for galleries and collections with LEDs. If we don't, we might end up with more shocking news like we had in 2012.

In addition, we will address how to approach lighting at the back-of-house area and the exhibition spaces so that curators and conservators can be assured that they see artworks in the same light condition while restoring, preparing and exhibiting. To finish up, we dare a brief outlook into the near future development and upcoming LED technologies that will be soon available. 


\title{
Evaluation of Colour Rendition Methods Through Museum Lighting Investigations and Determination of Preferred Conditions for Fine Art Paintings
}

\author{
Péter Csuti, Ferenc Szabó, Renáta Kéri \\ University of Pannonia, Veszprém \\ csutip@gmail.com
}

The aim of the investigation was to test and compare two colour rendition methods through museum lighting experiments and determine the preferred lighting conditions for fine art paintings. A further object of the study was to specify which colour rendition method is more suitable for museum lighting application and design. One method is the commonly accepted and used CRI $R_{\mathrm{a}}{ }^{1}$ colour rendering index and the other one is the IES TM-30-152 colour rendition method. General Colour Rendering is defined as the effect of an illuminant on the colour appearance of objects in comparison with their colour appearance under a reference illuminant. The problem with CRI $R_{\mathrm{a}}$ colour rendering index is that this method provides information only about fidelity and it doesn't provide any information on saturation. In contrast, TM-30-15 uses the Gamut Index $\left(R_{g}\right)$ to describe differences in saturation. Furthermore, CRI $R_{\mathrm{a}}$ uses only fourteen colour samples to determine colour fidelity, while the method of TM-30-15 uses 99 colour samples. So, TM-30-15 method provides more information than CRI $R a$.

During the visual experiment one series of test lights are optimized according to the CRI $R a$ colour rendering index and another series of illuminations are realized based on the IES TM-30-15 method. Furthermore, the influences of illuminance level and correlated colour temperature (CCT) are investigated as well. Five illuminance levels (50 lx, 100 lx, 200 lx, 400 lx and 600 lx) and four CCTs $(2850 \mathrm{~K}, 4000 \mathrm{~K}, 5000 \mathrm{~K}$ and $6500 \mathrm{~K})$ are selected, so there are 20 scenarios of the viewing conditions in case of both series. The visual experiments are conducted at the University of Pannonia, in Hungary, where the experimental room is equipped with three special museum lighting prototype LED luminaires in order to provide fully controllable lighting of the real test paintings.

During the testing process ten-word pairs are used for evaluating the paintings' appearance under each lighting conditions. Five of the scales are associated with appearance of the painting (low contrast - high contrast, cold - warm, dark - bright, pale - colourful, moist - dry) while five others are associated with atmosphere (artificial - natural, soft details - crisp details, unpleasant pleasant, depressing - relaxing, boring - lively). Each scale is evaluated by using a four-point categorical scale. 
At the end of the visual experiments the results of the two-colour rendition methods are evaluated statistically and compared. Based on this investigation it can be determined which colour rendition method is more suitable for museum lighting application as well as the preferred lighting conditions become definable.

\section{Acknowledgments}

The authors would like to express thanks for the financial support of the HI-LED EU FP7 project (grant number: 619912) in producing the above research.

\section{$\underline{\text { References }}$}

Commission Internationale de l'Eclairage (CIE), "Method of Measuring and Specifying Colour Rendering Properties of Light Sources". Publication 13.3," Vienna, 1995.

2 R. MP., "IES TM-30-15 is approved - now what?," LEUKOS, vol. 12, pp. 3-5, 2016 


\title{
Take deLIGHT in Colours
}

\author{
Francesca Feltrin¹, Francesco Leccese ${ }^{1}$, Peter Hanselaer², Kevin Smet $^{2}$ \\ Department of Energy, Systems, Territory and Constructions, University of Pisa ${ }^{1}$, Light \& \\ Lighting Laboratory, Catholic University Leuven, College Gent, Gent2
}

francesca-feltrin@virgilio.it

\section{Introduction}

Many contemporary approaches to museum lighting are oriented towards the fulfilment of qualitative standards, in order to provide visitors with a well-lit space and visual comfort, failing to consider that the surround and the background of the exhibit have a huge impact on visitors' visual perception of artworks. Moreover, lighting design in art exhibitions seldom highlights the uniqueness of each painting or achieve a real enhancement of its colours, in order to provide the museum visitors with the best visual experience, in terms of both visual comfort and enjoyment of the show. This project aims to analyse the factors affecting the visual perception of painted artworks displayed in museum settings and to establish, through a survey, whether there is a preference pattern for the observers. The experiment was conducted at the Light \& Lighting Laboratory of KU Leuven Technology Campus Gent, recreating a simple museum scene and conducting a survey. The study investigated the influence of three factors: the Correlated Colour Temperature (CCT) of a LED spotlight, used as accent lighting on the paintings, the lightness of the background and the overall hue content of the paintings. The purpose of the study was to determine a scheme able to provide, depending on the main colours of the paintings and the visual effect required, the most suitable background lightness and colour temperature of the light source.

\section{Experiment Design}

A simple museum scene was recreated in the laboratory, building a setup made of a frontal wall, were the paintings were hanged, and two tilted walls, whose function was creating the broadest possible field of view and the feeling of immersion for the observers (Fig. 1). The different background lightness was obtained using curtains of three different colours - white, grey and black - which were set along the perimeter of the setup and manually changed during the tests (Fig. 2). Regarding the light sources, a tunable LED spotlight was used as accent lighting on the paintings, positioned frontally and tilted of $32^{\circ}$ in relation to the vertical plane. The spotlight had four channels: the single tunable colours - the R(ed), G(reen) and B(lue) channels - and a fixed warm white channel (phosphor white with a CCT of $3200 \mathrm{~K}$ ). As ambient lighting, four fluorescent lamps with a CCT of $5900 \mathrm{~K}$ were positioned at the top of the setup, above the observers' position, in order 
to provide mostly horizontal illuminance and avoid a complete dark surround (uncommon for museum exhibitions), at the same time minimizing the interference with the accent lighting on the paintings. The setup dimensions, the light sources position and the position of the observers were designed following the conventional guidelines for museum lighting [1-2]. The illuminance at the location of the painting resulting from both the ambient lighting and spotlighting was approximately 160 lux (Standard deviation: 10 lux) and satisfied typical light exposure limitations - "Low responsive" category for artworks conservation as stated by the CIE 157:2004 Technical Report [3] - recommended for museum lighting. Regarding the artworks, five paintings were selected among the artworks of the contemporary artist Leonid Afremov [4]: four paintings with different predominant hues - red, blue, green and yellow - and one painting without a predominant hue (Fig 3).
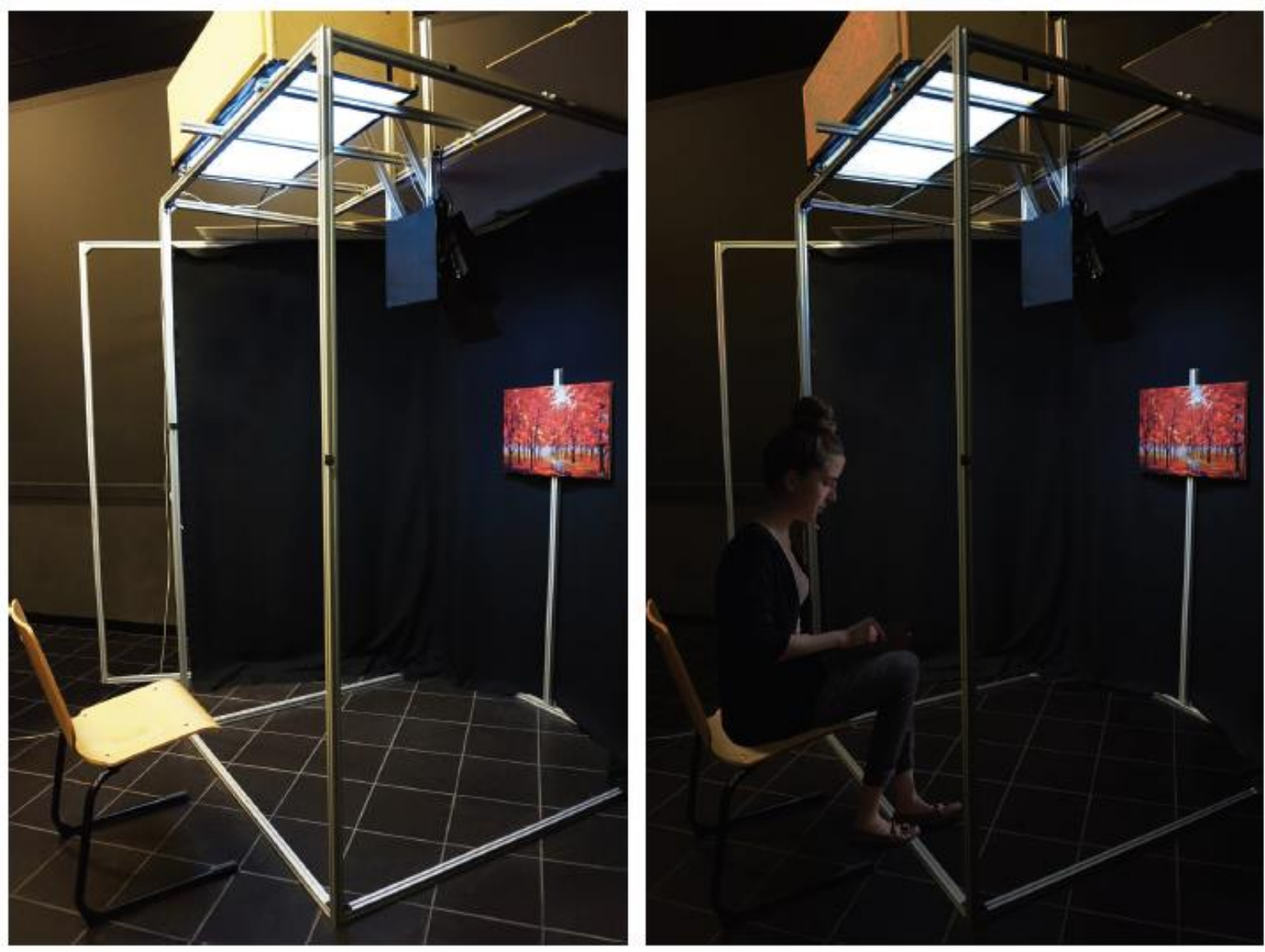

Fig. 1 - Pictures of the experiment setup and of a test subject completing the test. 


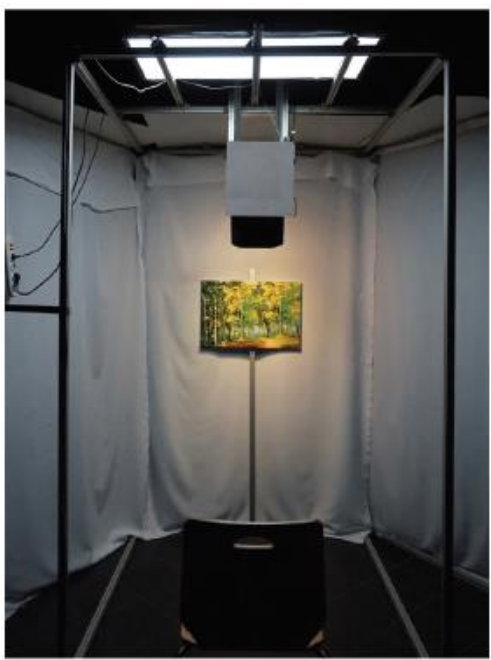

(a)

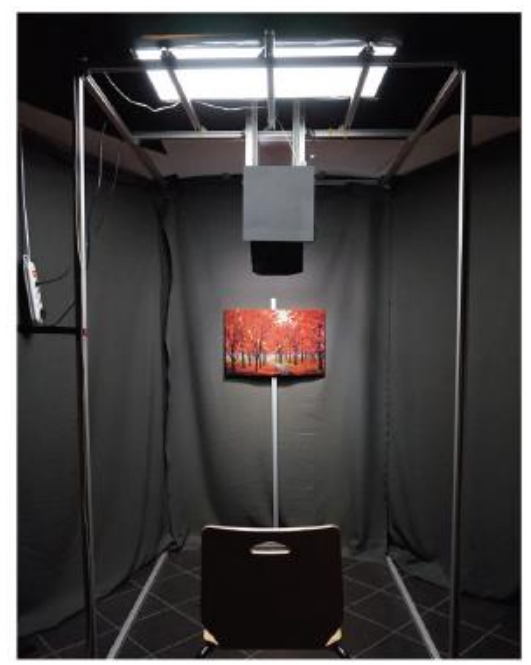

(b)

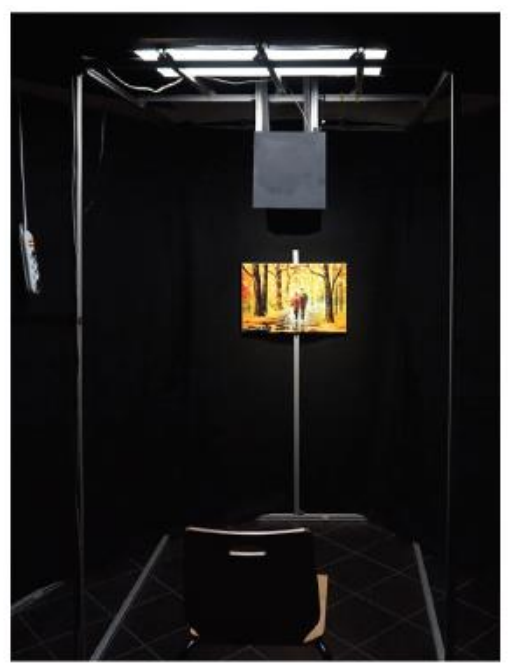

(c)

Fig. 2 - Pictures of the experiment setup with the three different backgrounds: (a) white background, (b) grey background and (c) black background.

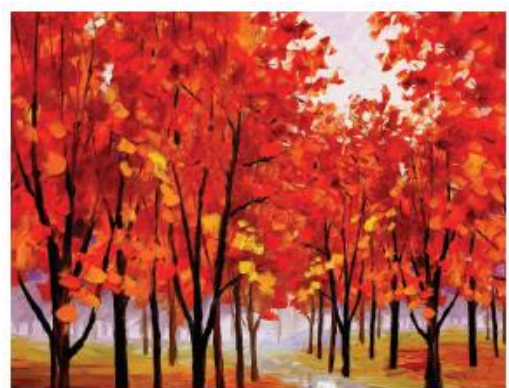

(a)

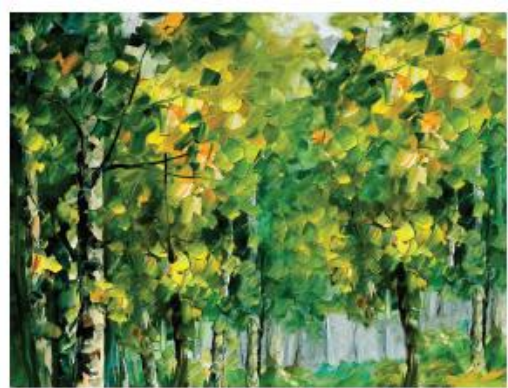

(b)
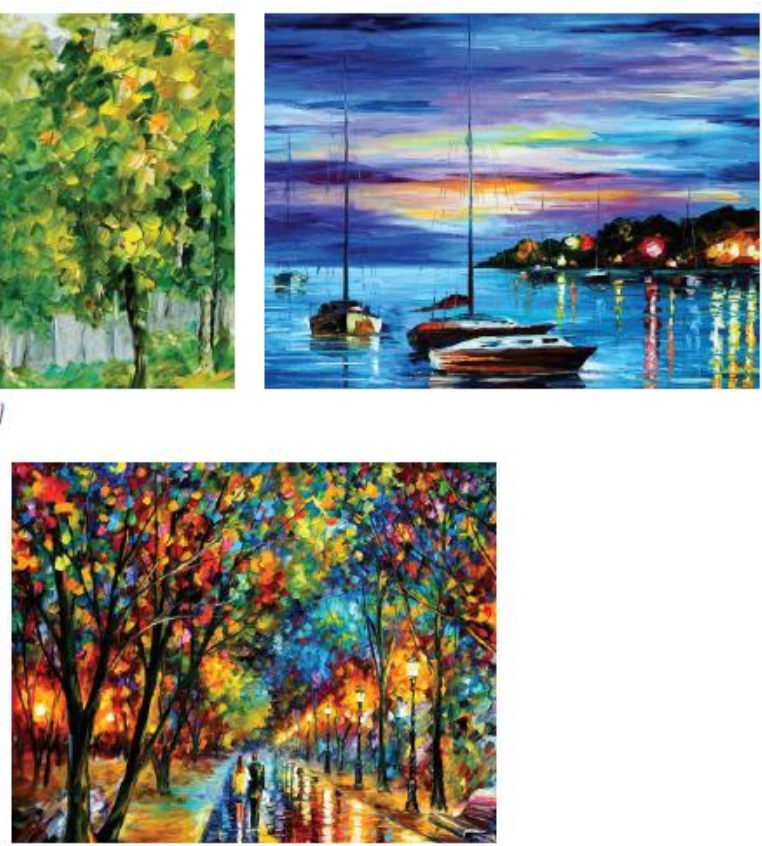

$(e)$

Fig. 3 - Leonid Afremov's paintings: (a) Pink Fog, (b) Summer Forest, (c) Mystery of the Night, (d) Happy Couple and (e) When dreams come true.

\section{Lighting Settings}

The tunability of the LED spotlight allowed to obtain five CCT target values, keeping at the same time the colour rendition parameters sufficiently high. The ratio of each channel was optimized using MATLAB and five different CCT values were determined:

- $3000 \mathrm{~K}$ and $3500 \mathrm{~K}$ (warm CCT);

90 । P a g e 
- $4000 \mathrm{~K}$ and $5000 \mathrm{~K}$ (neutral CCT);

- $6000 \mathrm{~K}(\mathrm{cool} \mathrm{CCT})$.

The spectra of each configuration are shown in Fig. 4, measured on the grey background. All configurations had the white point approximately on the Planckian locus, with a Duv factor equal to 10-3. The CIE Colour Rendering Index, Ra, [5] the IES Colour Fidelity Index, Rf [6], and Smet's Memory Colour Rendition Index, Rm [7], all had to have at least a value of 85, whilst the target value for the IES Colour Gamut Index, Rg [6] was 100. As can be seen from Tab. 1, all parameters were sufficiently high and constant across the various configurations.

\section{Experiment Procedure}

After measuring each configuration and ensuring a stable replicability of the arrangements, the experiment proceeded with a survey. The multiple configurations were presented to a group of 25 observers, 14 males and 11 females, aged between 22 and 55 years old. Among the participants, 14 were naïve observers, with no prior knowledge of lighting nor art, 9 were employees of the Light and Lighting Laboratory (Researchers and PhD students), one architect and one lighting designer. All observers had normal colour vision, screened with the 24-Plate Ishihara Color Vision Test. During the tests, the observers were asked to evaluate the following factors, on a bipolar scale from 1 to 10 :

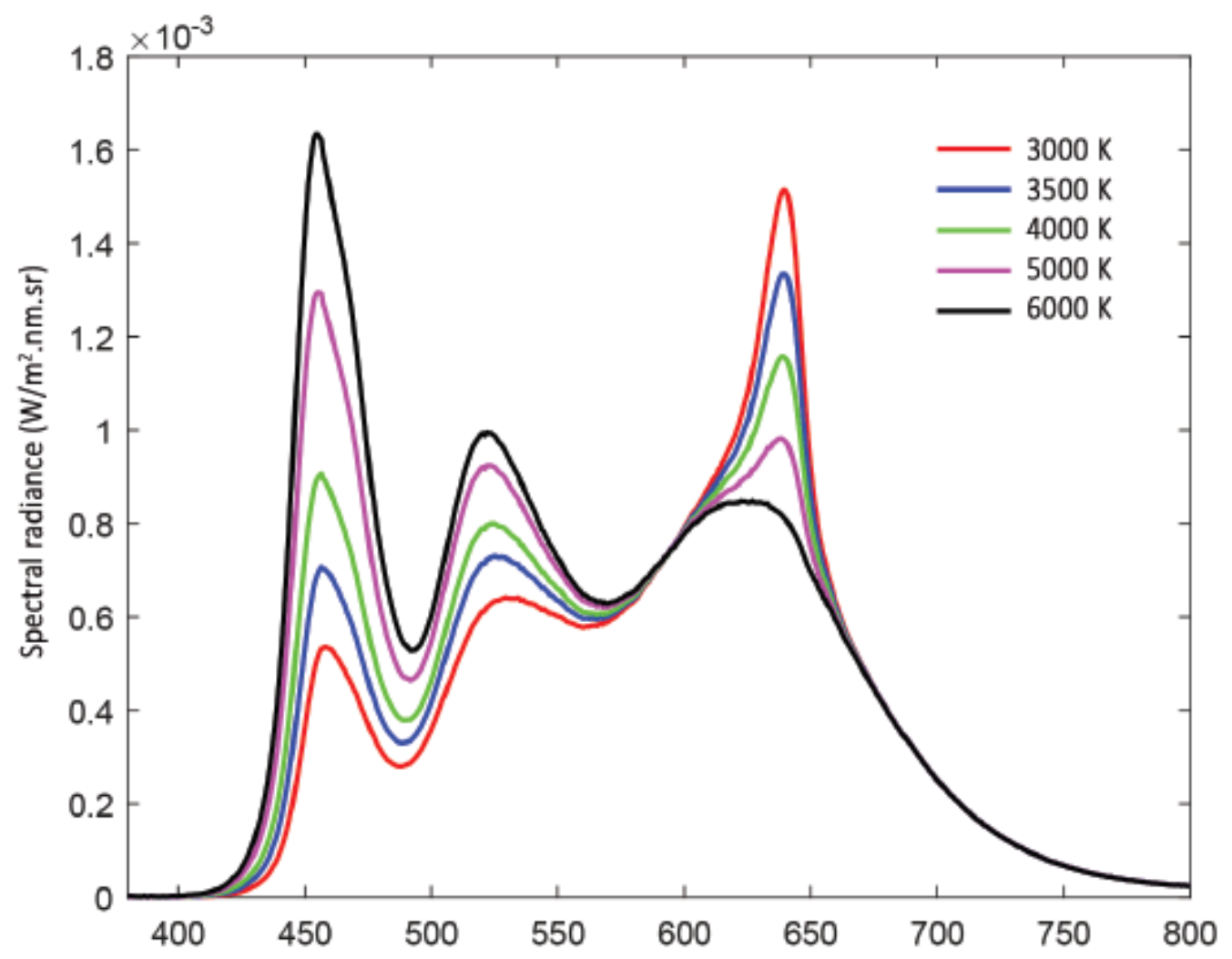

Fig. 4 - Spectra of the LED spotlight for the various CCTs. 
Tab. 1 - Colour Rendering parameters for the various configurations.

\begin{tabular}{|c|c|c|c|c|c|c|}
\hline & CCT $(\mathrm{K})$ & Duv & $R_{0}$ & $R_{t}$ & $R_{g}$ & $\mathrm{R}_{\mathrm{m}}$ \\
\hline \multirow{5}{*}{$\begin{array}{l}\text { White } \\
\text { Background }\end{array}$} & 3000 & 0,000 & 91 & 89 & 101 & 92 \\
\hline & 3500 & 0,000 & 90 & 88 & 101 & 92 \\
\hline & 4000 & 0,000 & 90 & 88 & 101 & 93 \\
\hline & 5000 & 0,000 & 90 & 88 & 102 & 93 \\
\hline & 6000 & 0,000 & 90 & 88 & 102 & 94 \\
\hline \multirow{5}{*}{$\begin{array}{c}\text { Grey } \\
\text { Background }\end{array}$} & 3000 & 0,000 & 91 & 89 & 101 & 92 \\
\hline & 3500 & 0,000 & 91 & 88 & 101 & 92 \\
\hline & 4000 & 0,000 & 90 & 88 & 101 & 93 \\
\hline & 5000 & 0,000 & 90 & 88 & 101 & 93 \\
\hline & 6000 & 0,000 & 90 & 88 & 102 & 94 \\
\hline \multirow{5}{*}{$\begin{array}{c}\text { Black } \\
\text { Background }\end{array}$} & 3000 & 0,000 & 90 & 89 & 101 & 92 \\
\hline & 3500 & 0,000 & 90 & 89 & 101 & 92 \\
\hline & 4000 & 0,000 & 90 & 88 & 101 & 93 \\
\hline & 5000 & 0,000 & 90 & 88 & 102 & 93 \\
\hline & 6000 & 0,000 & 90 & 88 & 102 & 94 \\
\hline
\end{tabular}

- the vividness of the colours of the painting (dull/rich);

- the attractiveness of the colours of the painting (low/high);

- the warmth of the colours of the painting (warm/cold);

- the brightness of the colours of the paintings (dark/bright);

- the level of appreciation of the background colour (low/high);

- the overall level of appreciation of the combination light/background/painting (low/high).

The observers completed the experiment seated at a distance of $1,40 \mathrm{~m}$ from the paintings and each of them assessed a total of 90 different arrangements: 5 paintings, 3 backgrounds and 5 CCTs, for a total of 75 combinations and 15 additional repeated configurations to assess observers ${ }^{6}$ consistency. The test was divided into three sections, one for each background: once set the background, they had to assess each painting at a time under the five different lighting configurations (Fig. 5). For each painting, before starting to evaluate, all configurations were randomly displayed, in order to let the observers adapt to the average luminance level and 92 I P a g e 
give them an idea of the differences between the configurations.
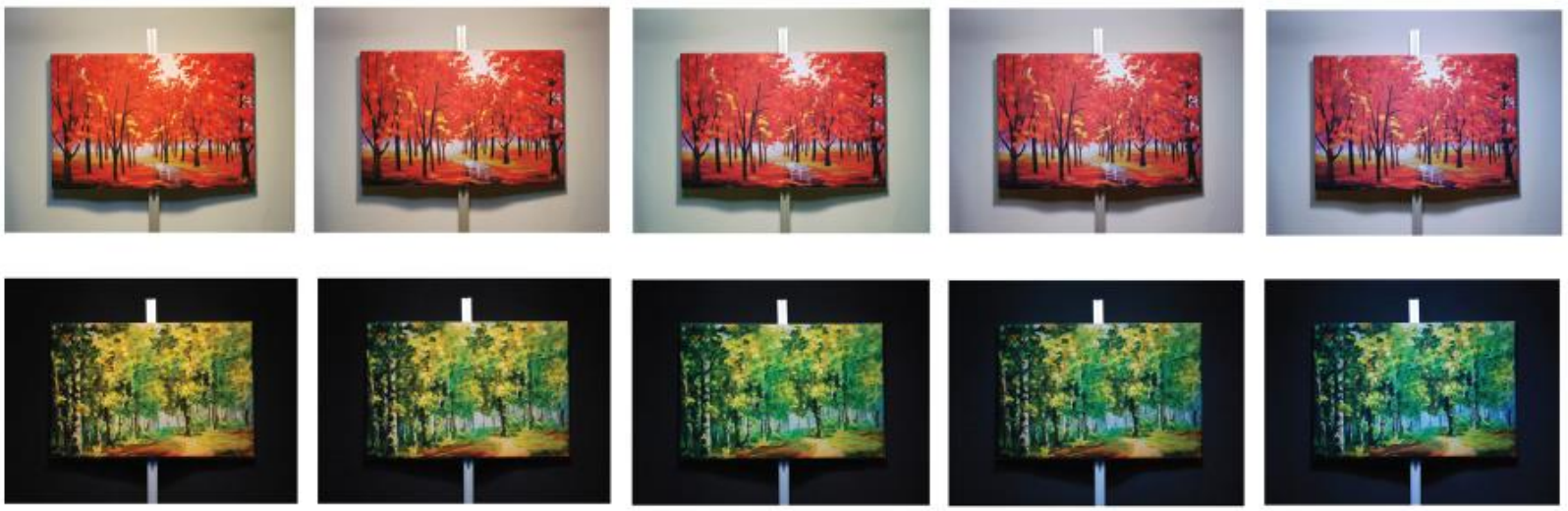

Fig. 5 - Pictures of the red painting on the white background and the green painting under the black background under the various configurations (from warm to cool CCT).

\section{Results Discussion}

The results of the experiment were analysed by computing the geometric mean, its standard error and the median of the 25 evaluations for each quality factor (Overall Appreciation, Background Appreciation, Warmth, Brightness, Vividness and Colours Attractiveness), for every combination Painting-Background-CCT. This analysis allowed to display how the average evaluation of the six factors - Overall Appreciation, Background Appreciation, Warmth, Brightness, Vividness and Colours Attractiveness - varies along with the change of CCT of the paintings' illumination, as illustrated in Fig. 6 for the reddish painting "Pink Fog".

Firstly, it was observed that the results for the three backgrounds with different lightness- black, grey and white - are not significantly different from each other, showing that the change of background slightly affected the observers' assessments. On the other hand, the observers were able to indicate their favourite background colour at the end of the test: 23 of them preferred the black background and the other two the grey one.

Secondly, it is possible to say that both the warmest and the coolest lighting arrangements were the least appreciated, whilst a CCT of $4000 \mathrm{~K}$ was the favourite one for all paintings, although the discrepancies of the assessments between $3500 \mathrm{~K}, 4000 \mathrm{~K}$ and $5000 \mathrm{~K}$ are very small.

Lastly, from the collected data it is clear that the predominant hue of the paintings has no impact on the preferred arrangements for the lighting, contrary to what was expected before conducting the experiment.

A second analysis step consisted of comparing the results between the various quality factors. The trends of the Overall Appreciation and the Colours Attractiveness tend to be quite similar to each other for each CCT, effect that could indicate that, when assessing the setting of art exhibitions, 93 I P a g e 
people concentrate more on the artworks than on the surround, and that their satisfaction about the colours' appearance is extremely relevant for their overall enjoyment of the exhibition. Furthermore, it can be observers that the Warmth has a downward trend along with the increase of CCT, whilst the Brightness has an upward trend and the peak of the Overall Appreciation lies in the middle.
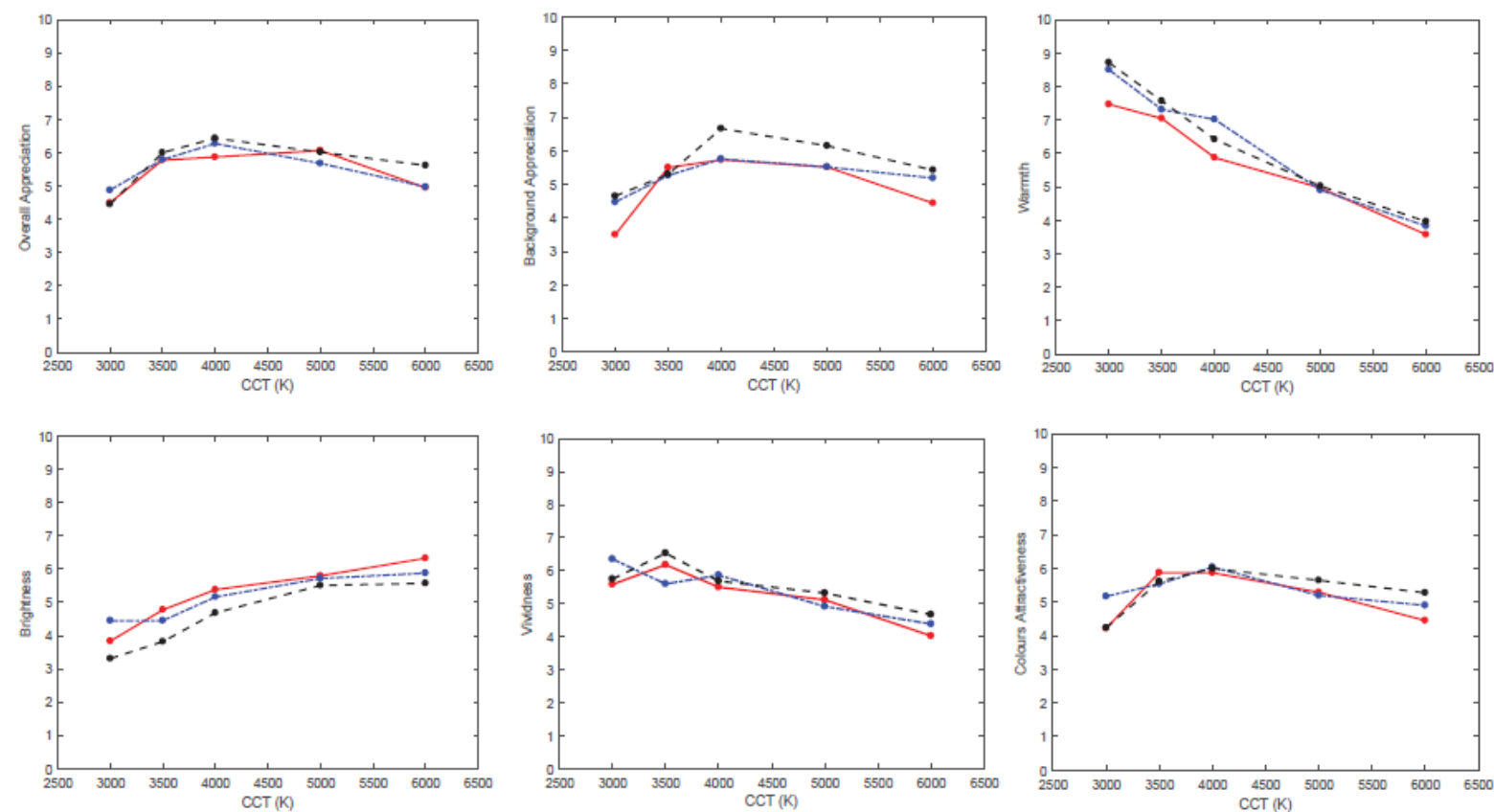

Fig. 6 - Plotted results for the Reddish painting "Pink Fog” for each quality factor.

\section{Conclusions}

In conclusion, neither the predominant colours of the artworks nor the background lightness were found to have a relevant impact on people's assessments of art exhibitions' settings. In this study, CCT was the main factor affecting people's appreciation of art exhibitions and proper lighting configuration neither too warm nor too cold was found to enhance the artworks as effectively as possible. Furthermore, it was observed that the Overall Appreciation of the scene could be interpreted as a trade-off between the perceived Warmth and the perceived Brightness and it is mostly correlated with the perceived Colours Attractiveness.

\section{References}

[1] C. Cuttle, Light for Art's Sake. Lighting for Artworks and Museum Displays, ButterworthHeinemann , 2007, pp. 288. ISBS: 978-0750664301.

[2] M. Bonomo., C. Bertolaja, Lilluminazione delle opere d'arte negli interni. Guida alla progettazione, Ediplan, 2013, pp. 120, ISBN:978-8896726099. 
[3] Commision International de l'Eclairage, CIE 157- Control of Damage to Museum Objects by Optical Radiation, Vienna (A), 2004.

[4] The official online gallery of Leonid Afremov, https://afremov.com/, accessed on 10th April 2017.

[5] K. Houser, M. Mossman, K. Smet, L. Whitehead, Tutorial: Color Rendering and its Applications in Lighting, LEUKOS, Vol. 12, pp.

[6] A. David, P.T. Fini, K.W. Houser, Y. Ohno, M.P. Royer, K. Smet, M. Wei, L. Whitehead, Development of the IES method for evaluating the color rendition of light sources, Optics Express, Vol.23, pp. 15888-15906, 2015. DOI: 10.1364/OE.23.015888.

[7] K. Smet, W.R. Ryckaert, M.R. Pointer, G. Deconinck, P. Hanselaer, A memory colour quality metric for white light sources, Energy and Buildings, Vol. 49, pp. 216-225, 2012, DOI: 10.1016/j.enbuild.2012.02.008. 


\title{
LED lighting quality in museum showcases: results of an experimental case study
}

\author{
Gabriele Piccablotto ${ }^{1}$, Anna Pellegrino ${ }^{2}$, Chiara Aghemo²
}

\begin{abstract}
Laboratory of Analysis and Modelling of Environmental Systems (LAMSA), Department of Architecture and Design, Politecnico di Torino ${ }^{1}$; Department of Energy, TEBE Research Group,
\end{abstract}

\section{Politecnico di Torino ${ }^{2}$}

gabriele.piccablotto@polito.it

The use of Solid State Lighting (SSL) in museums and exhibitions is becoming increasingly more frequent, especially in showcases. According to a proper exhibit fruition and visual comfort for visitors, LED sources within showcases should provide high colour rendering, appropriate light quantity and distribution, as well as avoiding glare and visual distraction effects. Nevertheless, their impact on visual perception should be further investigated, due to differences from incumbent lighting technologies. This work presents the results of an experimental study on testing the performance of SSL systems inside a typical "free-standing" museum showcase (Figure 1). The main goal of the research was the definition of an assessment method for lighting quality perceived by visitors when LEDs with different colour temperature, spatial arrangement and illuminance level on exhibits are used inside the showcase. The assessment of lighting and visibility conditions was firstly based on luminance metrics, evaluating light distribution on exhibit and assessing discomfort glare for visitors. Hereafter a subjective evaluation was carried out by delivering a questionnaire focussed on lighting quality, reflected glare on the glass hood and assessment of direct glare. A panel of 22 observers was involved in the study (mainly painting restorers of the Conservation and Restoration Centre "La Venaria Reale", Italy). Each observer was engaged in several trials concerning different lighting configurations. The lighting configurations inside the showcase consisted in three different positions of luminaires (layout $1=$ light from below with LEDs on the base corners; layout $2=$ light from below with LEDs on the base sides; layout $3=$ light from above with LEDs on the top corners) using cool white LEDs (CCT=6500 K, CRI=80) for all the layouts and also warm white LEDs (CCT=3300 K, CRI=91) only for the layout 1 (Figure 2). During the experiment, for each lighting layout the luminaires were dimmed in order to achieve the illuminance level of $50 \mathrm{~lx}$ and $300 \mathrm{~lx}$ on the exhibit, considering the light exposure range recommended by Italian Guidelines on Conservation for Museum Collections. A further level of $1000 \mathrm{~lx}$ was also considered to represent a not dimmed configuration. In the first phase of the experiment (objective evaluation), the luminance distribution inside the showcase was measured for every lighting layout by means of a Technoteam LMK 98-3 videophotometer. Luminance ratios between exhibit, display plane and LED luminaires were evaluated in order to assess visibility conditions and discomfort glare issues for visitors. Summarizing the results obtained from the 
luminance images and the Unified Glare Rating (UGR) index calculations, the layout 1 was the most uncomfortable in terms of direct glare. For the subjective evaluation, a questionnaire based on semantic scale technique was defined and organised in four sections. In the first section, a set of semantic scales was used to evaluate the general illumination within the showcase, whilst the second section covered the evaluation of lighting, colour quality and detail discrimination of the exhibit (an enamel statuette and a colour samples set). The third section concerned the appraisal of 'visual noise' related to multiple reflections on glass hood caused by internal LED luminaires. The fourth section was devised to assess direct glare using a multi-criterion scale based on Hopkinson's glare scale. To analyse the questionnaire results the semantic scales were grouped in four different factors. The "Pleasantness" factor (PL) for the semantic scales expressing the degree of pleasure the light scene instils, i.e. pleasant, attractive and stimulating. The "Visibility" factor (VS) for the semantic scales related to the ability to discriminate shape and details and to provide a clear impression of the exhibit. The "Colour Quality" factor (CQ) for the semantic scales expressing colour rendering and colour discrimination. The definition of these three factors derived from previous studies on preferred lighting conditions in museums (Loe et al. 1982, Kesner 1993). A similar approach has been followed for the last factor called "Visual Noise" (VN) to include the semantic scales assessing annoyance caused by multiple reflections of LED luminaires. Figure 3 summarizes the observers' responses for the four factors and direct glare rating. For PL, VS and CQ factors the low value of the scale (=1) generally means an unsatisfactory or negative evaluation of lighting, whilst the high value $(=6)$ represents a satisfactory or positive evaluation. The scale has a reverse order for the $\mathrm{VN}$ factor: in this case the annoyance related to reflected glare increases proportionally to the 6-point scale. Pointing out some of the most relevant findings, there was not a noticeable difference in terms of Pleasantness between cool-white (CW) and warm-white LEDs (WW) at different illuminance levels, but Colour Quality was rated higher under the coolwhite ones, especially in terms of colour discrimination. Considering Visual Noise, layout 1 was the most annoying due to multiple internal reflections of LEDs on showcase glass hood. For the direct glare appraisal, it was just perceptible for layout 3 whilst glare was considered uncomfortable for layout 1 at the same LED dimming configuration, proving the influence of luminaires position in glare perception of the observer. Hence the subjective survey demonstrated that layout 3, with light coming from above of the exposed object, is the preferred one, with highest scores for all the evaluation factors. In conclusion, the assessment method presented in this work, based on objective evaluation (luminance metric) and subjective evaluation (visual appraisal by questionnaires), was effective to test lighting quality of museum showcases equipped with high luminous intensity and small size light sources such as LEDs. Furthermore, the results obtained from the study provided useful information for practitioners in order to design appropriate lighting systems for museum showcases. 

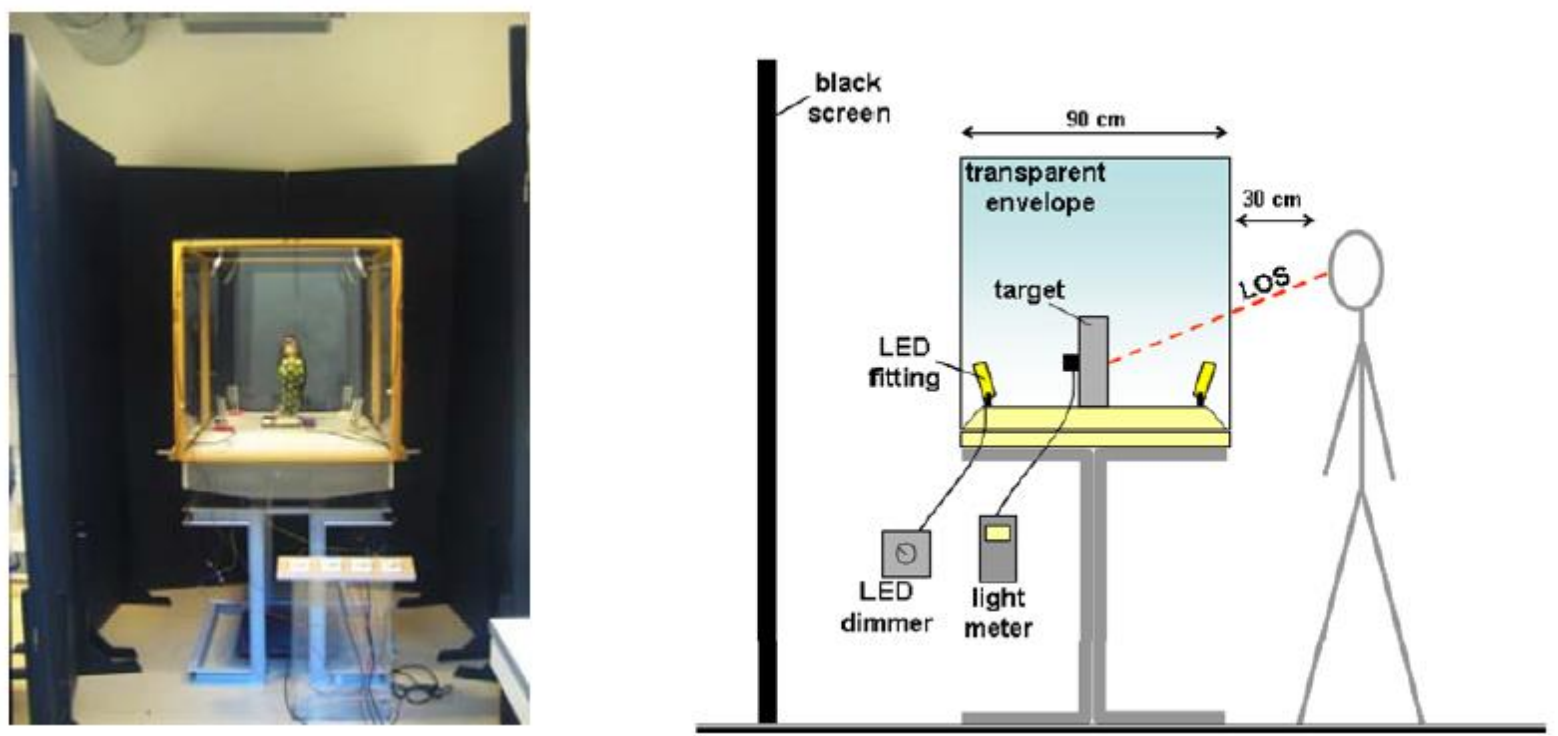

Figure 1 - The pedestal "free-standing" showcase and the experimental set-up.

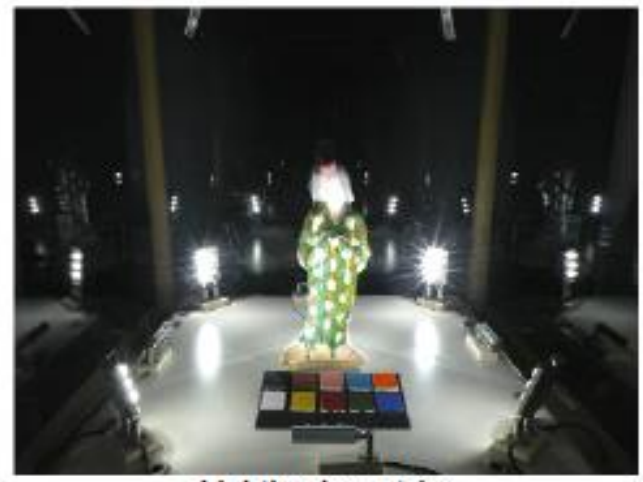

Lighting layout 1.a

- Light direction: from below

- Luminaire ppsition: on the base comers

- Colour tonality: Cool White (CW-LED)

- Illuminance on exhibit: 50-300-1000 lx

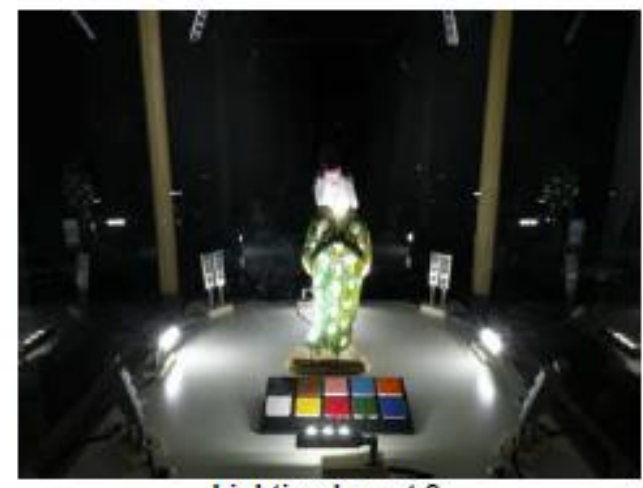

Lighting layout 2

- Light direction: from below

- Luminaire position: on the base sides

- Colour tonality: Cool White (CW-LED)

- Illuminance on exhibit: 50-300-1000 Ix

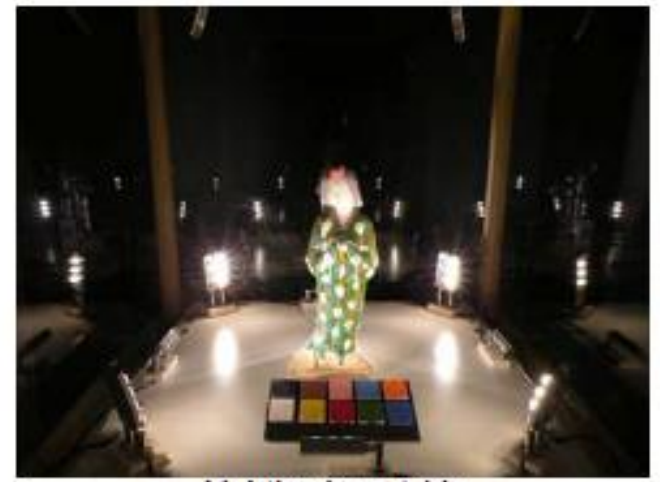

Lighting layout 1.b

- Light direction: from below

- Luminaire position: on the base corners

- Colour tonality: Warm White (WW-LED)

- Illuminance on exhibit: 50-300-1000 Ix

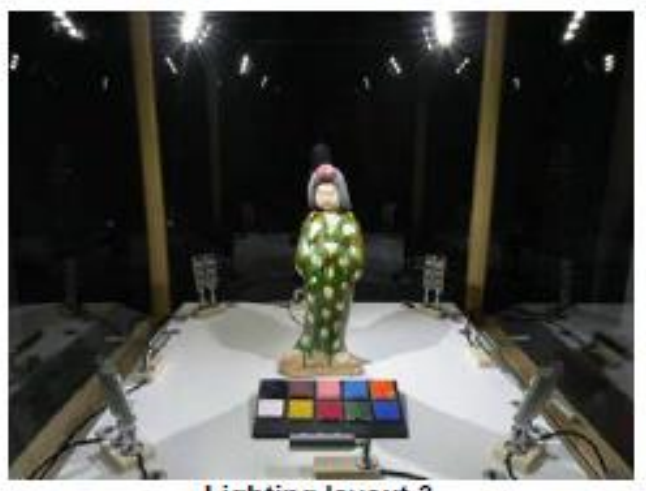

Lighting layout 3

- Light direction: from above

- Luminaire position: on the top comers

- Colour tonality: Cool White (CW-LED)

- Illuminance on exhibit: $300 \mathrm{~lx}$

Figure 2 - LED lighting layouts inside the showcase.

$98 \mid \mathrm{P}$ a g e 


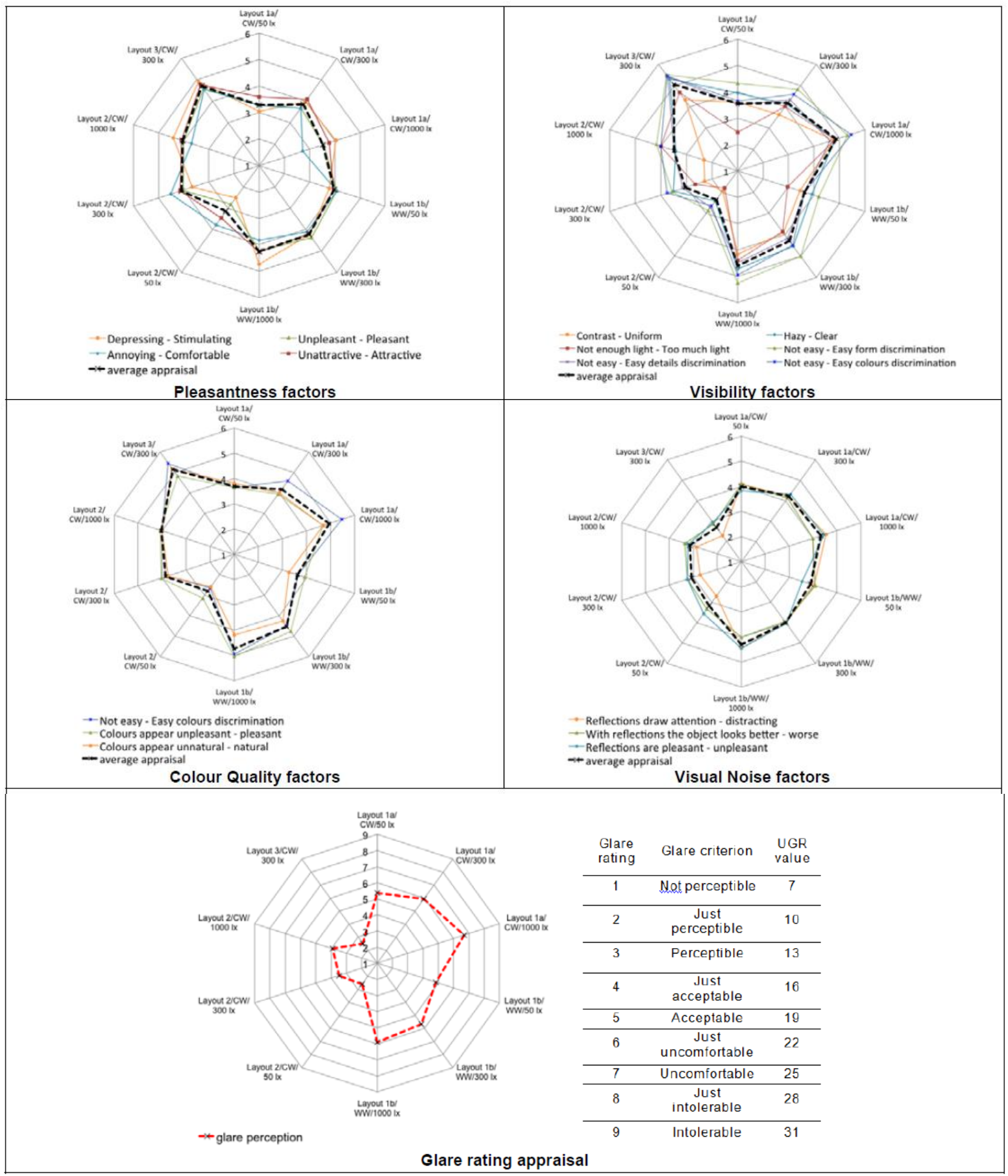

Figure 3 - Observers' responses for the different sections of the questionnaire. 


\title{
The Interactions between Museum Lighting and Optically Coated Glazing
}

\author{
Jennifer Booth
}

True Vue

jbooth@tru-vue.com

Glazing is increasingly being used within museums and galleries to protect works of art and cultural heritage. This can take the form of a sheet of glass or acrylic within the frame for $2 \mathrm{D}$ material, or as cases and vitrines for 3D items. The benefits of such protection are manifold, from the obvious physical barrier hindering theft and vandalism, to acting as a buffer against fluctuating environmental conditions. However, there are often many curatorial concerns with using glazing. Depending on the type of material used and the lighting conditions, glazing can impact upon the aesthetics of an artwork or artefact, potentially altering viewer engagement and understanding of a piece.

The most common concern with using glazing is reflection. It is reflections that can prevent the viewer from fully seeing the work, and make the glazing itself perceptible. Action can be taken to minimise the impact of reflections, and if done successfully, this can render the glazing nearly invisible. The majority of low-reflective glazing products currently on the market have coatings applied to the surface to reduce reflection using optical interference. However, it is rare that using a low-reflective glazing product, in isolation from any consideration of the light source in an exhibition environment, will produce an outcome that curators are fully happy with. The best results are achieved using a combination of lighting and low-reflective glazing, and by considering the interactions between them.

This presentation will provide an overview of the different types of glazing currently on the market, and will explain the manufacturing process of optical coatings and how they interact with light to reduce reflections. Lighting technology is developing rapidly and has changed considerably over the last few years. This means that many museums are using diverse light sources, which can even vary between exhibition spaces within one institution. Examples will be shown of the diversity in the amount and appearance of reflections that can occur depending upon various lighting scenarios. The effects of different light sources, colour temperatures, and light position relative to the work, will be described. It is hoped that by increasing awareness of the relationship between lighting and glazing, any interference of the material between the observer and an art or heritage item will be minimised, leading to greater appreciation and understanding of the work in question. In addition to aesthetic considerations, another protective feature of certain glazing material is the provision of blocking against UV radiation. However, figures and literature provided by some manufacturers can be misleading. In some instances, UV protection arises as a by-product of the 
optical coatings, and in others through the addition of UV absorbent material. How you tell the difference and what this means for choice of light source, and for calculations of exposure, are some of the questions that will be addressed. With developments in lighting technology, and a trend towards the use of LED lighting in gallery spaces, many museums argue that there is no longer a need for sourcing glazing that provides extra UV protection. Whilst LEDs generally have minimal UV emissions, the choice of whether or not to use UV protective glazing should involve other factors used in conjunction with an assessment of the light source in an exhibition space.

When it comes to making decisions relating to the display of art and cultural heritage, an understanding of both the lighting and protective glazing options definitely needs to be developed. The overall aim of this presentation is to show that these two factors should be considered together rather than independently, as one can have a major impact upon the other. As there can be significant implications for budget, the earlier in the planning process that consideration can take place, the more likely the display and conservation requirements will be met successfully. 


\title{
Moths to the flame: An investigation of the influence of lighting on museum visitor behaviour
}

\author{
Jessica Glaisher \\ University College London \\ jessica.glaisher@gmail.com
}

\section{Background}

Visitors to museums make decisions about which objects to examine closely and which to walk past. Not all objects are viewed, and people's attention is not equally distributed among the objects on show (1). Most will make decisions about which objects to examine closely based on what they see from a distance. In the case of most museums, even those with relatively small collections, it is not possible to view all of the objects on display in one visit so a selection is made, perhaps influenced by interest in particular subjects or time period, perhaps by access needs or proximity. What these studies aim to investigate is the extent to which lighting can influence the close examination of objects in a museum context. Since museum lighting is subject to restrictions due to conservation issues, many objects cannot be lit at high levels due to their vulnerability to light (2) and other environmental factors (e.g. temperature, humidity (3)), and so not all objects can be lit at high levels. Rather, the style of lighting must be examined in relation to the level of interest the object holds for a viewer. The way in which form is revealed to a viewer can alter their perception (4) of an object, hence the way the object is lit, which is an essential part of revealing form (5), logically has an influence on their perception, and interest as well. If the lighting of objects can influence whether or not they are examined closely by visitors, thereby justifying their display, lighting could, in theory, have an influence on visitor numbers and experience.

\section{Method}

Using the collections in the Victoria and Albert museum in South Kensington, a selection of objects was investigated using human participants. It has been noted that 'lighting [objects] dramatically increase[s] their chances of being noticed' (6) by the general public; in these studies, the aim is to further investigate this claim using specific objects as examples. These studies look at the influence of lighting on the decision to examine an object more closely. Two studies were carried out to investigate this. The primary study involved volunteer participants who were taken on a predecided route around the Victoria and Albert Museum in South Kensington and asked to fill in a survey about 9 objects in the collection. The objects were chosen so as to provide variety for participants and the study. Amongst the 9 objects were some the author considered to be lit 'well, 
and some which they considered to be lit 'poorly'; this allowed for comparison between the author's subjective observations with the results of the study. The objects ranged in vulnerability and type, including textiles, stonework and metalwork. This was done partly to reduce the likelihood that participants would mark objects low or high on the scale due to their interest in the subject, although this effect could not be eliminated entirely. The secondary study involved counting the number of people who stopped to look at each of the 9 objects from the primary study in a half hour period. This study was then compared with the results from the primary study in order to find correlations.

\section{$\underline{\text { Results }}$}

The results from both studies were compared to gain insight into visitor behaviour. Results in the primary study tended to generally follow the expectations of the author, whereas the popularity of objects in the secondary study seemed also to be influenced by the position of the object within the museum.

The primary study showed that an object which was chosen as an example of a 'poorly' lit object was the least popular among participants. This object was also the least examined by those observed in the secondary study. When the results of the two studies are compared, an interesting picture emerges. For example, the most popular object of the primary study, had the third fewest people stop to look at it during the secondary study. This could suggest that the position of the object, in a corridor which is a thoroughfare between two exits and the cafe/shop, had an effect on whether people would notice the object at all, let alone stop to investigate it further. It was found that lighting can influence visitor behaviour, but that the extent to which this is the case requires further study.

\section{$\underline{\text { Conclusions }}$}

These studies have shown that lighting can have an effect on the behaviour of museum visitors in terms of the desire to examine objects more closely. The extent to which the lighting has this effect, however, would require further study. It has been shown that objects which are in low light or suffer from veiling reflections are of less interest to people than those which are lit in a way which contrasts them from their background and the surrounding objects. It has also been shown that the location of objects has an effect on the likelihood of further examination; that objects in thoroughfares and corridors between other places of interest (e.g. the cafe, exits, shop etc.) may get more foot traffic but, because of the spaces transitional nature, may not entice many people to look closer - they may be more focussed on getting to their destination than on looking at the objects that surround them. It is interesting to note that there was not much of a difference between those participants with lighting experience and those without, suggesting that the factor of lighting can be noticed by those who are not necessarily attuned to its specifics. Lighting has been shown to have an influence on visitor behaviour to an extent which warrants further research into the field. 103 | $\mathrm{P}$ a g e 
Although not wholly conclusive, the studies carried out have given credence to the assertion that lighting can influence whether or not a museum visitor will examine a particular object.

(1) Monti and Keene 2013: p1

(2) SLL, 2015: p26

(3) SLL, 2015: p24

(4) Cuttle, 2007: p33

(5) Engineer, J.H.S.M.E., 2014: p133

(6) Monti and Keene, 2009: p2 


\title{
Light and Art - LED and the new possibilities in object lighting
}

\author{
Kay-Uwe Dingeldein, Dario Maccheroni, Ralf Maller
}

\author{
Zumtobel Lighting GmbH
}

kay-uwe.dingeldein@zumtobelgroup.com

The optimal lighting of objects of art, is also an art requiring in-depth knowledge, sensitivity and feel. LED luminaires have captured this exciting field of application. Innovative LED lighting solutions are not only energy-efficient and long-lasting, but also flexible and versatile, offering perfect visual quality and sympathetic display of precious objects. In the following, some important aspects will be explained:

\section{Colour rendering and colour temperature (light colour)}

Colour rendering is an essential feature of the light quality. A light source whose light contains all spectral colours, such as sunlight, makes the colours of the illuminated object look natural. Depending on the location and visual requirements, artificial light should ensure the most favourable colour perception (as with natural daylight). Colour rendering characteristics are expressed on a scale of the "general colour rendering index", Ra.

A light source with $\mathrm{Ra}=100$ shows all colours at their optimum. The lower the Ra value, the less true the colours are reproduced. With the introduction of LED technology, the number of reference colors to be evaluated has been increased from originally 8 to 14 . In addition to the general color rendering index $\mathrm{Ra}$, special color rendering indices are often used to better assess the quality of a light source, for example the R9 for saturated red. At the same time, high-quality LED products, especially for illumination of objects of art, require an Ra value $>90$ or even $>95$.

Whether the LED or the luminaire has a warm or cooler light is determined by the colour temperature. The higher the colour temperature, the cooler the light acts and the greater the luminous flux available in many cases. A colour temperature of 3,000 K is called warm white. 4,000 $\mathrm{K}$ is considered neutral white and $>5,500 \mathrm{~K}$ daylight white.

The colour temperature plays a key role in the correct staging of art. A simple change of colour temperature is an ideal way of achieving sensitive lighting solutions which are perfectly attuned to any art era and exhibition concept; quality of perception can also be selectively influenced this way. The previously set colour temperature is accurately maintained even when the LED luminaire is dimmed and materials retain their natural appearance. A lighting solution that offers modifiable colour temperatures in the white light spectrum allows exhibition designers to 
underscore the attributes of an objet d'art emotionally and emphasize content and substance succinctly.

\section{Conservational aspects}

LED light is virtually free from infrared light and ultraviolet light, therefore opening up the possibility of completely new forms of lighting for museums and art galleries. Professional calculation of radiation time on the basis of potential damage from the lighting solution ensures optimum protection. A study from Zumtobel - "Surveying the lighting of Pablo Picassos" Harlekin "(1916) in the Stadtmuseum Lindau" - conducted in collaboration with Darmstadt University has produced a useful knowledge base.

Warm LED light with a colour temperature of 2700 to $3500 \mathrm{~K}$ significantly lowers the risk of potential damage when compared to lighting using conventional halogen technology or cool white LED lighting. Luminaires with tunable white technology make it possible to select the optimum light colour for individual objects.

A great advantage of LED luminaires is their precise dimming to the maximum permissible level. The color temperature remains constant in contrast to dimmable conventional solutions, e.g. Halogen lamps.

\section{Miniaturization and flexibility}

LEDs offer the grandiose opportunity for the consequent miniaturization of luminaires and give new possibilities to light up the work of art. Now it is up to the skill of the product designers and technicians to implement this by e.g. drivers can be moved into the track or inside the suspended ceiling.

With beam angles from Superspot to Wideflood, anti-glare tubes for optimal glare control and framing attachments for precise borders. Modular systems made from high-quality exchangeable lenses, optics and attachments allow optimum and quick adaptation reflect the specific lighting task. The lighting tools enable maximum curatorial freedom with beam angles ranging from $8^{\circ}$ to $65^{\circ}$. This offers architects, lighting designers and curators the greatest possible flexibility and precision when implementing sophisticated lighting concepts.

\section{$\underline{\text { Service life \& maintenance }}$}

Because of their extremely long service life (50,000 hours before residual luminous flux is reached), LEDs allow longer maintenance intervals. The long-life expectancy of LED luminaires minimizes expensive maintenance work - especially in situations where relamping requires considerable effort. Museums with high ceilings or elaborately protected and secured display cases containing 
valuable exhibits are just two examples where a durable LED luminaire soon pays for itself. LED spotlights are designed for optimal thermal management and feature either active cooling with innovative fan technologies or passive cooling using a heat dissipation solution.

\section{Digitization and Connectivity}

For some time, the term "IoT - the Internet of Things" has been circulating through our daily lives and does not stop us from the museum or art world. On the one hand, it is important to learn from the visitors and, on the other hand, to increase the visitors experience - a "give and take".

You get a more detailed insight into how the visitor uses the museum and measure the success of a (temporary) exhibition not only on the number of tickets you sold.

- What paths do the visitors take?

- Where do the visitors spend their time?

- Which exhibits receive the most and which receive the least attention?

This allows curators active and individualized tours and connects with an increasingly digital generation. Subsequently, visitor location and object recognition can be combined and the visitor receives interactive information directly on his mobile device. For the younger generation, the "Pokemon GO" principle could be used to search for hidden objects in an exciting and interesting way and be guided through the museum itself.

\section{Conclusion}

LED lighting creates new possibilities to stage an exciting and lively art world, to arouse a partial lost interest in it, to win new audiences and, in part, to combine historical and modern technology.

On the poster, we will discuss how these criteria take influence on the visitor's experience. 


\title{
Lighting in museums, visitors' experience and satisfaction in a heritage context. Study cases in Northwest Argentina
}

\author{
L.N. Bazán $1,2,3$, R.F. Ajmat ${ }^{1,3}$, J.D. Sandoval ${ }^{1,3}$ \\ Institute of Research in Light, Environment and Vision (ILAV) ${ }^{1}$; National Council for Scientific \\ and Technical Research (CONICET)2 ; Department of Lighting, Light and Vision (DLLyV) \\ National University of Tucumán (UNT) ${ }^{3}$ \\ nataliabzn@gmail.com
}

Lighting design in Museums in Argentina is mainly aimed to meet quantitative requirements for objects' conservation and preservation not particularly oriented to meet visitors' satisfaction. Visitors' visual comfort and quality of exhibitions are not always considered to meet their satisfaction while visiting the museum.

This study aims to analyse the relationship between measured illuminance levels in exhibitions, the subjective evaluation of lighting and overall satisfaction of visitors. Visitors' subjective assessments of lighting, and overall satisfaction were carried out in two museums in San Miguel de Tucumán, Argentina:

- Museo Casa Histórica de la Independencia (1st museum - high symbolic connotation; natural and artificial light)

- Museo de Arte Sacro de Tucumán (2nd museum - unfrequented; mostly artificial light)

Data collection was done through a survey (questionnaire), based on findings of relevant literature on museums, with four sections of information considered relevant for visitors' satisfaction and divided into two parts (Figure 1).

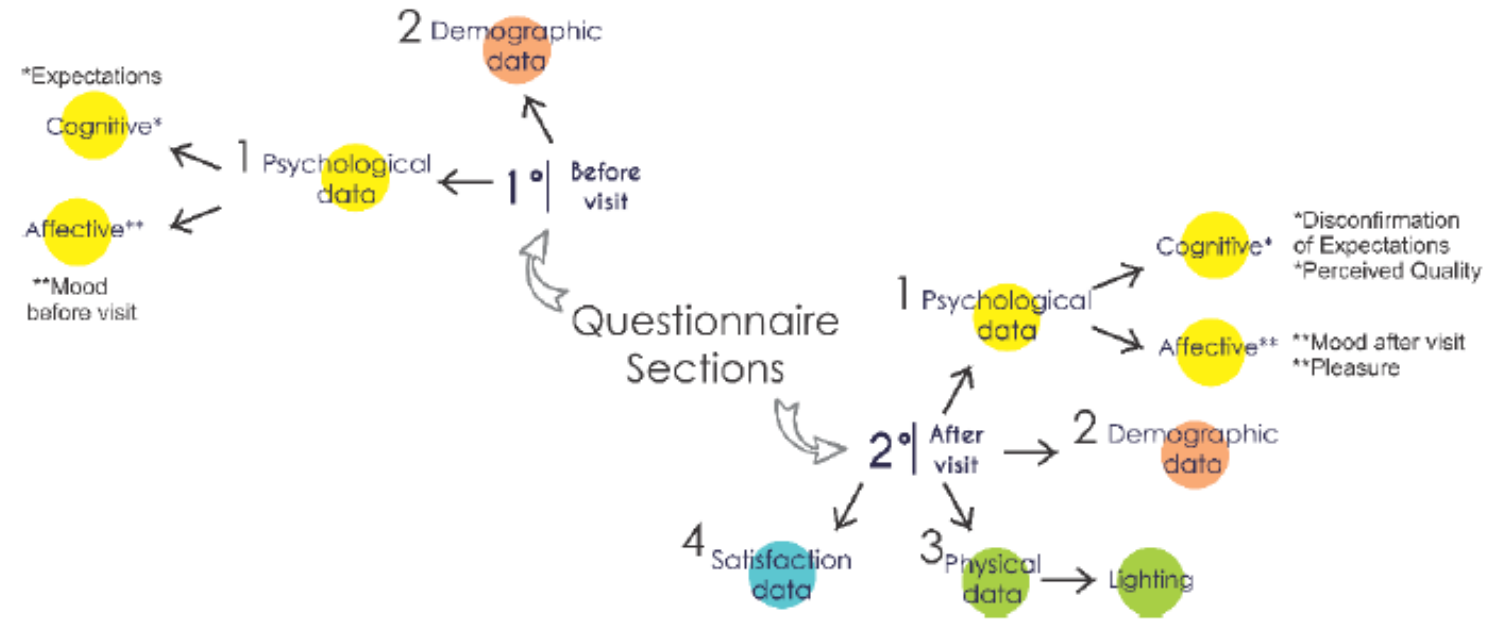

Fig. 1- Questionnaire structure

108 | P a g e 
The subjective data obtained were processed through descriptive statistical analysis and compared with objective data measured in situ in both museums (Figures 2,3):

- Luminance distribution measured from 1 or 2 points of view per room (scenes).

- Vertical or horizontal illuminance values on objects.

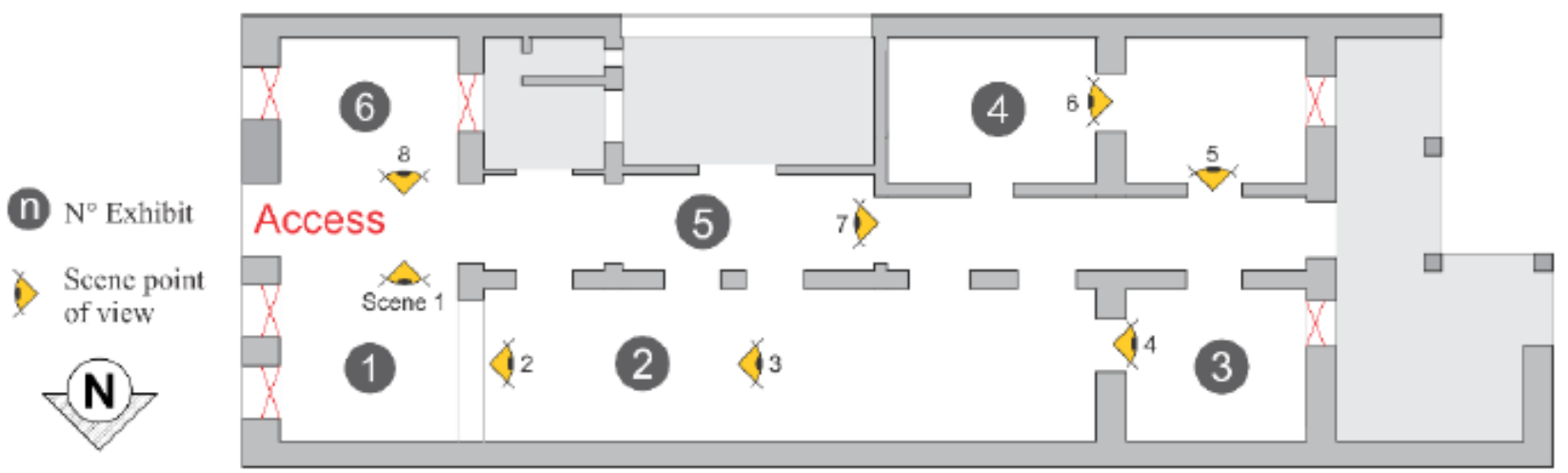

Fig. 2 - Location of exhibitions and points of view of scenes in the 2nd museum

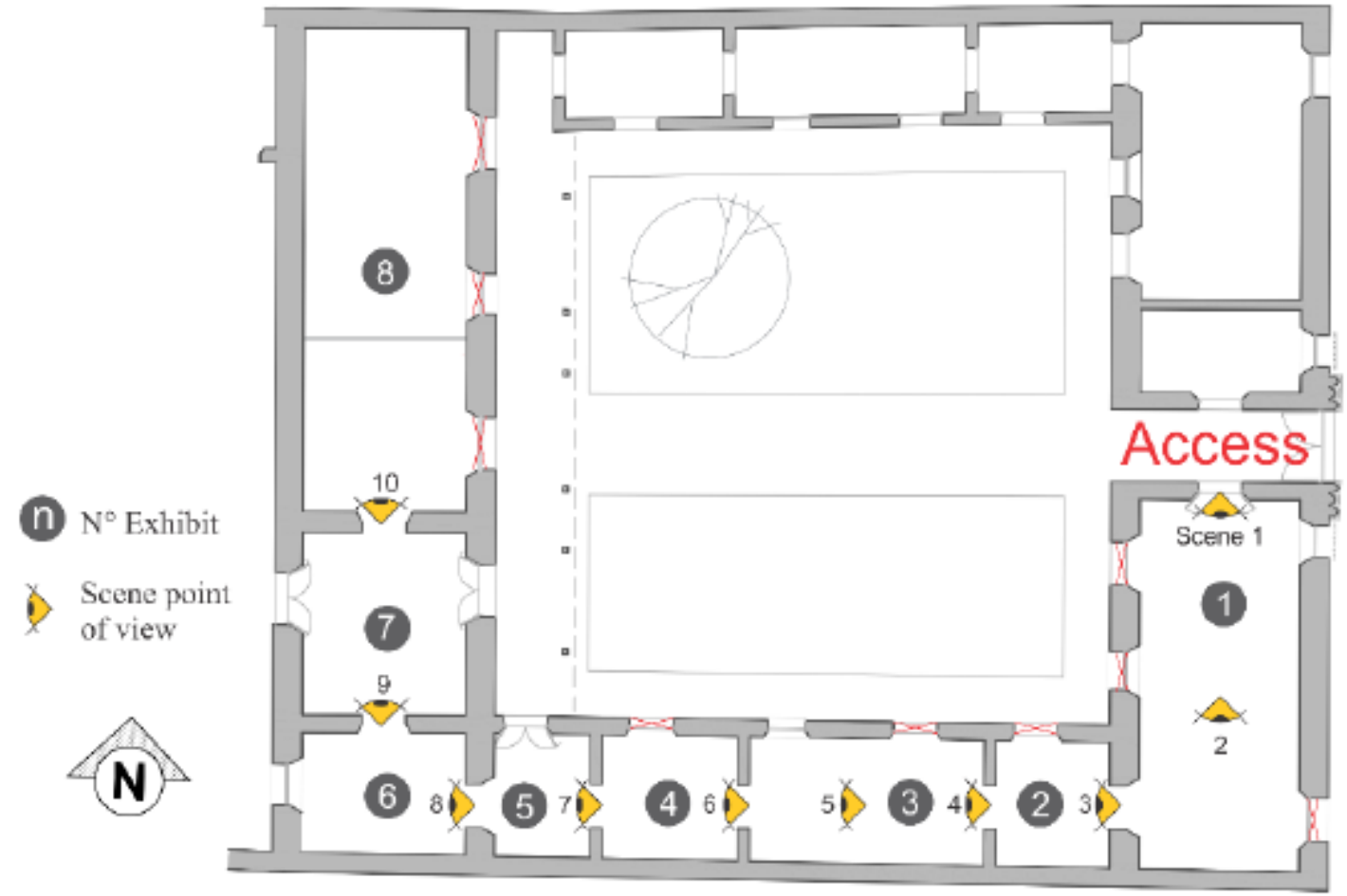

Fig. 3- Location of exhibitions and points of view of scenes in the 1st museum

\section{Results}

\section{Subjective data}

Means and frequencies of all the variables were calculated, establishing 3 cut-off points: 1 to 2.5 low/unsatisfied; 2.51 to 3.5 medium/somehow satisfied; 3.51 to 5 high/satisfied. 
Lighting

1st Museum: Visitors considered that the museum had a medium-low lighting level, with a mean value of 2.68 . $61 \%$ of the visitors perceived poorly lit areas within the museum, $70 \%$ of which pointed to exhibitions 1,8 or both and the other $30 \%$ to all the exhibitions in general. However, only $43 \%$ of the visitors reported visualization problems. The $22 \%$ reported glare problems from high contrasts between artificial and natural light.

2nd Museum: Visitors considered high lighting levels, with a mean value of 3.56 . Only $28 \%$ of visitors perceived poorly lit areas within the museum, half of them reporting problems with reflections on glass cases and the other half with low levels in exhibitions 1,6 . The $19 \%$ reported visualization problems, and the $21 \%$ glare problems from reflections over paintings or cases.

\section{Visiting experience}

1st Museum: 49\% of visitors were satisfied with their visit, 30\% somehow satisfied and another $21 \%$ was dissatisfied. The average overall satisfaction was 3.18 , suggesting that visitors were somehow satisfied (medium satisfaction) with their visit.

2nd Museum: The $38 \%$ of visitors were satisfied with their visit, $41 \%$ somehow satisfied and the remaining $21 \%$ dissatisfied.

Figure 4 shows the mean values obtained for all variables analysed for both museums.

1st

Museum
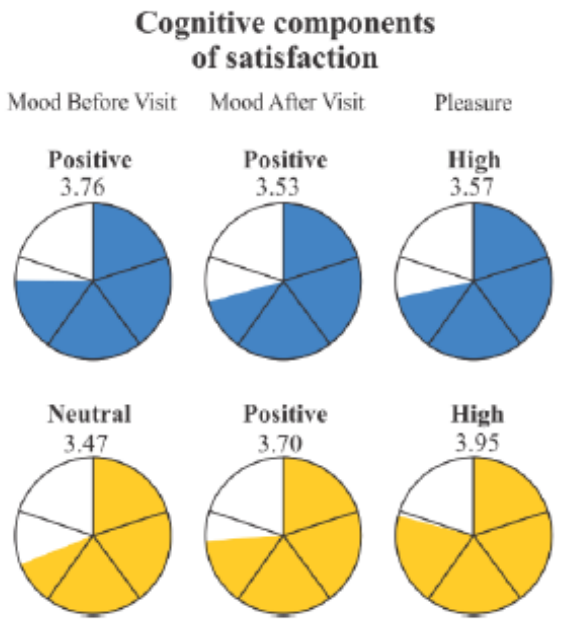
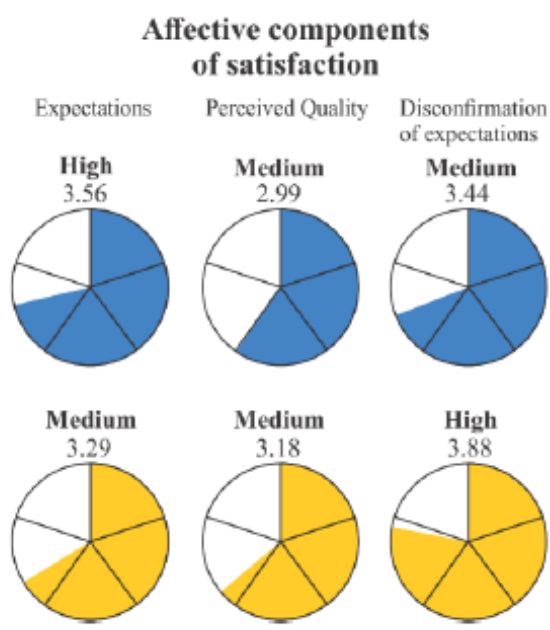

Visit Satisfaction.
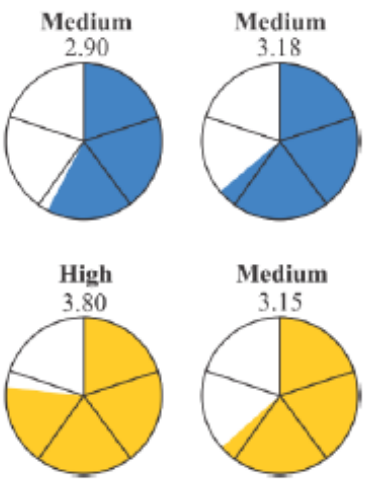

Fig. 4- Comparative graphs of the mean values obtained for all variables analysed for both museums. 


\section{Luminance in scenes:}

1st Museum: In rooms 1,2,4,8 the range of luminance values from the points of view selected was of $2-30 \mathrm{~cd} / \mathrm{m} 2$ with few exceptions of higher levels (Figure 5). In rooms 3,5,6,7 was of $10-100 \mathrm{~cd} / \mathrm{m} 2$ with presence of values higher than $1000 \mathrm{~cd} / \mathrm{m} 2$ in the visual field, due to the use of natural lighting. The highest luminance values were on the background of each scene.

2nd Museum: In rooms 1,2,4,5 the range of luminance values was of 8-100 cd/m2 except for a few points on exhibitions 2,4 with higher values on the self-illuminated cases; in 3 was of $4-40 \mathrm{~cd} / \mathrm{m} 2$, and in 6 of $6-20 \mathrm{~cd} / \mathrm{m} 2$ (Figure 6). In exhibitions 2,4,5 the highest luminance values on each scene were on the objects, but in exhibitions 1,3,6 they were on the background.

\section{Illuminance on objects:}

1st Museum: In rooms 1,2,4,8 the range of illuminance values was of 20-80lx with few exceptions of higher levels but lower than100lx. In rooms 3,5,6,7 the range was of 100-250lx with some points of 500lx maximum.

2nd Museum: Illuminance levels were similar for all the exhibitions and varied according to the object in a range of 50-400lx (Figure 7), but higher values can be found, such as 1000lx and up to 2000lx over some paintings in exhibitions 2,4,5 (Figure 8).

Figures 9-10 show the range of illuminance and luminance values obtained in each exhibition for both museums.

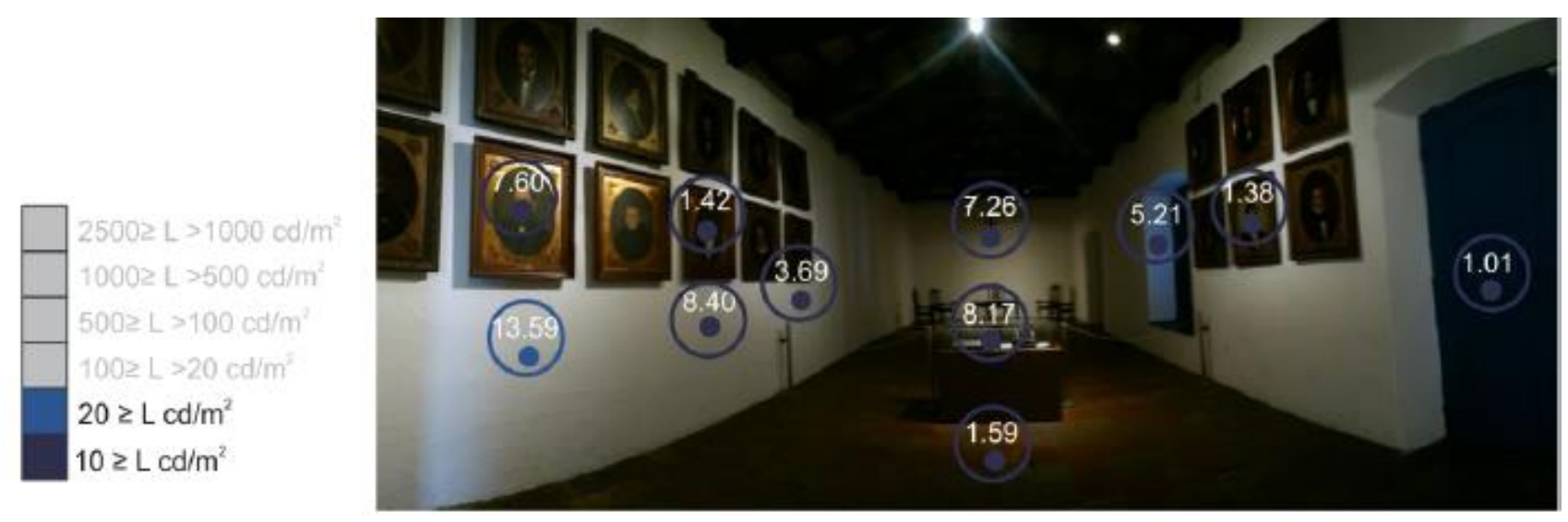

Fig. 5 - Points and values of luminance measured in scene $N^{\circ} 10$ in the 1 st museum 


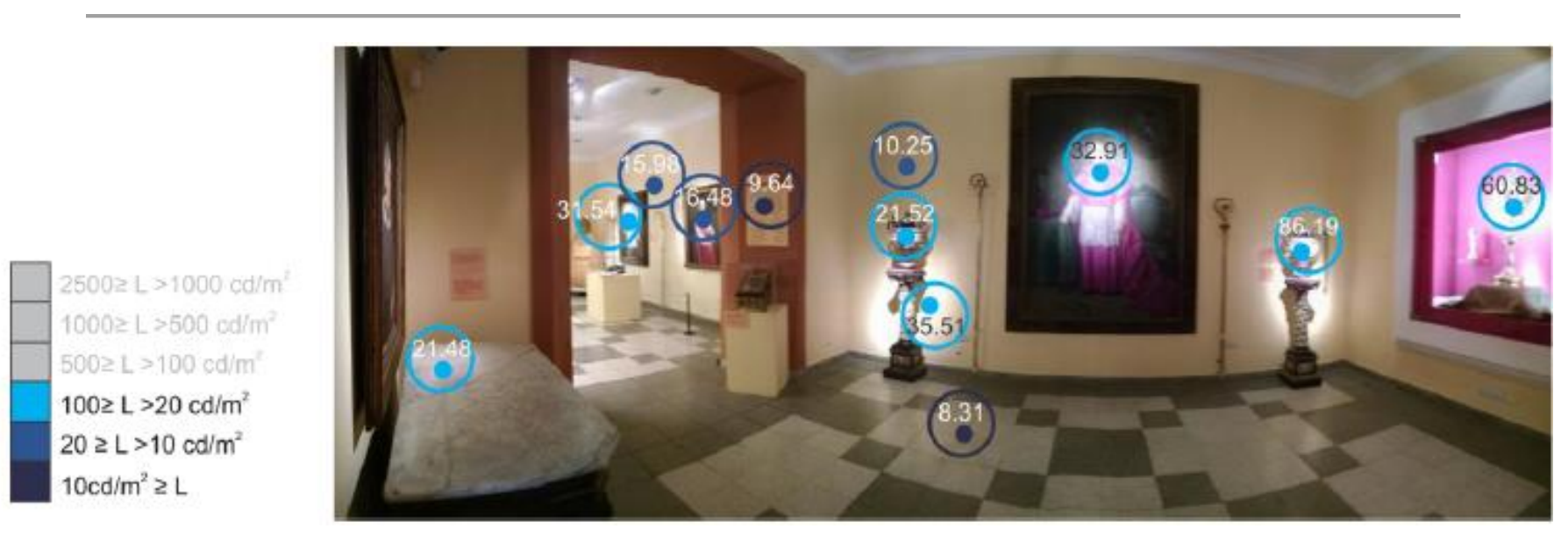

Fig. 6 - Points and values of luminance measured in scene $N^{\circ} 5$ in the 2 st museum

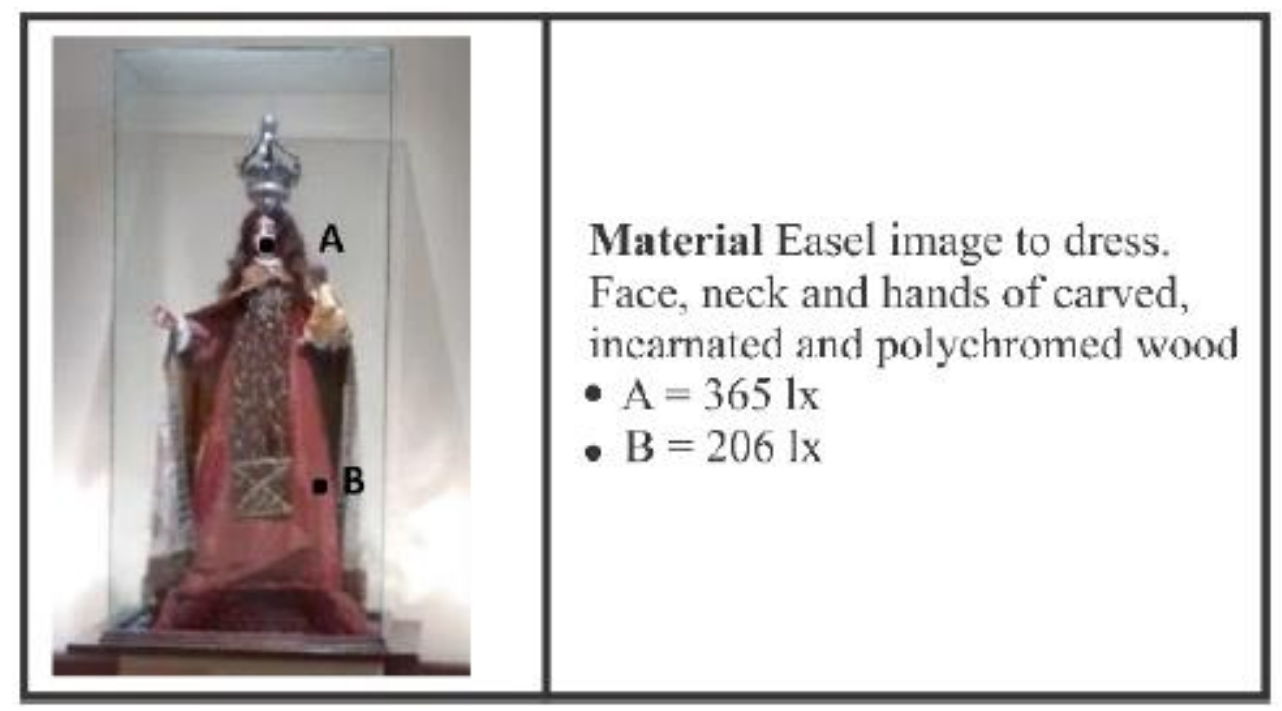

Fig. 7- Measuring points and illuminance values over object in exhibition 1

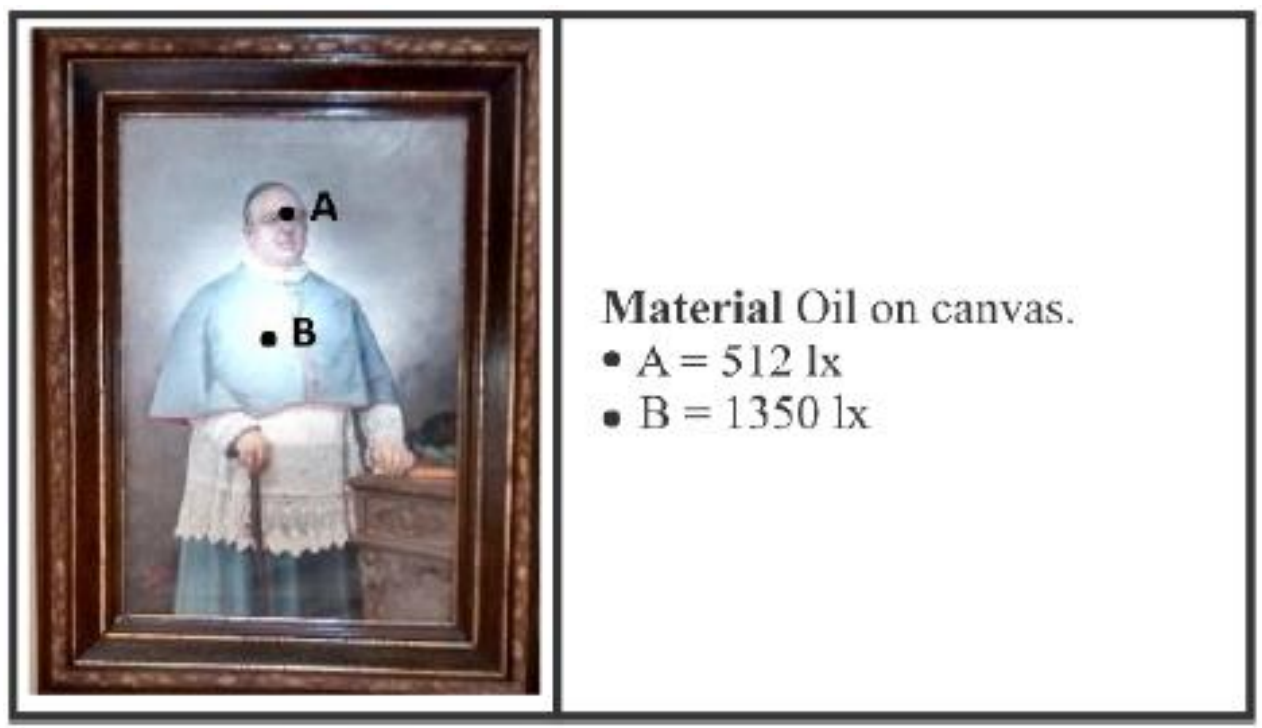

Fig. 8 - Measuring points and illuminance values over object in exhibition 4 


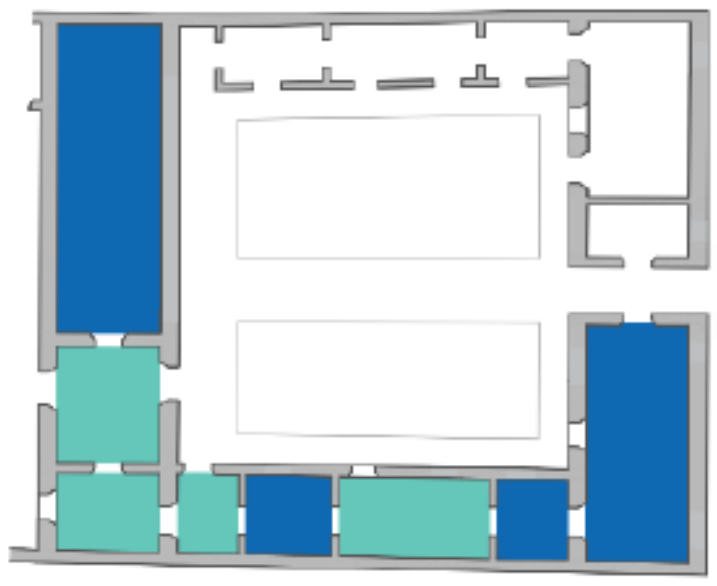

L: $2-30 \mathrm{~cd} / \mathrm{m} 2$

Lratio:

\begin{tabular}{r|r}
$1.5: 1$ & Background-object \\
$8: 1$ &
\end{tabular}

E: $20-801 x$

L: $10: 100 \mathrm{~cd} / \mathrm{m} 2$

Lratio:

$1.5: 1$ Background-object

$8: 1$

$40: 1$

E: $100-250 \mathrm{~lx}$

Fig. 9- Ranges of (L), (Lr) and $(E)$ in the 1st museum

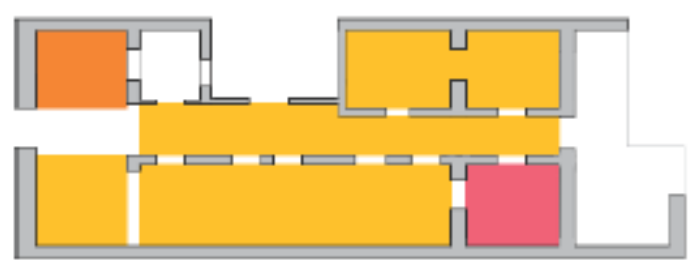

L: $4-40 \mathrm{~cd} / \mathrm{m} 2$

\section{Lratio:}

1.3:1 Background-object

$2.8: 1$

$8: 1$

E: $50-2001 \mathrm{x}$

\section{L: $8-100 \mathrm{~cd} / \mathrm{m} 2$}

\section{Lratio:}

12:1 object-Background $2: 1$

40:1

E: $100-4001 \mathrm{x}$

L: $6-20 \mathrm{~cd} / \mathrm{m} 2$

\section{Lratio:}

1.3:1 Background-Object

$3: 1$

E: $100-3501 x$

Fig. 10- Ranges of (L), (Lr) and (E) in the 2nd museum

\section{Conclusions}

- Although the illuminance values were somewhat higher in the 2 nd museum, the difference of levels between museums is not as great as it would be expected, since the 2 nd one has 
an average satisfaction with lighting much higher than the 1st one. This ample difference in the clarity/brightness perception between one another may be related to:

o The ratios of luminances. In both museums when the background luminance values were higher than those of the objects, visitors perceived the exhibitions as darker than the ones where the opposite occurred. This was the situation in almost all the exhibitions within the 1 st museum.

o Low luminance and illuminance even distribution levels between exhibitions. This is due to the use of natural lighting only in some exhibitions creating adaptation problems on the visual system.

- The higher level of perceived quality and the positive disconfirmation of expectations in the 2 nd museum may be related to the better illumination perceived in it.

- Despite the fact that the second museum has higher average values for all variables analysed, the satisfaction in both museums is almost the same. This may be because:

o The 1st museum has a high historic and symbolic value (home for the declaration of national Independence).

o Sacred art seems not a very popular topic amongst young people, mostly the sample, therefore it would be interesting to take into account cultural preferences of the volunteers for future research.

- Taking into account regulations and recommendations on maximum illuminance values permitted for preservation and conservation, seems to be possible to create lighting designs for museums that offer visual comfort and quality by using other variables; for example, luminance distribution and figure-background ratios. 


\title{
The role of light on visitors' experience of the Parthenon Marbles in the Acropolis Museum
}

\author{
Panos Andrikopoulos ${ }^{1}$, Kalliopi Fouseki ${ }^{1}$, Panos Mavros², Andy Hudson-Smith ${ }^{3}$, \\ Frangiskos Topalis ${ }^{4}$
}

\author{
UCL Institute for Sustainable Heritage ${ }^{1}$; Future Cities Laboratory, Singapore ETH Center ${ }^{2}$; \\ Bartlett Centre for Advanced Spatial Analysis'; Lighting Laboratory, National Technical \\ University of Athens ${ }^{4}$
}

panagiotis.andrikopoulos.15@ucl.ac.uk

\section{Introduction}

Museums are interesting buildings for architectural analysis. They are almost single purpose-built spaces: typically, visitors are expected to interact with museum exhibits and activities to acquire knowledge, therefore the efficiency of the space can be easily assessed. Human experience of and behaviour in architectural spaces, relies upon the spatial layout, the content of space and lighting conditions. Light in museums is an extremely complex issue, due to the limitations and the requirements in terms of collection care and vision. It depends on architectural design, latitude and time during daytime, or artificial lighting design during night-time. Light in architectural spaces, even more in museums, has profound effect on human psychology. Vision is our dominant sense: about $80 \%$ of human perception, cognition and activities are mediated based on what we see (Thinus-Blanc, 1997). Apart material properties and human sensorial capabilities, light governs the visual stimuli. Light stimulates emotions and instigates behaviour. It affects the way we perceive, understand, feel about and interact with our spatial environment. It defines our relationship with the exhibits and the museum space.

Despite its importance, the effect of light on human emotions and behaviour in museums spaces has been fairly invisible in the literature. Lighting research in museums, has mainly explored more tangible effects of illumination, such as colour appearance, light induced degradation and visual acuity. The effect of lighting parameters such as illuminance distribution, overall brightness and colour on visitor experience and behaviour have not been thoroughly discussed for several reasons. Large scale lighting research in museums, requires access to spaces and objects, a great amount of equipment, which in turn has an effect on the museum operations and visitors.

The Case of the Parthenon Gallery of the Acropolis Museum 
The Acropolis Museum is located in Athens, beneath the Acropolis outcrop. The Parthenon Gallery, which constitutes the third and top floor of the museum, is designed to be of the same scale and cardinal orientation with the Parthenon. The gallery houses the Parthenon marbles: the Metopes, the frieze and the pediments, all positioned in relatively similar to their original positions. The frieze and the metopes, run around the four sides of the gallery at high level and the pediments are east and west facing at eye level.

Apart from the historic and artistic significance of the exhibits, the Parthenon Gallery is ideal for lighting research due to its geographical position and the architecture of the museum: The frieze, consisted of 380 figures and 220 horses (some original and some reconstructions), which all are narrative of the Panathenaic Procession, and the metopes, depicting scenes from Greek mythology, are illuminated by different light in terms of spectral distribution, angle of incidence and intensity depending on time of the day and position in the gallery, while the high relief of the Metopes exaggerates the effect of the incidence angle.

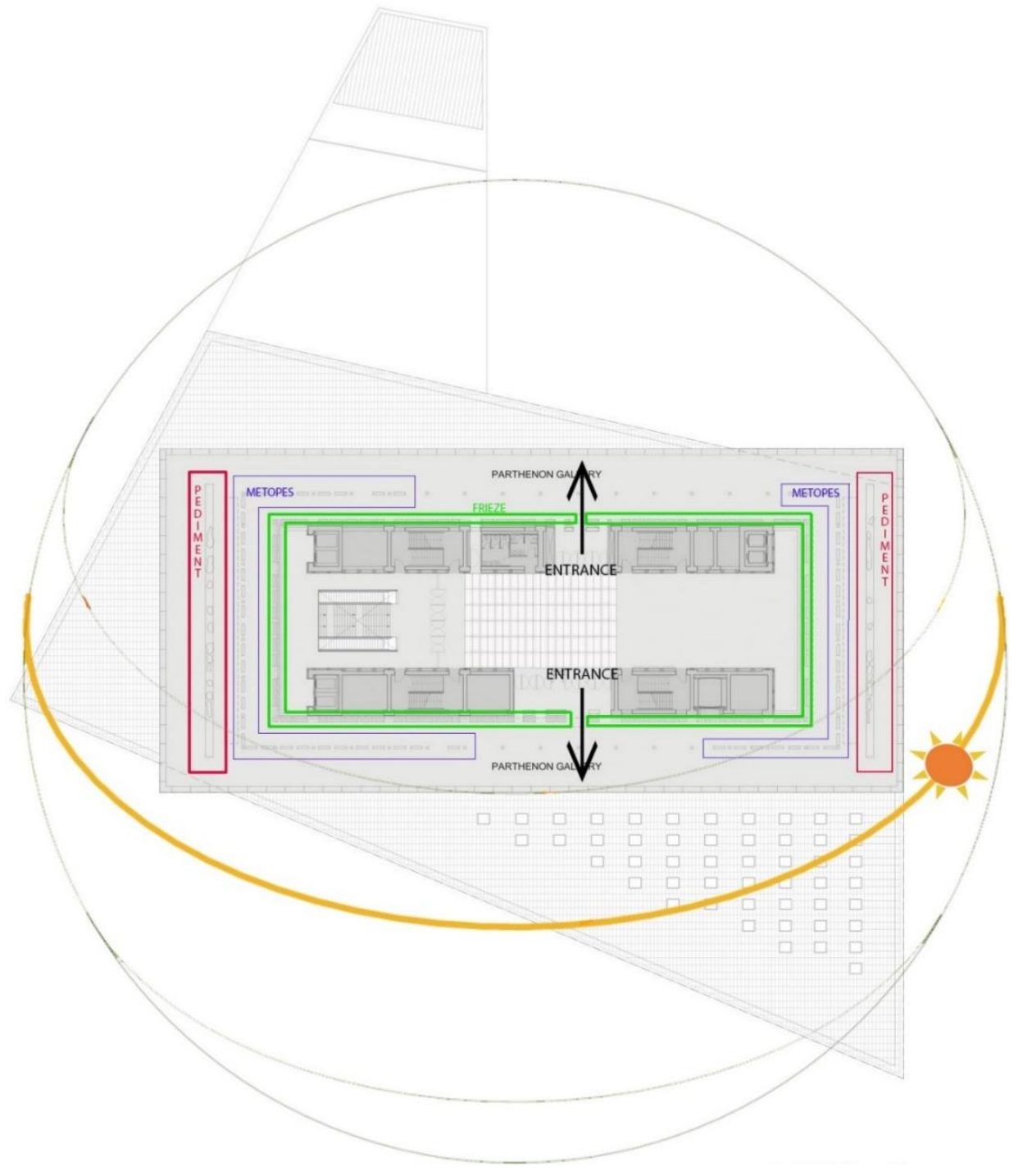

Figure 1 The Parthenon Gallery of the Acropolis Museum with sunpath. 


\section{The Experiment}

The purpose of the experiment is to investigate the casual relationship between light and visitor experience in the Parthenon Galley of the Acropolis Museum. The term 'visitor experience' is used to connote emotional, cognitive and spatial behaviour and engagement in the space. The three main research objectives are to explore:

1. the effect of different light conditions on visitors' physical movement and interaction in a museum context;

2. the effect of light on visitors' emotional responses to the museum exhibits;

3. the effect of light on visitors' spatial behaviour.

To achieve these objectives, this research project consists of two main studies. Part one will explore visitor experience by observing the movement and interactions with the exhibits in the Parthenon Gallery of 100 visitors 50 of whom will be asked to answer some quantitative questions on a tablet. This stage will provide a first sense of visitors' general engagement with the Parthenon Gallery. Visitors will be observed at the tree targeted light conditions (i.e. morning, afternoon and artificial). The data will also be used as complementary data to the data collected during part two.

\section{$\underline{\text { Data collection }}$}

Five different states of behaviour are considered:

a. Interest: when a visitor's stops and looks at an object for two to four seconds

b. Engagement: when a visitor stops and looks at an exhibit for more than four seconds and/or reads caption

c. Contact: When visitor walks along the gallery looking at the exhibits. Three different types of contact are defined

a. Contact A: When a visitor walks along the gallery looking at the Metopes

b. Contact B: When a visitor walks along the gallery looking at the Frieze

c. Contact C: When a Visitor walks along the gallery looking at the Pediment

d. Distracted: When the visitor is not engaged with the gallery content. This does not include looking at the view. The gallery is designed so the view is considered part of the context, therefore looking at the view is examined as being a separate behavioural state 
e. View Appreciation: When the visitor looks at the view

Along with the use of methods such as on-site observations, and extending on the findings of part one, the experience of 90 visitors in terms of their emotional and cognitive state, will be monitored with the use of novel techniques. Participants will be recruited to visit the gallery in the same lighting conditions as described above, while wearing a mobile Electroencephalography (EEG) device, eye-tracking glasses and a skin conductance (also referred as GSR) monitoring bracelet.

\section{References}

Thinus-Blanc, C., \& Gaunet, F. (1997). Representation of space in blind persons: vision as a spatial sense? Psychological Bulletin, 121(1), 20-42. http://doi.org/10.1037/0033-2909.121.1.20 


\title{
Replicating Blue Wool Testing for Art Conservation Using a Smartphone Spectrometer
}

\author{
Rachel N. Ulanch and R. John Koshel \\ College of Optical Sciences, The University of Arizona \\ rulanch@optics.arizona.edu
}

Blue wool testing is a light comparative fading test from the textile industry ${ }^{[1-2]}$ that was adopted by the art conservationist community during a time when there was limited information on how museum objects faded due to incident radiation and environment [3]. This technique was first adopted by Feller ${ }^{[3]}$ who regarded it as a cost effective, readily available comparative standard for understanding lightfastness of museum objects and materials. He noted that it is not extremely accurate because the blue wool's wavelength dependence ${ }^{[5]}$ and environmental sensitivity will vary for different museum objects. Every object will fade differently depending on its chemical makeup (e.g., object format, type of material and application method(s) and so forth) and history of environment (e.g., humidity, temperature, etc.), which is why a method for replicating the blue wool test and extending it to testing the individual characteristics of each museum object is attractive.

Many replacements have been found since the suggestions of the blue wool standard (BWS), but these methods are still comparators or not possible for all conservators. The Canadian Light Damage Calculator and Lightcheck ${ }^{\circledR}$ are comparator guides for lighting museum objects, but are unable to predict a specific object's photochemical reaction [6-7]. The Berlin Model correlates the spectral response of objects to a damage index but requires expensive spectrometers and experienced personnel [8]. It is not practical for most settings though it gives a fairly accurate representative result that can predict damage to the object. A more practical technique is Microfadeometry, which unfortunately quickly fades museum objects at an advanced rate with a $0.4 \mathrm{~mm}$ diameter spot size ${ }^{[9]}$. It requires expensive equipment, knowledgeable personnel, and leaves visible marks of fading and does not accurately represent most museum object environments. A simpler method that places the seemingly advanced tools of science labs in the hands of conservationists, curators, and other personnel at museums is required.

Proposed and demonstrated is a smartphone spectroradiometer that correlates the BWS and the spectral response of a museum object due to their lighting environment, via absorption spectroscopy, to predict the lightfastness of objects. The collected data sets are used to continually build a database of museum objects based on year, artist, and current museum environment. Currently, the system provides a wavelength range of $393-650 \mathrm{~nm}$ limited by the camera's 
spectral response, geometry of the design, and noise control. It utilizes off the shelf components and a low resolution 3d printed parts. See figure 1 for the current design that attaches to a Samsung $\mathrm{S} 7$ and can be modified for an iPhone.

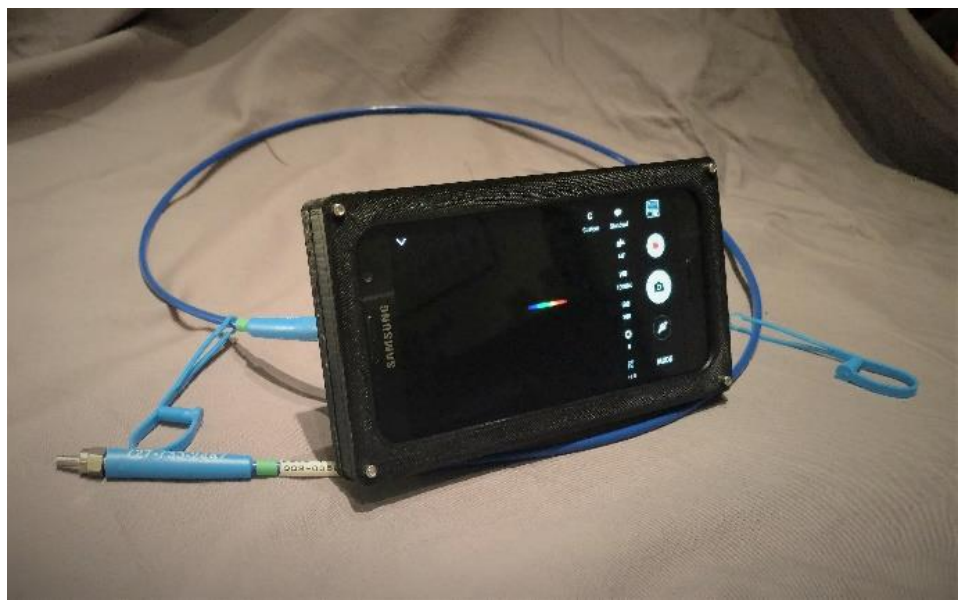

Figure 1: Smartphone Spectroradiometer.

The smartphone spectroradiometer includes the following components with a single unit costing around $\$ 357$, which can be reduced in quantities:

- Multimode fiber with SMA connector (pointing control of measurement),

- Collimation lens

- Grating (1200 line pairs/mm, diffracts light),

- 3D printed parts (aligns smartphone to optical system)

The smartphone spectroradiometer has $\pm 9.4 \mathrm{~nm}$ of resolution, 5 orders of magnitude of dynamic range, a spectral range from $393-650 \mathrm{~nm}$, and a radiometric error of $\pm 27.5 \%$.

For validation of the optical system various BWS were exposed under different illumination settings. Their absorption spectrum was found by subtracting the measured reflected spectrum of the blue wool from its measured illumination spectrum. The found absorption spectrum was used to correlate its total absorbed energy over time to its visible signs of deterioration. A sensitivity model was defined with a best fit equation of the parameters described. The current results show signs of predicting deterioration before it is even visible. However, more data is needed to support the found deterioration models. Fortunately, with the easy assembly, calibration and usability of the smartphone spectroradiometer the entire conservation community can help. The entire conservation community lay the ground work for an absorption spectrum database for better predictions of the deterioration of objects. 
This design breaks the current monetary and knowledge boundaries of the conservation community. Any conservationist can preserve high-value works of art with accuracy, less recurring costs and learning curves that are associated with current lightfastness techniques for museum objects.

\section{References:}

1. International Standard: Textiles -Tests for colour fastness - Part B01: Colour fastness to light: Daylight. ISO-105-B01. $6^{\text {th }}$ edition. Ref No. ISO 105-B01:2014(E), Geneva, Switzerland; 2014.

2. International Standard: Textiles -Tests for colour fastness - Part B01: Colour fastness to light: Daylight. ISO-105-B01. $6^{\text {th }}$ edition. Ref No. ISO 105-B01:2014(E), Geneva, Switzerland; 2014.

3. R. L. Feller, R. Johnston-Feller, "Use of the International Standards Organization's Blue Wool Standards for Exposure to Light" AIC Preprints of Papers presented at the 7th Annual Meeting, Toronto, Canada, 1979.

4. R. L. Feller, "Accelerated Aging: Photochemical and Thermal Aspects "Research in Conservation; 4 The Getty Conservation Institute, 1994.

5. H. Hattori, K. Yoshizumi P.C. Crews, "Wavelength Sensitivity of AATCC Blue Wool Lightfastness standards under light radiation" Dyes and Pigments 92 (2012) 936-941 Elsevier publishing published 12 July 2011.

6. Canadian Conservation Institutes' Online Light Damage Calculator. 2017, http://canada.pch.gc.ca/eng/1450464034106. March 2017

7. C. Cucci, A. Dupont, S. Gerlach, C. Loisel, M. Bacci, B. Lavédrine, H. Roemich. "Lightcheck ${ }^{\circledR}$, new system for monitoring lighting conditions in museums," The Research and Technical Studies Specialty Group of the American Institute of Conservation of Historic and Artistic Works, Manuscript from 32 $2^{\text {nd }}$ annual meeting of American Institute for Conservation and Historic and Artistic Works. Research and Technical Studies (RATS). Ref \#: ISSN:2167-9851. Volume 1 2004, pp. 11- 1[JK1] 8.

8. CIE (International Commission on Illumination. Control of Damage to Museum Objects by Optical Radiation. CIE publication No. 157-2004. Vienna, Austria: CIE Central Bureau; 2004 .

9. P.M. Whitmore, X. Pan, C. Baillie, "Predicting the fading of objects: Identification of fugitive colorants through direct nondestructive lightfastness measurements, "Journal of the American Institute of Conservation. Vol. 38, pp. 395-409, 1999. 


\title{
Lighting preference of artworks under multiple correlated colour temperatures condition
}

\author{
Qiang Liu ${ }^{1}$, Rui Peng ${ }^{1}$, QingMing Li $^{1}$, Yang Tang ${ }^{1}$, MeiHua Tang ${ }^{1}$, KaiDa Xiao ${ }^{2}$, \\ Ming Ronnier $\mathrm{Luo}^{3}$
}

\section{School of printing and packaging, Wuhan University1; School of design, University of Leeds'; State Key Laboratory of Modern Optical Instrumentation, Zhejiang University ${ }^{3}$ \\ liuqiang@whu.edu.cn}

Lighting preference for artworks was reported to be impacted by several contextual factors, which include lighting application for different artworks, regional cultural difference of observers, illuminance levels, age difference and so on. Such research works indeed contributed to the development of light quality evaluation of museum lighting, but also brought in new problems in the meantime. That is, to choose a proper light source, there are a lot of factors to be concerned. In many cases, such task is not simple even for experts. Therefore, for general museum lighting, a simple and universal approach is actually needed, which could achieve a reasonable balance among those contextual factors and thus help end users to make the right decision. In this study, a series of psychophysical experiments were conducted to investigate and compare the effect of certain factors on lighting preference for artworks, including spectral power distribution of light, lighting application for different artworks, regional cultural difference and gender difference. Most of the experiments were implemented in a light booth while a wall painting experiment was carried out in a museum.

A broad range of typical artworks were adopted in psychophysical experiments, which includes five Chinese traditional calligraphies with different background colours and four different kinds of paintings Besides, certain special groups of observers from different native places of China were also involved, in order to study the influence of regional cultural difference on artworks lighting preference. Five LED spectral with different correlated colour temperatures were used to illuminate such artworks.

Participant response was quantified by a 7-level categorical judgment method or a 5-level rank ordering method. It was found that the preferred illumination for different artworks exhibited a similar trend and the influence of light was significantly stronger than those of other factors. That is, for $2500 \mathrm{~K}$ the average values of the observer rating were always low, while for $3500 \mathrm{~K}$ and $4500 \mathrm{~K}$ the values were mostly high. Another interesting finding is the negative correlation $r$ between the average value and standard deviation of each trail. Such result is consistent with previous studies, which indicates that when observers generally prefer certain lighting conditions, the distribution 
of their ratings will be concentrated, while if they generally dislike certain lighting conditions, the distribution will tend to be scattered.

Therefore, we conclude that end users for general museum lighting should mainly concern about the property of light as for general multi-CCTs condition. In addition, some of the gamut-based light quality metrics correlated well with the participants' response, which collaborates with the viewpoint that lighting preference associated with colour saturation. Moreover, the familiarity to the artworks remarkably affected the rating interval for each experiment while the colour feature of the artworks also impacted lighting preference. 


\title{
Preference of Paintings under LED Lightings with Variations of CCT, Colour Fidelity and Colour Gamut
}

\author{
Qiyan Zhai ${ }^{1}$, Ming Ronnier Luo ${ }^{1,2}$, Ching-Ju Chou ${ }^{3}$, Hung-Shing Chen ${ }^{3}$ \\ State Key Laboratory of Modern Optical Instrumentation, Zhejiang University ${ }^{1}$; School of Design, \\ Leeds University2; Colour, Imaging and Illumination Centre, National Taiwan University of \\ Science and Technology ${ }^{3}$ \\ zhaiqiyan@zju.edu.cn
}

\section{INTRODUCTION}

LED lightings possess most of the qualities required for Museums and Galleries such as low radiation damage, high energy efficiency, high visibility, and high colour fidelity. Paintings were widely used to study the museum lightings. The lighting parameters such as illuminance, CCT (Corrected Colour Temperature) and colour fidelity of the lighting were extensively studied recently. ${ }^{1-8}$ It was found large variations on the preferred CCT from different labs between $3500 \mathrm{~K}$ and 57002-7. The concept of 'comfort zone' in terms of CCT and illuminance were used to evaluated the visibility and preference of the museum lighting ${ }^{1,4}$ but no study paid attention to the gamut shape and size of the LED lightings. Some studies (not including painting samples) have concluded positive effects of colour gamut on the preference of colourful objects ${ }^{9-13}$ and a single colour fidelity index such as CIE- $\mathrm{R}^{14}$ is not enough to describe the colour quality of lighting. Recently, CIE TC190 proposed IES-TM-3015 metric for test trials. It evaluates not only colour fidelity but also colour gamut size of a lighting. The present experiment has been designed to investigate the impact of lighting parameters on 5 colourful fine art paintings.

\section{EXPERIMENT}

The experiment was conducted in a viewing cabinet with multichannel LED illumination system 'LEDcube' produced by ThousLite Inc., China. The paintings were painted by Chinese artists. The lightings are given in Table 1 and the experiment was divided into 4 sections. Fifteen lightings varied in CCTs $(3500 \mathrm{~K}, 4500 \mathrm{~K}, 5700 \mathrm{~K})$, IES-TM-30 $\mathrm{R}_{\mathrm{f}}$ values ${ }^{15}$ (70, 80 and 90), IES-TM-30 $\mathrm{R}_{\mathrm{g}}$ values $^{15}$ (100 and 110), and gamut shape (Yellow-Blue and Red-Green). Note that the three CCTs selected are the most preferred CCT found by different research teams ${ }^{2-7}$ and the IES-IM-30 samples ${ }^{15}$ were used to define the gamut shape. The experiment was designed to have all lights in each section to have very similar chromaticity coordinates for which observers cannot distinguish the colour differences of the grey cabinet background. However, their spectral power distributions were largely different. In other words, these lights are metamers. 


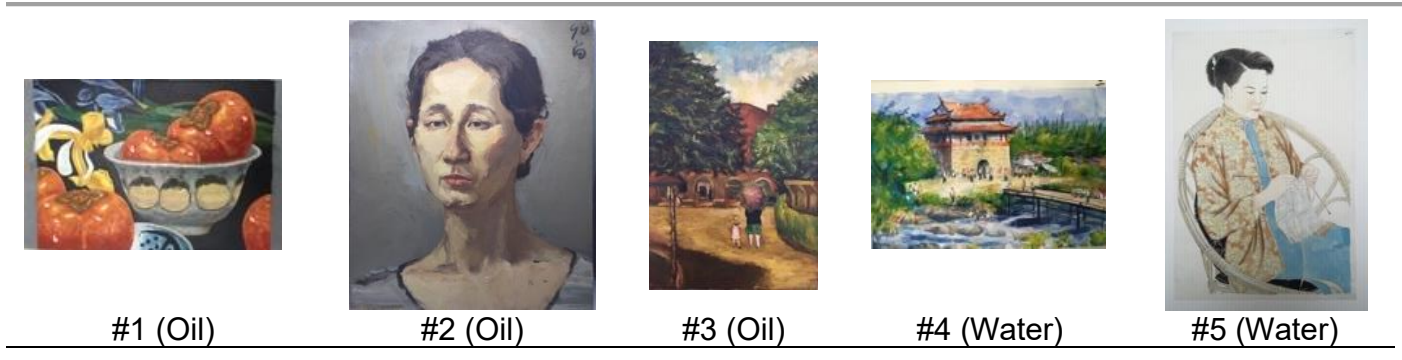

(a)

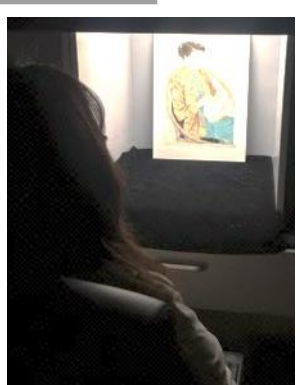

(b)

Figure 2 Paintings in the experiment. (a) paintings and their pigment types; (b) experimental situation.

Table 1 Lightings used in each section. The gamut shapes of the lightings were calculated in CAM02-UCS with IES-TM-30 samples and averaged into 16 hue bins.

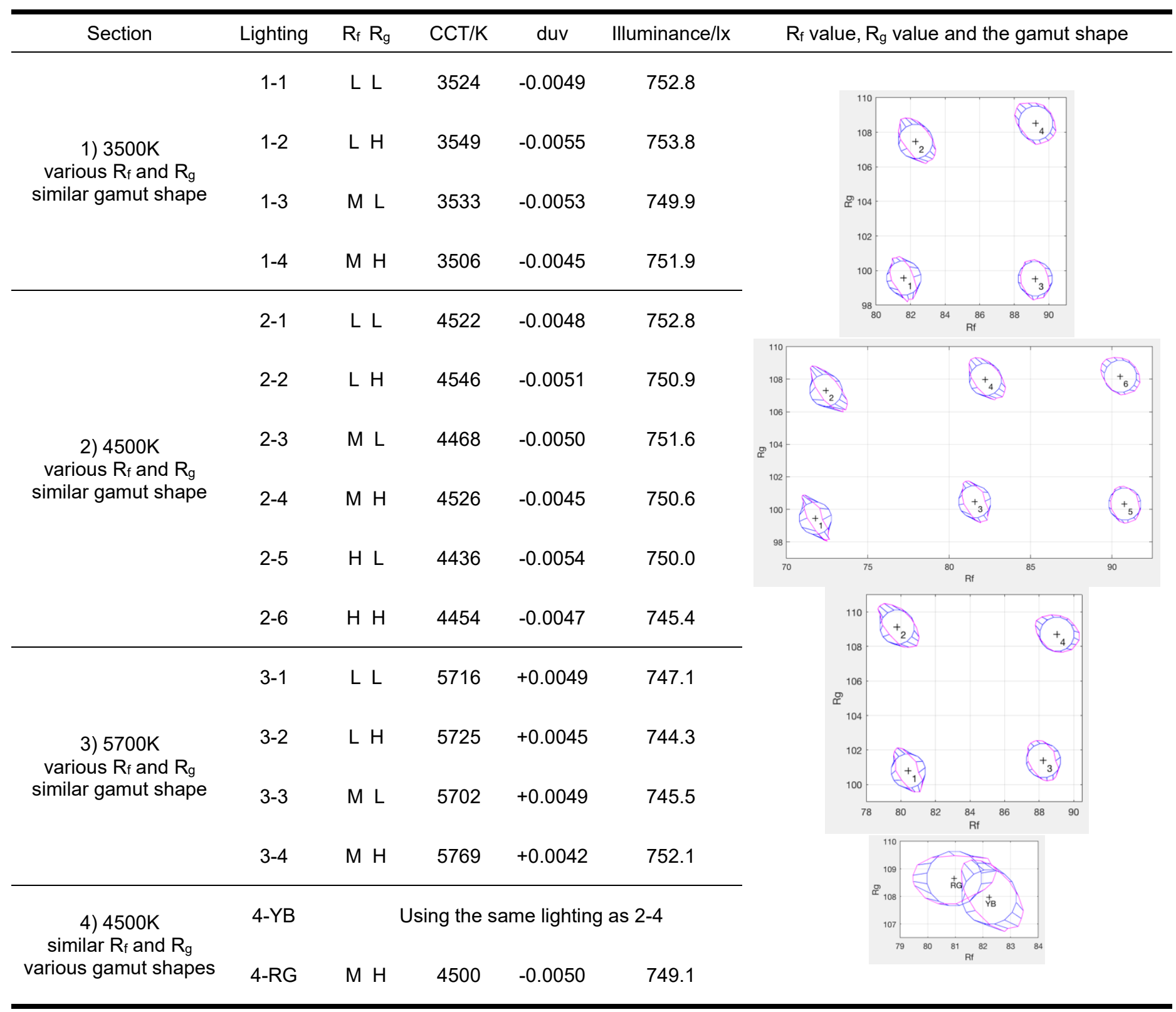


In each section, all the lightings were assessed using the pair comparison method. The observer first adapted to the high-Rf/low-Rg lighting (such as lighting 1-3) for one minute. Then the first lighting of a random pair will illuminate the painting for 3 seconds followed by the second lighting of this pair for another 3 seconds; Observers need to choose a more preferred one from these two lightings, and then go into another random pair until all the lighting pairs were compared twice. Fourteen observers (males/females=6/8) finished all lightings in each section for every individual painting.

\section{RESULTS}

The percentage of the preference choice was transferred to z-score in each section and conclude as following: a) For oil paintings, observers prefer lightings with higher colour gamut; b), Observers prefer lightings with higher colour fidelity for all the paintings except Painting \#4; c) Colour gamut shape of the lightings had more significant effects on the water colour paintings than the that of oil paintings.

To illuminate the colour changes of the paintings under different experimental lightings, colours of each painting was measured by a tele-spectral-radiometer and compared in CAM02-UCS space. The result indicates that the colours of Painting \#4 produced a largest colour shift under lightings with different gamut, and the gamut shape had more impact than gamut size $\left(\mathrm{R}_{\mathrm{g}}\right)$. The reason of some insignificant results is that people had different opinions on preferences of these kinds of colour shifts. To prove this, the observers are grouped into 4 groups. In the grouped results, some of the trends are much clearer and, in some cases, become opposite comparing to the average result. The observer preference of colour fidelity and colour gamut of museum lighting will vary according to the types and contents of the paintings, and the individual observer's aesthetic view. In some cases, observers preferred as original as possible while in other cases colour shifts may increase the preference.

\section{REFERENCES}

1. Zhai, Q., Luo, M.R. (2016) A Brief Review of Colour Quality Assessments of LED Lightings for Museums. The $5^{\text {th }}$ China Academic Conference on Printing and Packaging.

2. Yoshizawa, N. et al. A Study on the Appearance of Paintings in the Museum Under Violet and Blue LED. CIE x038 (2012), pp. 374-381.

3. Chen, H. S. et al. Museum lighting environment: designing a perception zone map and emotional response models. Lighting Research \& Technology. 2015

4. Zhai, Q. et al. The impact of illuminance and colour temperature on viewing fine art paintings under LED lighting. Lighting Research \& Technology. 2015; Vol. 47(7): 795-809

126 | P a g e 
5. Zhai, Q. et al. The impact of LED lighting parameters on viewing fine art paintings. Lighting Research \& Technology. 2016

6. Szabo, F. et al. Colour fidelity for picture gallery illumination, Part 1: Determining the optimum light-emitting diode spectrum. Lighting Research and Technology. 2014

7. Nascimento, S.M.C., Masuda, O. Best lighting for visual appreciation of artistic paintingsexperiments with real paintings and real illumination. Journal of the Optical Society of America A 2014; 31: 214-219.

8. Padfield, J. et al. Optimisation of Artwork Illumination Spectra by Museum Professionals. Proceedings of the CIE Conference, Melbourne, 3-5 March 2016. CIEx042: 7-11.

9. Rea, M.S., Freyssinier-Nova, J.P. Color rendering: A tale of two metrics. Color Research \& Application, 2008: 33(3), 192-202.

10. Wei, M., Houser, K.W. What is the cause of apparent preference for sources with chromaticity below the blackbody locus? LEUKOS, 12(1-2), 95-99.

11. Khanh, T.Q. et al. Colour preference, naturalness, vividness and colour quality metrics, Part 1: Experiments in a room. Lighting Research and Technology. 2016

12. Royer, M.P. et al. Human perceptions of colour rendition vary with average fidelity, average gamut, and gamut shape. Lighting Research and Technology. 2016

13. Wei, M. et al. Colour gamut size and shape influence colour preference. Lighting Research \& Technology. 2016

14. Colour rendering of white LED light sources. CIE 177:2007.

15. David, A. et al. Development of the IES method for evaluating the color rendition of light sources. Optics Express 2015; 23(12): 15888-15906. 


\title{
Senses and thoughts: The light in the Kunsthaus Bregenz designed by Peter Zumthor
}

\author{
Seda Kaçel ${ }^{1}$ and Benson Lau ${ }^{2}$
}

\begin{abstract}
Department of Architecture, Faculty of Architecture, Istanbul Technical University ${ }^{1}$; Department of Architecture, Faculty of Architecture and the Built Environment, University of Westminster ${ }^{2}$
\end{abstract}

kacel.seda@gmail.com

\section{Senses and thoughts: The light in the Kunsthaus Bregenz designed by Peter Zumthor}

During his architectural career, Peter Zumthor has integrated senses and thoughts into his buildings. Zumthor works on the architectural essences in each architectural project through various materials, dimensions and functions without concerning about their styles (Spier, 2003). Zumthor indicated light as a design element to be considered at the beginning of the design process in two ways, either in relation to shadow or materials (Zumthor, 2006). Zumthor's unique way of orchestrating and harmonizing light along the spatial journey resulted in well-articulated luminous environments in his buildings.

Art related spaces play a significant role in the architecture of Peter Zumthor. The Kunsthaus Bregenz, a museum designed by Zumthor, was opened in 1997 on the coast of Lake Constance in Bregenz, Austria. The light of Lake Constance was one of the initial inspirations of Zumthor at the site (Mack, 1999). The design intention was to integrate this inspiration as a sidelighting source into the museum environment (Durisch, 2014). The building has a rectangular form constructed of three main materials: concrete, glass and steel (Bilgin, 2016).

As surrounding the building, the glazing system attained its translucency through the acid-etching process. Translucency is "as existing at a point along a spectrum, the polar ends of which are transparency and opacity" (Murray, 2013, p.1). The rationale for translucent facades includes enhancing daylight, providing glow on the building skin in the dark and creating a peaceful space (Murray, 2013). The glazing system contains the translucent glass panels supported by a steel frame. A concrete wall and glass stand 0.90 meters behind the translucent glass facade. The elegant design of the vertical translucent facade continues towards the interior exhibition spaces through the horizontal glass ceiling containing the acid-etched glass panels (Murray, 2013). The light, which filtered through the translucent glazing system and the cavity, reflects back to the glazing system through the reflective material on the concrete wall (Moe, 2010). The three concrete walls have multi-roles in the museum. They work as the structural walls, the architectural elements separating circulation zones and exhibit areas, the display walls and the house of building services systems (Charleson, 2015). The clerestory windows on the concrete wall are 
controlled through blinds. The blinds can be lowered to operate the daylight availability in the galleries through an illuminance sensor on the roof (Moe, 2010). As Zumthor stated in an interview, the museum space expressed its identity with its individual materials and surfaces such as concrete and glass being opposed to the concept of entirely white surfaces (Mack, 1999).

The daylight penetrates first through the facade, then through the ceiling and reaches to the exhibition space. The deliberate intention to allow the interplay of space and light can be best appreciated on the section of this museum building which is the unique "articulation and variation of light" (Bilgin, 2016). Having plotted on the same plan layout, differences in the floor heights resulted in variations in the intensity of light (Durisch, 2014). As the light that fills in the ceiling comes through the facade as a sidelighting source, this provides the "not even" light distribution (Mack, 1999, p.102) as Zumthor aspired. The pattern of light on the translucent ceiling and intensity of daylight in the galleries decreases towards the deeper zones. The daylighting design has allowed feeling the diurnal changes and weather-based changes of the natural light (Spier, 2003). For the design of the gallery spaces with "the translucent daylight ceilings", the scale model study provided to assess impact of sidelight (Durisch, 2014, p.137).

The gallery space generates its "serene atmosphere" throughout its "indirect" relation with the facade (Murray, 2013, p. 37). This relation can be described as the journey of light. In this journey, the source of the light gradually disappears. However, the inspiration of the luminous environment explicitly increases. This study aims to investigate the relation between the spatial experience and luminous environment in the Kunsthaus Bregenz by Zumthor through both qualitative and quantitative studies. The relation between the spatial sequence, lighting quality and visual perception were explored. At first, the luminous environment of the museum building has been investigated qualitatively. The subjective appreciation of light and spatial sequence has been obtained through personal site visit and literature review, which was based on written materials and photographs. Following this, quantitative analysis was carried out through computer-based daylight modelling. Distributions of daylight and brightness contrast in the selected views have been evaluated. The subjective appreciation of light and space was compared with the quantitative analysis results. The visual comfort conditions have been compared to the relevant daylighting design benchmarks for museums and gallery spaces.

In conclusion, the Kunsthaus Bregenz was designed as a luminous image during both the daytime and night-time by Peter Zumthor, who defined the image as being in relation with architecture (Zumthor, 1999). The daylit museum environment Zumthor created through careful material selection and architectural form making has given meaning to its luminous environment. The light distribution patterns enhance and enrich the spatial sequence resulting in a well-orchestrated spatial and perceptual experience. The assessment of this building through qualitative and 
quantitative analysis provides a comprehensive and holistic understanding of the poetics and pragmatic aspects of the Kunsthaus Bregenz.

Keywords: Museums and art galleries, spatial sequence, luminous environment, lighting quality, visual perception.

\section{$\underline{\text { References: }}$}

Bilgin, İ. (2016). Mimarın soluğu: Peter Zumthor mimarlığı üzerine denemeler (English translation from Turkish - The breath of the architect: Essays on the architecture of Peter Zumthor). Istanbul: Metis Yayınları.

Charleson, A. (2015). Structure as architecture: A source book for architects and structural engineers. $2^{\text {nd }}$ edition. Oxon: Routledge.

Durisch, T. (2014). Peter Zumthor, 1985-2013: Buildings and projects. Volume 1 (eds). Zurich: Verlag Scheidegger \& Spiess AG.

Kunsthaus Bregenz (2017). [online] http://www.kunsthaus-bregenz.at/ehtml/ ewelcome00.htm

Mack, G. (1999). Art museums into the 21 ${ }^{\text {st }}$ century. Basel: Birkhauser.

Moe, K. (2010). Thermally active surfaces in architecture. New York: Princeton Architectural Press.

Murray, S. (2013). Translucent building skins. Oxon: Routledge.

Spier, S. (2003). Swiss made: New architecture from Switzerland. New York: Princeton Architectural Press.

Zumthor, P. (1999). Thinking architecture. Basel: Birkhäuser.

Zumthor, P. (2006). Atmospheres. Basel: Birkhauser. 


\title{
Influence of LED lighting on the stability of modern paint materials
}

\author{
Valentina Pintus ${ }^{1}$, Ferenc Szabo ${ }^{2}$, Peter Csuti ${ }^{3}$, Federica Cappa ${ }^{1}$, Carlotta
} Salvadori ${ }^{1}$, Renata Kari ${ }^{2}$, David Noel That ${ }^{2}$, Rita Wiesinger ${ }^{1}$, Marta Anghelone ${ }^{1}$, Zafia Nyari ${ }^{2}$

Institute of Science and Technology in Art, Academy of Fine Arts, Vienna ${ }^{1}$; Light and Colour

Science Research Laboratory, University of Pannonia, Veszprem²; School of Civil \& Building

\section{Engineering, Loughborough University ${ }^{3}$}

v.pintus@akbild.ac.at

Indoor museums exhibiting artworks like paintings most of the time need a proper illumination system to provide the best viewing conditions for the art objects and a comfortable atmosphere for visitors, while avoiding the harmful effects of optical radiation, which could cause some damages on the paintings, for example by colour fading. The traditional use of incandescent light source has been gradually pushed to the background mostly due to harmful infrared radiation, which produces some heating effects to the paintings, while modern light sources such as Light Emitting Diode (LED)-based ones can provide high luminous efficacy, long lifetime and reliable operating characteristics avoiding radiation in the damaging (UV and infrared) wavelength range. Therefore, LED systems are found nowadays in an increasing number of applications in museums, where also modern and contemporary artworks are exposed.

Within the Bilateral Research Project (Project No. HU 08/2016) between the Light and Colour Science Research Laboratory of the University of Pannonia, Veszprem, Hungary and the Institute of Science and Technology in Art at the Academy of Fine Arts, Vienna, Austria three different types of high colour quality illumination such as two newly developed LED-lighting systems, one based on a short wavelength blue LED and the other one on a long wavelength blue LED, and a halogen lamp are being tested on self-made paint materials based on different types of binding media such as acrylic, alkyd and linseed oil mixed with several inorganic pigments. An illuminance level of $2000 \mathrm{~lx}$ was calculated, thus exposing the samples for 5000-6500 hours of irradiance period as the threshold effective radiant exposure.

In order to determine any chemical changes on the surface of the paint material as well as in the paint structure caused by the exposure to the different illumination systems, reflectance measurements, $\mu$-Raman, FTIR-ATR, and Py-GC/MS analytical techniques are used.

Preliminary results obtained with reflectance measurements showed the highest damage effect of the LED with short wavelength blue and halogen lamp on the linseed oil binder mixed with ultramarine blue pigment in comparison to the other samples, based on the largest colour difference values. This result was supported by FTIR-ATR and Py-GC/MS by the detection of 131 | P a g e 
oxidation products and oxidative chain cleavage due to the photo-oxidative degradation of the oil binder. Additionally, the ultramarine blue pigment colour change was further sustained by broadening of the S2- yellow chromophore band in the spectra acquired by $\mu$-Raman analysis.

Acknowledgments: The authors gratefully acknowledge the support of their research by the Austrian Agency for International Cooperation in Education and Research (OeAD-Gmbh) and National Research, Development and Innovation Office (grant number: TT_15-1-2016-0017). 


\title{
Lighting beyond art: choreographing views and appearances for the perceptive body
}

\author{
Veronika Mayerboeck ${ }^{1}$, Elke Oberthaler², Sabine Penot ${ }^{2}$, Alison Ritter
}

ALLES oder Licht ${ }^{1}$., KHM Vienna ${ }^{2}$

info@allesoderlicht.com

„The secret was to get inside whatever I was looking at.“(John Berger)

source: „John Berger oder die Kunst des Sehens“, Film von Cordelia Dvorak, ARTE, Deutschland 2016

The poster is taking the 1:1 realization of a new lighting concept for Vermeyen Cartoons at Museum of Art History Vienna (KHM) as a starting point. Reporting the demanding spatial situation within historic architecture portrays museumlighting at the intersection between technical restrictions, conservation of artwork and human centered perception of art.

The Vermeyen cartoons offer a rare opportunity to move as a spectator in a "close up" situation in between large scale artworks: Our gaze is "flipping" and we are constantly visually overwhelmed. A perfect challenge to study how lighting can help the spectator to chose what's significant within a particular perspective without beeing too manipulative dramaturgically on the other hand. Standing at short distance eye to eye with lifesize figures, the spectator finds himself in between battlefields or perspectives of detailed topographic landscapes far above.

Aside the presentation of an alternative lighting solution to improve the status quo, the survey of the connectivity between visual perception and movement has a central focus: The experience of the visitor is enhanced by a subtle dramaturgy of conscious views and appearances, „choreographing cognition“ woven into the lighting design as a key to reading art.

The subtle lighting design takes into account the various layers of texture and pigment within the artwork using different types of lightsources and colorspectrum helping to structure the largescale content from foreground to background. Further multidirectional lighting helps to emphasize plasticity and countours of the cartoon texture. The set of these scenes has been connected to approach and passage of a visitor along selected cartoons. Therefore several lighting scenes have been elaborated to be connected within a dynamic lighting sequence including the aspect of time and change and can be studied next to each other within the poster. 


\section{BILDER}

Image below: Excerpt from Vermeyen cartoon, / Ausschnitt von Vermeyen Karton

Left: exemplary scheme for compositional analyse / Beispielschema Analyse Bildaufbau

Right: all even surface impression / gleichmässige Oberfläche unverändert

(Source/ Bildquelle: "Die Belagerung der Festung La Goleta, der Tunisfeldzug Karls V., 4.Karton) Jan Cornelisz Vermeyen aus "Kaiser Karl erobert Tunis” KHM Wien 2013, S. 81)

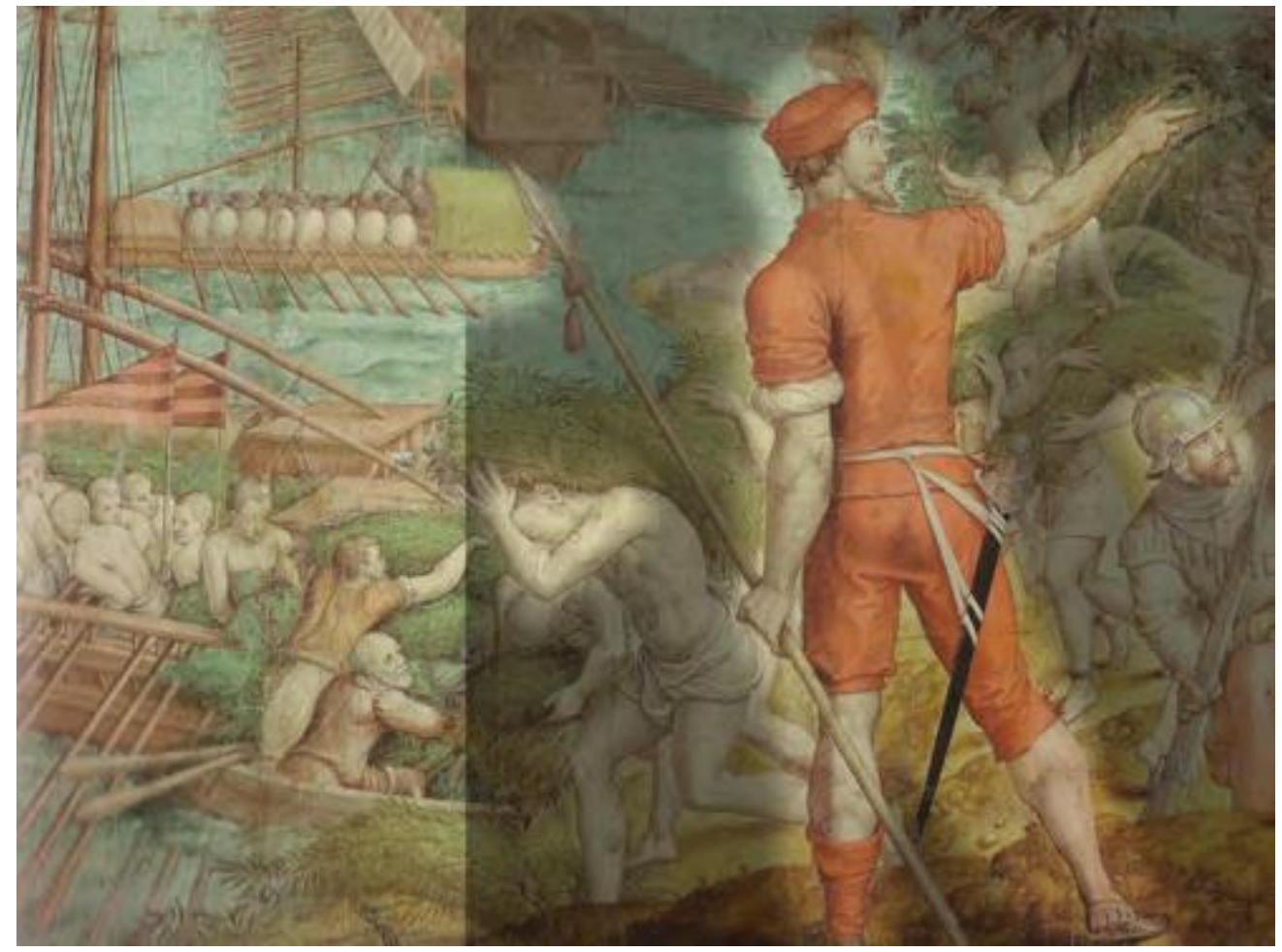

Image below: Detail Vermeyen tapisserie and cartoon, / Ausschnitt von Vermeyen Karton und Wandtepich

Left: detail of tapisserie/ Ausschnitt des Wandteppichs

Right: detail of cartoon/ Ausschnitt der gezeichneten Kartonvorlage

(Source/ Bildquelle: "Die Belagerung der Festung La Goleta, der Tunisfeldzug Karls V., 7.Tapisserie/ 6.Tapisserie) Jan Cornelisz Vermeyen aus "Kaiser Karl erobert Tunis" KHM Wien 2013, S. 108-109) 


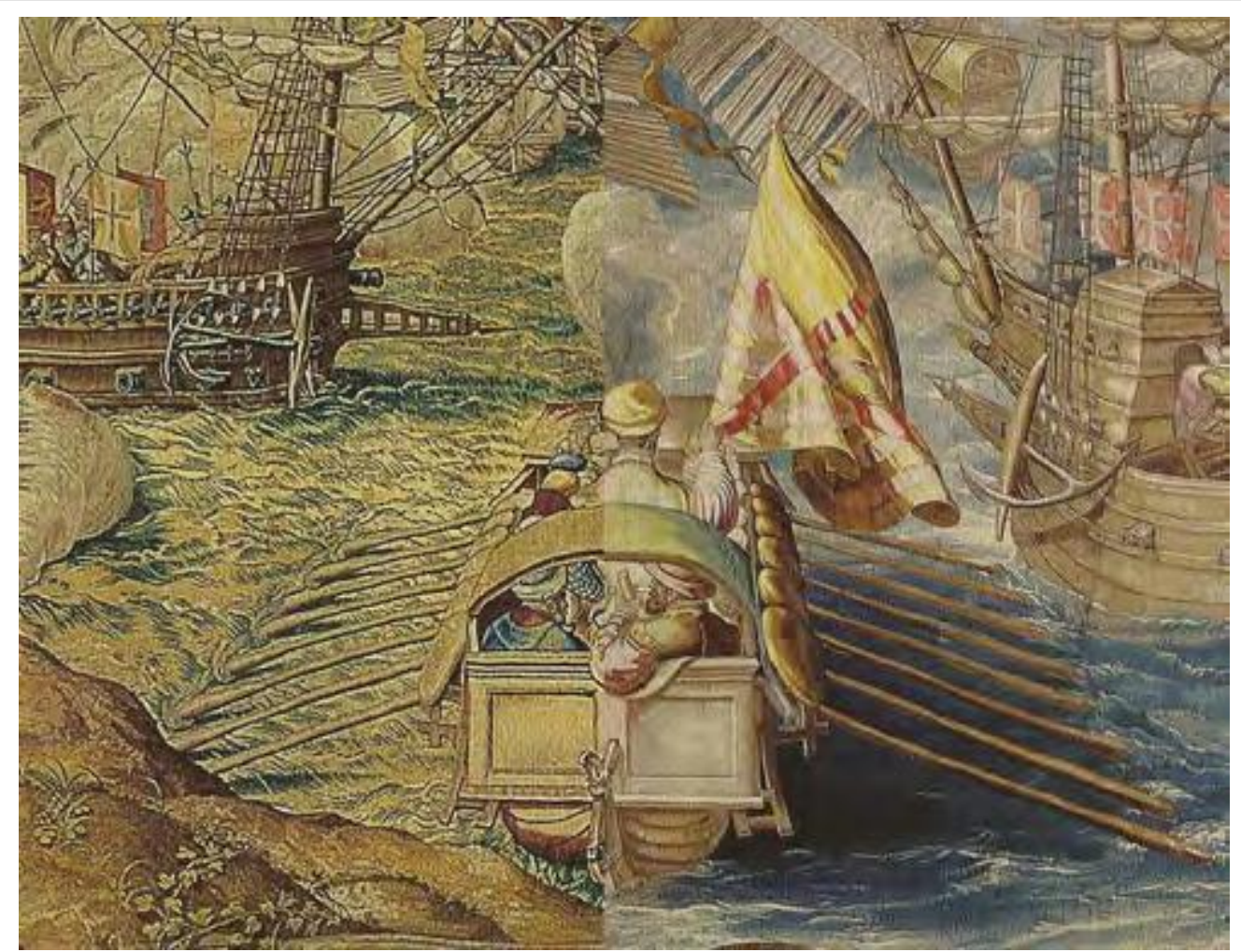




\section{Workshops}

Workshop A: Relighting the Petrie Museum: Smart Lighting and Proximity Aware Services in Museums

In association with:

\section{XICATO}

\section{Presenters:}

- Boris Pretzel, Head of the Science Section, Victoria and Albert Museum

- Stephen Elliot, Managing Director, Llama Digital

- Anna Garnett, curator, Petrie Museum

- Roger Sexton, VP Xicato

The new lighting for the Petrie Museum will be revealed. For the purpose of this workshop the Petrie Museum of Egyptian Archaeology will be relit, using the latest LED light sources with bluetooth beacons for remote control and indoor positioning. After a summary of what smart lighting can offer museums, proximity aware services will be demonstrated in the Petrie Museum with a standard application. This workshop will explore the capabilities of smart lighting and will produce an expanded brief on what this application could ideally achieve. The follow-up is for the organisers to implement, as far as possible, this brief. 


\section{Workshop B: Precision LED drivers for viewing and digital imaging}

In association with:

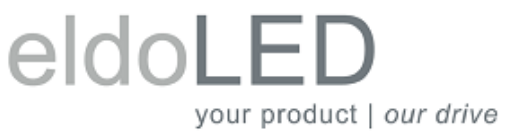

\section{Presenters:}

- Scott Geffert, Advanced Imaging Manager at the Metropolitan Museum of Art, New York

- Gé Hulsmans, director specifier service, ELDOLed

The technology behind precision LED control for viewing and imaging. Learn about precision LED control and real-world applications for cultural heritage. Scott Geffert, Advanced Imaging Manager at the Metropolitan Museum of Art, New York, will discuss the application of precision tuneable multispectral LED flash light sources for cultural heritage imaging applications. Gé Hulsmans will explain the deep technical detail and secrets of LED dimming, the cause of light flicker and its effect on viewers. 


\section{Workshop C: Neuropsychological methods for lighting design and research}

In association with:

\section{ZUMTOBEL}

\section{Presenters:}

- Anya Hurlbert, Professor of Visual Neuroscience, Newcastle University; Scientific Trustee, National gallery London

- Panos Andrikopoulos, PhD researcher, UCL Institute for Sustainable Heritage

- Panos Mavros, Project Coordinator \& Postdoc Researcher of Cognition, Perception, and Behaviour in Urban Environments, Future Cities Laboratory, Singapore ETH (remotely)

Recent technological developments have allowed the production of low cost scientific equipment democratising research in physiological activity. This workshop will discuss the integration of novel methods for understanding the effect of light on humans using neuroscience, technology and cognitive science. Methods such as Electroencephalography and Electrodermal Activity will be demonstrated and explained as a tool for lighting design and research. 


\section{Workshop D: Modern Colour Science for Museum Lighting}

In association with:

\section{SORAA}

\section{Presenter:}

- David Aurelien, Principal Scientist Soraa

This Workshop will teach various aspects of colour rendition for museum lighting. After an introduction to colour science fundamentals, it will present the concept of colour metrics with particular focus on the recently-published TM-30 method. It will then explain how these concepts can specifically be harnessed in museum illumination. The Workshop will be supported by live visual demonstrations of spectral tuning and its impact on object colours.

Cover Image: musée des civilisations de l europe et de la méditerranée, reproduced with permission from Licht Kunst Licht AG 